\title{
An Investigation of the Ward Leonard System for Use in a Hybrid or Electric Passenger Vehicle
}

\author{
Cody L. Telford \\ Brigham Young University - Provo
}

Follow this and additional works at: https://scholarsarchive.byu.edu/etd

Part of the Mechanical Engineering Commons

\section{BYU ScholarsArchive Citation}

Telford, Cody L., "An Investigation of the Ward Leonard System for Use in a Hybrid or Electric Passenger Vehicle" (2012). Theses and Dissertations. 3529.

https://scholarsarchive.byu.edu/etd/3529

This Thesis is brought to you for free and open access by BYU ScholarsArchive. It has been accepted for inclusion in Theses and Dissertations by an authorized administrator of BYU ScholarsArchive. For more information, please contact scholarsarchive@byu.edu, ellen_amatangelo@byu.edu. 
An Investigation of the Ward Leonard System for use

in a Hybrid or Electric Passenger Vehicle

Cody L. Telford

A thesis submitted to the faculty of

Brigham Young University

in partial fulfillment of the requirements for the degree of

Master of Science

Robert H. Todd, Chair

Christopher A. Mattson

Carl D. Sorensen

Department of Mechanical Engineering

Brigham Young University

June 2012

Copyright () 2012 Cody L. Telford

All Rights Reserved 


\section{ABSTRACT \\ An Investigation of the Ward Leonard System for use in a Hybrid or Electric Passenger Vehicle \\ Cody L. Telford \\ Department of Mechanical Engineering, BYU \\ Master of Science}

Since the early 1900's demand for fuel efficient vehicles has motivated the development of electric and hybrid electric vehicles. Unfortunately, some components used in these vehicles are expensive and complex. Todays consumer electric vehicles use dangerously high voltage, expensive electronic controllers, complex battery management systems and AC motors. The goal of this research at BYU is to increase safety by lowering the operating voltage and decrease cost by eliminating expensive controllers and decrease the number of battery cells.

This paper specifically examines the use of a Ward Leonard Motor Control system for use in a passenger vehicle. The theory of the Ward Leonard system as an Infinitely Variable Transmission (IVT) is presented along with its history and past uses. Analogous systems are presented and similarities made in an attempt to enlighten designers to a broader design approach to increase safety and decrease cost of an electric or hybrid electric vehicle.

The results of this research include a characterization of the Ward Leonard system as an IVT for use in an electric or hybrid (EV or HEV) passenger vehicle. These results include a study of past uses of the Ward Leonard system and what method is now used as a replacement. The theory of the Ward Leonard system and it operation is explained to an extent that someone not familiar with electronics can understand its working principles. A Control Factor metric was developed as a result of this research to measure the Ward Leonard System's ability to reduce the size of the electronic controller for application in an EV or HEV. The potential cost reduction of the electronic controller that would be used to control the Ward Leonard System compared with current EV and HEV vehicles was also research and identified. A bench top model of the Ward Leonard system was tested validating the Control Factor metric. The Ward Leonard system is capable of reducing the controller size by $77 \%$ and potentially reducing its cost by $68 \%$ or more. This work also provides performance characteristics for automotive designers and offers several design alternatives for $\mathrm{EV}$ and $\mathrm{HEV}$ architectures allowing the reduction of high voltage, the use of AC inverters, AC motors, expensive controllers and high cell count battery packs.

Keywords: Cody Telford, electric vehicle, Ward Leonard, motor testing, CVT, IVT, low cost, DC, LabView, shunt wound, DC motor, hybrid, variable voltage, control factor 


\section{ACKNOWLEDGMENTS}

I would like to acknowledge the other members of my research group, Ben Groen, Dax Wells, John Wyall, Austin Randall, and Mike Saunders. They have helped with ideas, hardware and testing.

I express my appreciation to the Capstone Program and Department of Mechanical Engineering for the use of their resources. Especially Kevin Cole for help securing hardware and help during testing, also Ken Forster for help in fabrication of parts and input. Additionally I would like to thank Scott Daniel of the Physics Department for his help in acquiring experimental equipment.

I would like to express my appreciation for my graduate advisor Dr. Robert Todd, for the opportunity to continue my education and making it possible to persue a higher education. The guidance, support and counsel he gave me during my research, work and other aspects of life have helped immensely in my education and life. I appreciate his encouragement throughout this project.

I would like to thank my family for their support financially and encouragement throughout my college education. I also thank my wife Whitny for her love and support. Finally I acknowledge my Heavenly Father for the guidance and knowledge that have been given me. 


\section{TABLE OF CONTENTS}

LIST OF TABLES $\ldots \ldots \ldots \ldots \ldots \ldots \ldots \ldots \ldots$ viii

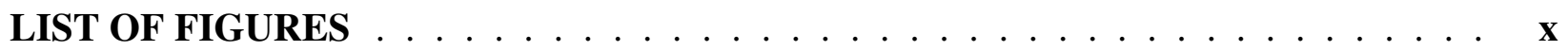

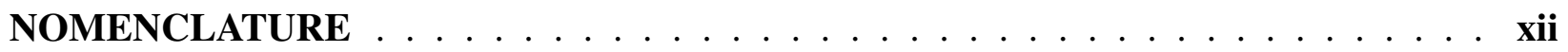

Chapter 1 Problem Statement $\ldots \ldots \ldots \ldots \ldots \ldots \ldots$

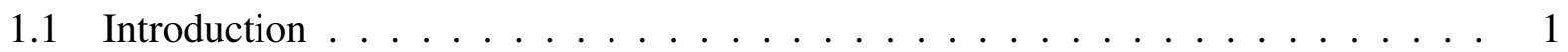

1.2 Motivation for use of EVs and HEVs . . . . . . . . . . . . . . . . 1

1.2 .1 Emissions . . . . . . . . . . . . . . . . . . . 1

1.2 .2 Fuel Prices . . . . . . . . . . . . . . . . . . . . 2

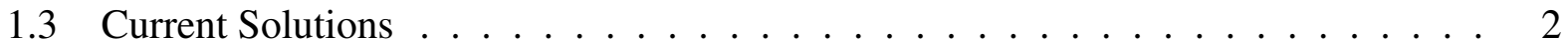

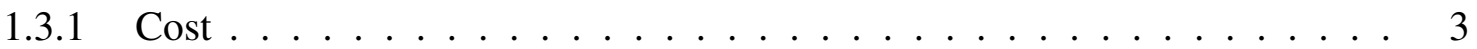

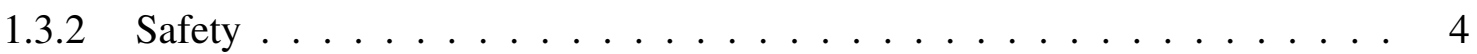

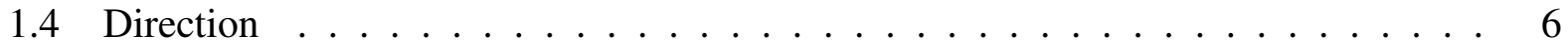

1.5 Research Objectives . . . . . . . . . . . . . . . . . . . . 6

1.6 Research Benefits . . . . . . . . . . . . . . . . . . . . . . . . 6

Chapter 2 Background $\ldots \ldots \ldots \ldots \ldots \ldots \ldots \ldots$

2.1 Electric Powertrain Construction . . . . . . . . . . . . . . . . . . . . 9

2.1 .1 Power Source . . . . . . . . . . . . . . . . . . . . . . . 10

2.1.2 Controller . . . . . . . . . . . . . . . . . . . . . . 10

2.1 .3 Motor . . . . . . . . . . . . . . . . . . . . . 10

2.1 .4 Efficiency and Fuel Economy _ . . . . . . . . . . . . . . 11

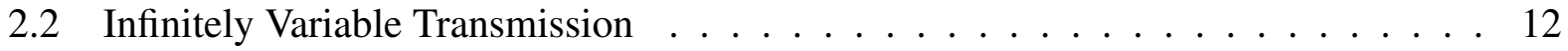

2.2.1 Hydrostatic Transmission . . . . . . . . . . . . . . . . . . . . . 14

2.2.2 Mechanical Differential . . . . . . . . . . . . . . . . . . . 14

2.3 Transistors . . . . . . . . . . . . . . . . . . . . . . 16

2.4 Ward Leonard . . . . . . . . . . . . . . . . . . . . . . . . . 16

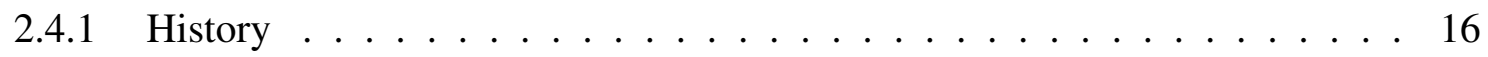

2.4 .2 Layout . . . . . . . . . . . . . . . . . . . . 18

2.4 .3 Electromagnetism . . . . . . . . . . . . . . . . . . . . . . . . 19

2.4 .4 Generators . . . . . . . . . . . . . . . . . . . . 20

2.4.5 Separately Excited DC Machines _ . . . . . . . . . . . . . . 21

2.4.6 Ward Leonard Empirical Model . . . . . . . . . . . . . . . . . 22

2.4 .7 Field Weakening . . . . . . . . . . . . . . . . . . . . . . 23

2.4 .8 Prime Mover Control . . . . . . . . . . . . . . . . . . . . . . . . . . . . . 24

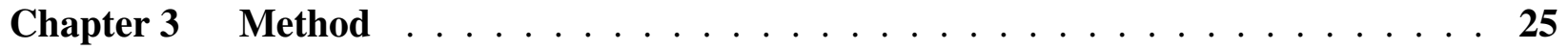

3.1 Control Factor . . . . . . . . . . . . . . . . . . . . . . . 25

3.2 Prime Mover . . . . . . . . . . . . . . . . . . . . . . 26

3.3 Vehicle Application . . . . . . . . . . . . . . . . . 27 
3.4 Testing Objectives . . . . . . . . . . . . . . . . . . . . . . . . . . 27

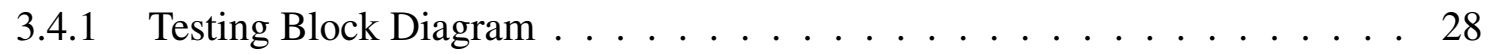

3.4 .2 Generator Control Testing . . . . . . . . . . . . . . . . 28

3.4.3 Speed Control by Generator Field Manipulation . . . . . . . . . . . . . . . 29

3.4.4 Speed Control with Added Motor Field Weakening . . . . . . . . . . . . . 29

3.4 .5 Efficiency . . . . . . . . . . . . . . . . . . . 30

3.4.6 Torque Output Control . . . . . . . . . . . . . . . . . . . . . 31

3.4.7 Power Relationships and Control Factor . . . . . . . . . . . . . . . . 31

3.5 Testing Hardware . . . . . . . . . . . . . . . . . . . . . . . . . . . 32

3.5.1 National Instruments cRIO . . . . . . . . . . . . . . . . . . . . . 32

3.5 .2 Modules . . . . . . . . . . . . . . . . . . . . 33

3.5 .3 Prime Mover . . . . . . . . . . . . . . . . . . . . . . . 34

3.5.4 Motor and Generator . . . . . . . . . . . . . . . . . . . . . . . . . 34

3.5 .5 Power Supplies . . . . . . . . . . . . . . . . . . . . . . . . . . . . 34

3.5 .6 Loading Motor . . . . . . . . . . . . . . . . . . . . . . . 35

3.5 .7 Sensors . . . . . . . . . . . . . . . . . . . . 37

3.5.8 Completed Assembly . . . . . . . . . . . . . . . . . . . . . . . . . . 39

3.6 LabView Code . . . . . . . . . . . . . . . . . . . . . . . . . . . 39

$3.6 .1 \quad$ FPGA . . . . . . . . . . . . . . . . . . . . . . . 39

3.6.2 Block Diagram (Real Time) . . . . . . . . . . . . . . . . . 40

3.6.3 Front Panel (Real Time) . . . . . . . . . . . . . . . . . . . . . . . 41

3.6 .4 Project Settings . . . . . . . . . . . . . . . . . . . . . . . 42

3.7 Calibration and Troubleshooting $\ldots \ldots \ldots \ldots . \ldots \ldots$

Chapter 4 Results . . . . . . . . . . . . . . . . . . . . 45

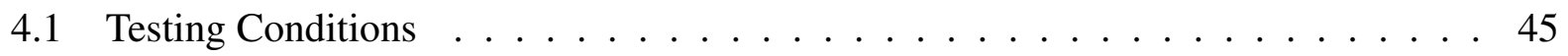

4.2 Generator Test . . . . . . . . . . . . . . . . . . . . . . . 47

4.3 Speed Control by Generator Field . . . . . . . . . . . . . . . . . . . 47

4.4 Speed Control with Motor Field Weakening . . . . . . . . . . . . . . . 48

4.5 Efficiency . . . . . . . . . . . . . . . . . . . . . . . 49

4.6 Torque Output Control . . . . . . . . . . . . . . . . . . . . 52

4.7 Power Relationships . . . . . . . . . . . . . . . . . . . . 53

4.7.1 Generator Field Control . . . . . . . . . . . . . . . . . . 53

4.7 .2 Motor Field Control . . . . . . . . . . . . . . . . . 53

Chapter 5 Discussion of Results . . . . . . . . . . . . . . . . . . . . . 57

5.1 Generator Test . . . . . . . . . . . . . . . . . . . . . 57

5.2 Speed Control by Generator Field Control _ . . . . . . . . . . . . . . 58

5.3 Speed Control with Motor Field Weakening . . . . . . . . . . . . . . 58

5.4 Efficiency . . . . . . . . . . . . . . . . . . . . . . . 59

$5.4 .1 \quad$ Generator Field Control $\ldots \ldots \ldots$

5.4 .2 Motor Field Control $\ldots \ldots$. . . . . . . . . . . . . . 60

5.4 .3 Vehicle Efficiency . . . . . . . . . . . . . . . . . . . . 60

5.5 Torque Control . . . . . . . . . . . . . . . . . . . . . 60

5.6 Power Relationships . . . . . . . . . . . . . . . . . . . . . . . 61 
5.6.1 Generator Field Control _. . . . . . . . . . . . . . 61

5.6 .2 Motor Field Control _. . . . . . . . . . . . . . . . . 62

5.7 Control Factor and Cost . . . . . . . . . . . . . . . . . . . . . . . . . . . . . 63

5.8 Theoretical vs Experimental . . . . . . . . . . . . . . . 64

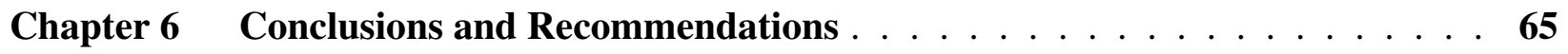

6.1 Restatement of Objectives . . . . . . . . . . . . . . . . . 65

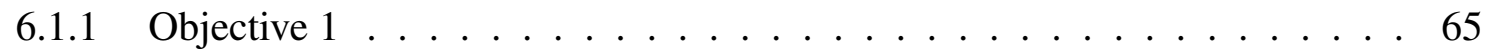

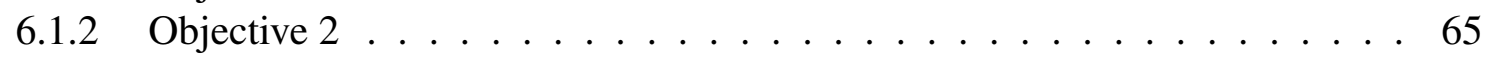

6.1 .3 Objective $3 \ldots \ldots \ldots \ldots$

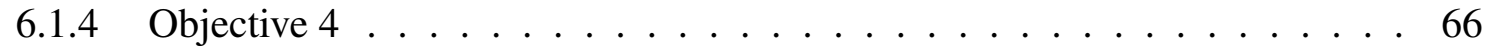

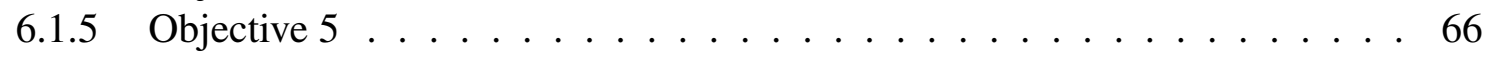

6.2 Conclusions . . . . . . . . . . . . . . . . . 66

6.3 Recommendations for Vehicle Design with Ward Leonard system . . . . . . . . 67

6.4 Future Work . . . . . . . . . . . . . . . . . . 68

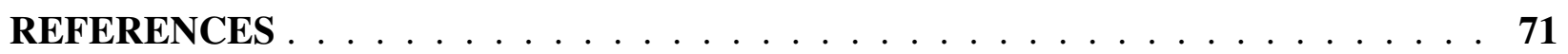

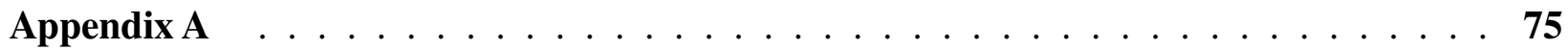




\section{LIST OF TABLES}

1.1 Number of Cells in a Battery Based on Operating Voltage . . . . . . . . . . . . 4

1.2 The Physical Effects of Electric Currents . . . . . . . . . . . . . . . . . . . 5

3.1 Theoretical Parameters . . . . . . . . . . . . . . . . . . . 31

3.2 National Instruments cRIO Modules Used in Experiment . . . . . . . . . . . . . 33

3.3 Specifications of Motors Used in Experiment . . . . . . . . . . . . . . 35

3.4 Specifications of Encoders Used in Experiment . . . . . . . . . . . . . . . 37

3.5 Specifications of Torque Sensor Used in Experiment . . . . . . . . . . . . 37

4.1 Loading Tests . . . . . . . . . . . . . . . . . . . 45

$5.1 \quad$ Experimental Parameters . . . . . . . . . . . . . . . . . . 63

5.2 Theoretical vs Experimental .......................... 64 


\section{LIST OF FIGURES}

1.1 Gasoline Price History $[1] \ldots \ldots \ldots$

2.1 Basic EV Powertrain Construction . . . . . . . . . . . . . . . . . 9

2.2 Cost of Controller Based on Rated Continuous Current . . . . . . . . . . . . . . 11

2.3 Comparative Fuel Economies and Drivetrain Efficiencies of FUDS and HEWFET Driving Cycles $[2] \ldots \ldots \ldots$

2.4 Overall Traction Drive System Efficiencies Using the FUDS and HWFET Drive Cycles $[2] \ldots \ldots \ldots \ldots$

2.5 Basic Diagram of an IVT . . . . . . . . . . . . . . . . . . . 13

2.6 Basic HydroStatic Drive . . . . . . . . . . . . . . . . . . . . . 15

2.7 Mechanical Planetary Differential Used as an IVT . . . . . . . . . . . . . . 16

2.8 Basic Transistor Operation . . . . . . . . . . . . . . . . . . . . . . . 17

2.9 Ward Leonard Block Diagram w/ Field Weakening . . . . . . . . . . . . . . . . . 19

2.10 Current Carrying Wire Moves in the Presence of a Magnetic Field . . . . . . . . 20

2.11 Components of a DC Motor/Generator [3] . . . . . . . . . . . . . . . 21

2.12 Magnetization of an Iron Core Showing Hysteresis [4] . . . . . . . . . . . 22

2.13 Schematic of a Separately Excited DC Machine . . . . . . . . . . . . . . . . . 22

2.14 Schematic of Ward Leonard Motor Generator Set . . . . . . . . . . . . . . . . 24

3.1 Typical EV Power Flow . . . . . . . . . . . . . . . . . . . . . . . 25

3.2 Ward Leonard IVT Power Flow _ . . . . . . . . . . . . . . . . . 26

3.3 Ideal Electric Vehicle Prime Mover . . . . . . . . . . . . . . . . . . . . . . 26

3.4 EV with Ward Leonard IVT . . . . . . . . . . . . . . . . . . . . . 27

3.5 HEV with Ward Leonard IVT . . . . . . . . . . . . . . . . . 27

3.6 Test Setup . . . . . . . . . . . . . . . . . . . . . . . . . . . . . . . . . . . 28

3.7 Photograph of Test Setup . . . . . . . . . . . . . . . . . . . . . . 33

3.8 Prime Mover with Controller . . . . . . . . . . . . . . . . . . . . . . . . 34

3.9 DC Shunt Wound 1/4 HP Motor Used in Testing . . . . . . . . . . . . . . . . . 35

3.10 Photograph of Loading Motor Used . . . . . . . . . . . . . . . . . . 36

3.11 Photograph of Resistive Heating Elements . . . . . . . . . . . . . . . 36

3.12 Photograph of Shunt used . . . . . . . . . . . . . . . . . . . . . . . 38

3.13 Photograph of Experimental Setup . . . . . . . . . . . . . . . . . . . . . . . . . 39

3.14 Quadrature Encoding [5] . . . . . . . . . . . . . . . . . . . . 40

3.15 FPGA Block Diagram . . . . . . . . . . . . . . . . . . . . 40

3.16 Real Time Block Diagram . . . . . . . . . . . . . . . . . . . . . . 43

3.17 Real Time Front Panel . . . . . . . . . . . . . . . . . . . . . . . . 44

3.18 Project Window . . . . . . . . . . . . . . . . . . . . . . . . 44

4.1 Control Number Defined by Field Voltages _ . . . . . . . . . . . . . . . 46

4.2 Field Power of All Tests According to Control Number . . . . . . . . . . . . . . . 46

4.3 Generator Output Voltage Control . . . . . . . . . . . . . . . . . . . . . . . . 47

4.4 Generator Power Output Control and Corresponding Control Power . . . . . . . . 48

4.5 Generator Control Factor . . . . . . . . . . . . . . . . . . . . . . . . . . . 48 
4.6 Speed Control by Generator Field Control . . . . . . . . . . . . . . . . . . . . . 49

4.7 Power Output vs Control Number . . . . . . . . . . . . . . . . . . . . . . . . 49

4.8 Output Speed Using Generator Field Control and Motor Field Weakening . . . . 50

4.9 Power Output vs Control Number with Field Weakening . . . . . . . . . . . . 50

4.10 Efficiency of the Generator under Varying Load . . . . . . . . . . . . . . . . 51

4.11 Efficiency of the Motor under Varying Load . . . . . . . . . . . . . . . . . 51

4.12 Efficiency of the Ward Leonard System with a PM Motor . . . . . . . . . . . . . 52

4.13 Efficiency of the Ward Leonard System with Field Weakening . . . . . . . . . . 52

4.14 Torque Output of a Stalled Motor vs Control Number . . . . . . . . . . . . . . . . . 53

4.15 Relationship of Control Power to Output Power . . . . . . . . . . . . . . . . 54

4.16 Control Factor Using Generator Field Manipulation Under Different Loads . . . 54

4.17 Output Power vs Combined Controller Power In . . . . . . . . . . . . . . . . . 55

4.18 Control Factor of System with Field Weakening . . . . . . . . . . . . . . . 55

5.1 Prime Mover Power vs Output Power . . . . . . . . . . . . . . . . 61

5.2 Power Output vs Controller Power . . . . . . . . . . . . . . . . . . . . 62

5.3 Power Output vs Controller Power . . . . . . . . . . . . . . . . . . . . 62

5.4 Trend of DC Controller Cost Based on Power Capabilities [6] [7] . . . . . . . . . . 64

A.1 Final Experiment Wiring . . . . . . . . . . . . . . 76

A.2 Motor Hierarchy Chart $[8] \ldots \ldots \ldots$. . . . . . . . . . . . 77 


\section{NOMENCLATURE}

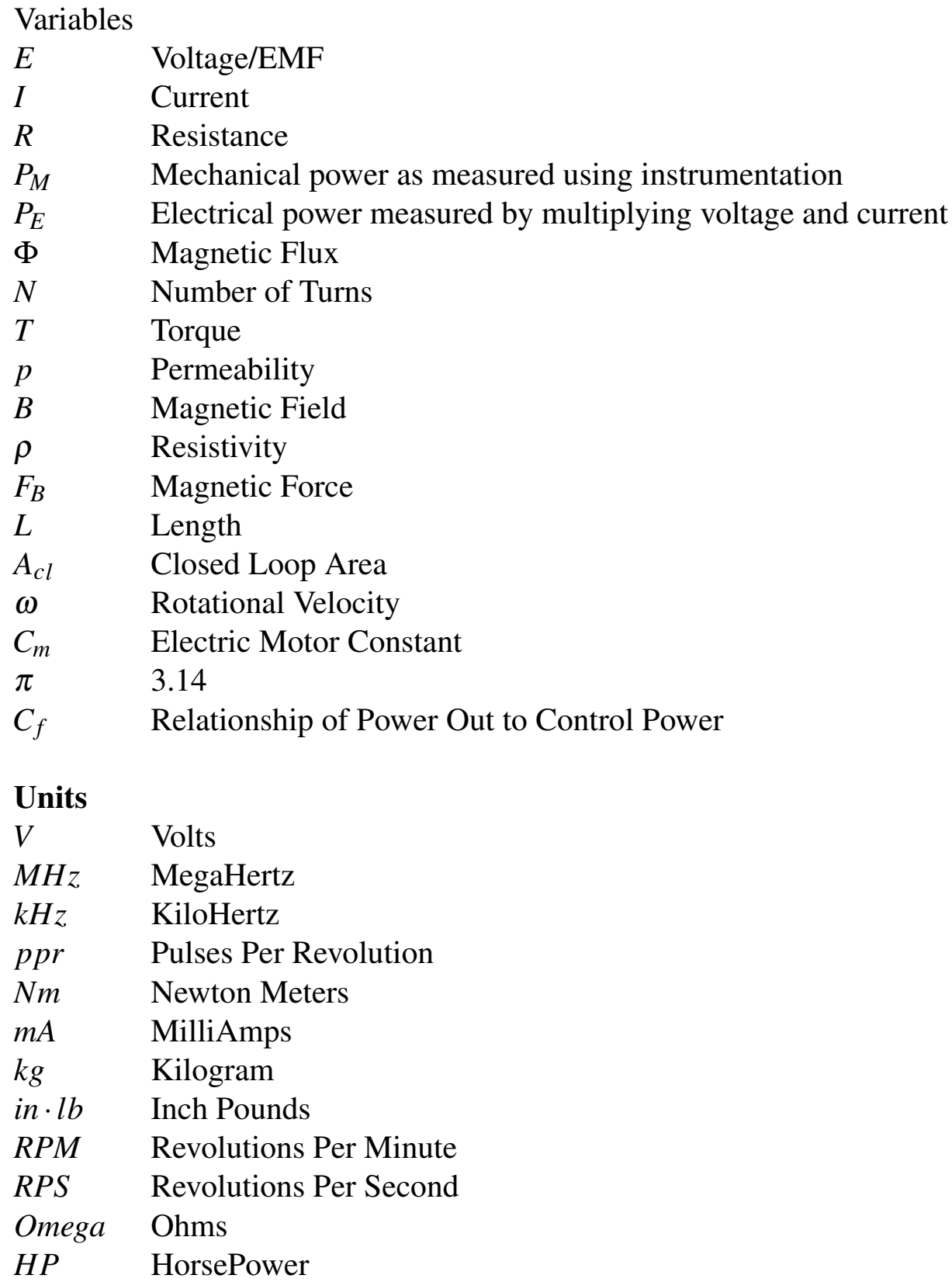

Units

V Volts

$\mathrm{MHz} \quad$ MegaHertz

$k \mathrm{~Hz} \quad$ KiloHertz

ppr Pulses Per Revolution

$\mathrm{Nm} \quad$ Newton Meters

$m A \quad$ MilliAmps

kg Kilogram

in $\cdot l b \quad$ Inch Pounds

RPM Revolutions Per Minute

RPS Revolutions Per Second

Omega Ohms

HP HorsePower

\section{Glossary of Frequently Used Terms and Acronyms}

Armature

Back EMF

Commutator

EMF

Field

Series Motor

Separately Excited
Rotating component conducting majority of current

Opposing electromotive force induced in a motor (sometimes called counter EMF)

Method of conducting current to a rotating armature typically via brushes

Electromotive Force

Stationary component providing magnetic field

A DC motor with a wound field connected in series with the armature

A DC motor with a separate power supply for the field 
Shunt Motor

AC

CAFE

CARB

CVT

DC

EREV

EV

EV1

FPGA

FUDS

HEV

HWFET

IGBT

ICE

IO

IVT

MOSFET

MPG

PM

PWM

SE

SCR

SUV

VFD

ZEV
A DC motor with a wound field connected in parallel with the armature

Alternating Current

Corporate Average Fuel Economy

California Air Resources Board

Continuously Variable Transmission

Direct Current

Extended Range Electric Vehicle

Electric Vehicle

Electric Vehicle produced by General Motors

Field Programmable Gate Array

Federal Urban Driving Schedule

Hybrid Electric Vehicle

Highway Fuel Economy Test

Insulated-Gate Bipolar Transistor

Internal Combustion Engine

Input/Output

Infinitely Variable Transmission

Metal Oxide Semiconductor Field Effect Transistor

Miles Per Gallon

Permanent Magnet

Pulse Width Modulation

Seperatly Excited

Silicon Controlled Rectifier

Sport Utility Vehicle

Variable Frequency Drive

Zero Emissions Vehicle 


\section{CHAPTER 1. PROBLEM STATEMENT}

\subsection{Introduction}

The first electric powered vehicles date back around the 1830 with several inventors credited [9]. The first production electric car was introduced as early as 1910 [10], however most automobiles today use a petroleum based fuel for propulsion. In the past several years the increase in demand for fuel efficient and less polluting vehicles has motivated the redevelopment of electric vehicles (EVs) and also hybrid electric vehicles (HEVs) [11]. Great progress has been made, and the viability of mass producing an electric vehicle is shifting to reality. However, this development has not come without challenges. Current electric vehicles intended for production by automotive manufacturers use complex and expensive components, such as electronic controllers, $\mathrm{AC}$ motors and many cells in a battery pack. This dramatically raises the complexity and cost of the vehicle [11]. The potential to reduce the cost of an EV is present [12]. One possible method of reducing the complexity and potentially reducing the initial cost of an EV is through the use of DC motors and an Infinitely Variable Transmission (IVT).

\subsection{Motivation for use of EVs and HEVs}

Although there are many reasons for the implementation of EVs and HEVs the two most relevant are air pollution emissions and fuel costs.

\subsubsection{Emissions}

Emissions produced by vehicles have become a concern for urban areas. Environmental impacts from increased motor vehicle activity in urban areas have caused government entities to regulate emissions from vehicles. Legislation is currently being worked on to increase the Corporate Average Fuel Economy (CAFE) standards by $25 \%$ by the year 2017 [13]. Agencies 
like the California Air Resources Board have instituted a Zero Emissions Vehicle (ZEV) mandate which requires auto makers in California to sell a certain percentage of their vehicles with no harmful emissions [14]. Smog produced from vehicles causes problems such as health risks for those living and working in cities throughout the world. There have been significant advances in the control of emmission in the last 50 years from internal combustion vehicles but the problem still exsists. Electrical engergy produced in a stationary location in large quantities from a coal fired power plant is cleaner and more efficient than from an internal combustion engine. Therefore it is logical that electrical power could be produced in large scale power plants and tranfered to each vehicle in order to reduce emissions and improve fuel consumption.

\subsubsection{Fuel Prices}

As nations like India and China develop, the demand for gasoline will continue to rise. Major sources of oil are located in foreign countries. As the world's demand for oil continues to rise the supply diminishes and causes energy dependency problems for the US. Figure 1.1 shows that the price of gasoline has been rising quickly over the past 12 years. Although there was a steep drop in late 2008 due to a recession, prices are predicted to rise. The average new passenger car in 2011 got 33.8 MPG [15]. With a cost of $\$ 3.50$ per gallon of gasoline, the vehicle will consume over $\$ 10,000$ in fuel alone over a 100,000 mile life. This cost in fuel is approaching the purchase price of some vehicles.

\subsection{Current Solutions}

The motivation is clean air and cheaper fuel. The solutions available to consumers today are EVs and HEVs. According to the 2009 National Household Travel Survey, 93\% of daily commuters drive alone for a round trip total of less than 25 miles [16]. This daily commute is well within the range of current EVs available on the market today such as the Nissan Leaf. Yet this limited range has caused what some call 'range anxiety'. Consumers fear that the vehicle will not provide sufficient range to meet their needs, expecially when delayed charge time is required before continued use. For this reason several companies have approached these concerns differently. General Motors has produced a 'Range Extended Electric Vehicle', the Chevy Volt, which is an 


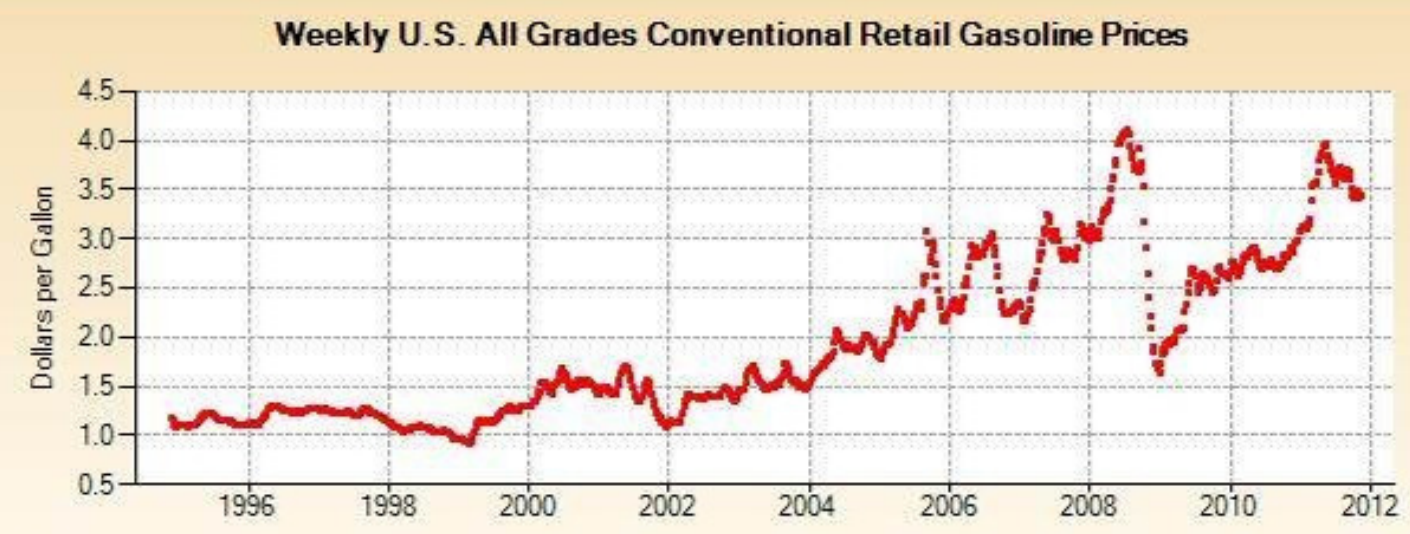

Source: U.S. Energy Information Administration

Figure 1.1: Gasoline Price History [1]

electric vehicle that also contains an internal combustion engine. Toyota now offers a Plug-in version of the popular hybrid Pruis. There are various basic models of vehicles that offer a hybrid powertrain such as the Toyota Camery and Ford Explorer which strictly have the goal to increase fuel mileage. With various companies developing solutions the vehicles vary greatly in structure and complexity. Although these vehicles are becoming more popular, there are some concerns for consumers, two of which are cost and safety.

\subsubsection{Cost}

Current production EVs and HEVs are expensive. Recently Tesla released its electric roadster with a price tag of over $\$ 100,000$. This price is of course too high for the general public. Last year, two plug-in electric vehicles were launched, the Chevy Volt and Nissan Leaf priced at approximately $\$ 41,000$ and $\$ 33,500$ respectively [17]. Even though this price is partially offset by government tax credits, it is still too high for the average consumer. The current Prius Hybrid offers around 50 MPG where most other HEVs only offer up to a 10 MPG increase over their gasoline equivalents [18]. With some conventional vehicles reaching 40+ MPG, the extra cost associated with an electrified vehicle may not be worth it. Jon Bereisa, President and CEO of Auto Lectrification LLC, was GM's Director of Advanced Engineering and Technology Strategy where he architected General Motors' Extended Range Chevy Volt was quoted saying: 
"Until now the hybrid-systems guys tried to solve the issues all by themselves, and I've seen that lead to excessive cost and complexity; such as two motors, four clutches, two inverters, all within the confines of the transmission (the GM Two-Mode system). Thats quite a technical accomplishment, but with an $\$ 8,000-\$ 10,000$ incremental cost! We've got to avoid super-efficient solutions at a non-usable price [19]."

Every other major automotive manufacturer also has plans to release a vehicle with an electric power train in the near future. If the electric vehicle is to be a success, the cost of the vehicle must be reduced so that it can be affordable to most consumers and still be profitable for manufacturers.

\subsubsection{Safety}

Current electric vehicles operate with a dangerously high voltage. The complex battery packs with many cells are always energized, creating a potentially dangerous situation in case of an accident or during maintenance and repairs. A decrease in operating voltage could decrease battery system complexity and cost, while also decreasing the risk of electrocution. The complexity of the battery system is largely dependent on the system operating voltage. The output voltage of each cell is dependent not on the size of the cell, but rather the chemistry of the cell. To achieve the desired vehicle operating voltage for today's controllers, cells in a battery pack must be connected in series, increasing the voltage of the pack. Because battery chemistry determines battery cell voltage, Table 1.1 illustrates that the higher the operating voltage, the higher the number of cells required in the battery pack. Because each cell must be carefully monitored for voltage and temperature, the number of cells contributes to the complexity and cost of the battery pack and its management system. The cells may be larger to increase amp hours yet the higher the voltage the more battery cells are necessary.

Table 1.1: Number of Cells in a Battery Based on Operating Voltage

\begin{tabular}{|c|c|c|c|}
\hline Operating Voltage & $375 \mathrm{~V}$ & $60 \mathrm{~V}$ & $48 \mathrm{~V}$ \\
\hline Typical Cell Voltage & 3.75 & 3.75 & 3.75 \\
\hline Min. Req Cells & 100 & 16 & 12.8 \\
\hline
\end{tabular}


One of the direct dangers of electric vehicles is the risk of electrical shock. The danger in electrical shock is the amount of electrical current that passes through the body. Current can cause pain, injury and even death depending on the amount and the path of the current flow through the body. Table 1.2 shows the physical sensation associated with various amounts of current in milliamperes [20].

Table 1.2: The Physical Effects of Electric Currents

\begin{tabular}{|c|c|}
\hline Current $(m A)$ & Physical Sensation \\
\hline$<3$ & Not Sensed \\
$3-10$ & Mild Sensation \\
$10-20$ & Painful \\
$20-30$ & Cannot let go \\
$30-40$ & Muscular paralysis \\
$40-100$ & Severe shock, can be fatal \\
$100-200$ & Usually fatal \\
$200-1000$ & Severe burns, breathing stops, often fatal \\
$>1000$ & Dismemberment \\
\hline
\end{tabular}

The amount of current that actually flows through the body is dependent on the applied voltage and the resistance to current flow of the body. This is often referred to as Ohm's Law of Safety and is represented in Equation (1.1).

$$
I=E / R
$$

This equation demonstrates why signs often read 'Danger High Voltage'. The higher the operating voltage the greater the potential for higher current flow through the body [20]. When dealing with higher voltages, precautions are often taken to increase the resistance of the body. This includes precautions like wearing high resistance gloves, sealed shoes and making sure the workers' hands are dry $[21,22]$. Safety standards also recommend using only one hand while working on the vehicle, but this can be cumbersome for the technician. Because the average resistance of a human body including skin, ranges from $1000 \Omega$ to $10000 \Omega$ [23], less than $60 \mathrm{~V}$ is considered a safer voltage to avoid severe electric shock. 


\subsection{Direction}

High voltage, $\mathrm{AC}$ inverters, $\mathrm{AC}$ motors and controllers definitely have benefits, yet these come at a cost. Therefore alternative methods of control must be explored to enable a less expensive approach to EV and HEV drive train design that would allow for a lower operating voltage in order to increase safety.

One alternative that was first used in the later part of the 19th century for stationary applications would be to use a Ward Leonard motor generator set. This application of the Ward Leonard system would enable the controller to be taken out of the path of the high power flow, thus enable a reduction in size and cost of the controller. The prime mover, either an internal combustion engine or low voltage DC motor could run constant at its most efficient RPM. The Ward Leonard control system is a type of an electrical IVT that has been around for a century, yet its use in an EV or HEV has been overlooked.

This research will explore the possibilities of the Ward Leonard motor generator set for use in an EV or HEV by accomplishing the following objectives.

\subsection{Research Objectives}

1. Develop an empirical model based on equations that can be used to describe the Ward Leonard system.

2. Define a quantitative method of testing the Ward Leonard's ability to reduce controller size and potentially cost.

3. Construct and test a bench top model of the Ward Leonard system to validate the quantitative theoretical data.

4. Test the extent and benefit of the addition of motor field weakening.

5. Provide recommendations based on result for implementing the Ward Leonard system in an EV or HEV powertrain.

\subsection{Research Benefits}

The goal of this research is to provide information to automotive engineers to aid them in the design of EV and HEV powertrains, specifically taking advantage of the characteristics 
and benefits of the Ward Leonard control system. The impact of this research could affect several components of the electric power train system including: cost, reliability, safety, efficiency, weight, size and maintenance. This information could enable auto manufacturers to pursue alternative methods to EV and HEV drive train structure and control. Potentially this information could aid manufacturers in being able to produce an electric vehicle that is affordable, safe and profitable in comparison with current EVs, HEVs and conventional gasoline powered vehicles. 


\section{CHAPTER 2. BACKGROUND}

This chapter gives background on current methods of EV and HEV speed control methods, history of the Ward Leonard control method, explanation of infinitely variable transmissions (IVTs) and a detailed description of how the Ward Leonard system works.

\subsection{Electric Powertrain Construction}

Current electric vehicle (EV) powertrains utilize a power source, controller and motor. In some vehicles the controller must control power to multiple motors along with power generation from regenitive braking or an on board generator. In any case all of the power from the power source that is applied to the electric motor that drives the vehicle has to pass through the controller to the motor as shown in Figure 2.1.

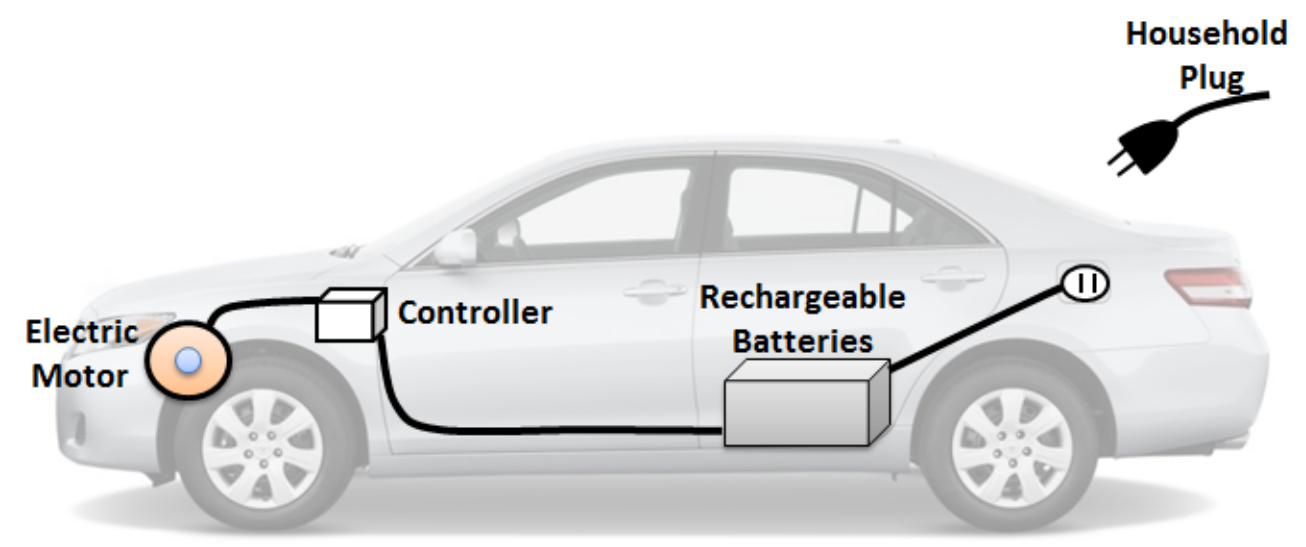

Figure 2.1: Basic EV Powertrain Construction 


\subsubsection{Power Source}

The most common form of power in an EV is the battery pack. Although there are many types of batteries they all provide a direct current (DC) power source. In some cases the power is produced by a fuel cell or ICE connected to a generator but in any case the power to and from the battery must be in the form of DC.

\subsubsection{Controller}

Current EV and HEV controllers utilize state of the art electronics and solid state switching devices. Currently there are two main types of controllers, DC and alternating current (AC). DC controllers mostly use pulse width modulation (PWM) in which the average amount of power provided from the controller to the motor is accomplished by switching on and off the power for specific amounts of time. AC controllers use a variable frequency drive (VFD) in which the controller must provide precise AC signals to the motor by turning on and off the power at a specified time, and in the case of 3 phase construction, a specific pole. PWM and VFD methods of speed control are complex and expensive. VFD controllers tend to cost more than PWM controllers nevertheless, the cost of the controller largely depends on it current carrying capabilities, for example the speed controller for a small computer fan only costs several dollars, where a 2000 amp PWM controller will cost around $\$ 5000$ [6]. The complexity and cost arise from the need to switch current flow on and off in a controlled manner. This switching is accomplished with the use of metal-oxide-semiconductor field-effect transistors (MOSFET) or insulated gate bipolar transistors (IGBT). Although advances in these technologies are allowing higher current ratings, current capacity is the limiting factor and the higher the current, the greater the cost. Various manufactures supply these controllers for various applications from go karts and golf karts to homebuilt EVs. A graph of cost vs. current capacity for these controllers is shown in Figure 2.2. Some controllers of the same current rating show a higher cost due to additional features provided.

\subsubsection{Motor}

There are various types of electrical motors used in EV and HEV applications. Consistent with controllers there are two main types, DC and AC. Most small EVs utilize a DC motor of 


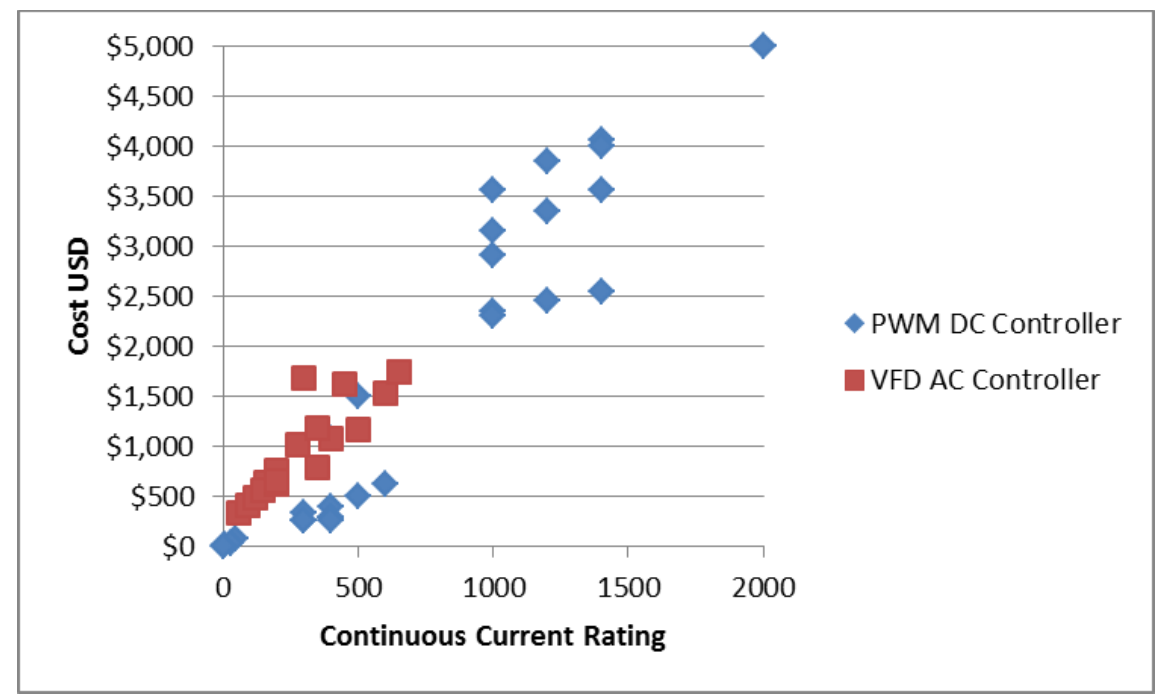

Figure 2.2: Cost of Controller Based on Rated Continuous Current

which there are various sub-types including series, shunt, cumulative, differential, wound and permanent magnet (PM) which require a PWM controller [8]. A motor heirarchy chart is shown in the Figure A.2 in the Appendix. Most mass produced HEVs employ an AC motor which are brushless DC or induction motors which require a VFD controller [8]. Each motor has its advantages and disadvantages which can be found in references listed under [8]. Because the power source is in the form of DC, it is logical to utilize a DC motor. DC motors only require one signal which is then commutated using brushes. Most AC motors are 3 phase which require 3 synchronized signals but do not have brushes. For this reason AC motors typically provide a slightly higher efficiency due to friction and commutation required by brushed DC motors.

\subsubsection{Efficiency and Fuel Economy}

Fuel economy of a vehicle is different than efficiency and is measured in miles per gallon (MPG). Fuel economy basically sums up the total wasted energy of a vehicle due to factors such as wind resistance, road friction, vehicle weight, energy conversion efficiencies and acceleration times. Efficiency of a drive train is a calculation of power loss which are factors like that of resistance, heat and friction. The relation of drive train efficiency and fuel economy can be seen in Figure 2.3 which was taken from a simulation of a mid sized SUV [2]. The internal combustion engine vehicle (ICEV) and hybrid electric vehicle (HEV) were simulated under two standard tests, 
the Federal Urban Driving Schedule (FUDS) for city (CITY) and HighWay Fuel Economy Test (HWFET) for highway (HWY). The power used to calculate drive train efficiency for the ICEV shown in Figure 2.3 was $100 \%$ input from the gasoline engine. The input for the HEV had $37.5 \%$ power provided by an electric motor. We can see that by adding an electric motor the fuel economy increased by 8.1 MPG for city conditions and 12.8 MPG for highway driving. The drivetrain efficiency gains were $6.1 \%$ for city and $23.9 \%$ for highway.

Comparative Fuel Economies (MPG) and Drive Train Efficiencies (\%) over the FUDS (City) and HWFET

(Highway) Drive Cycles

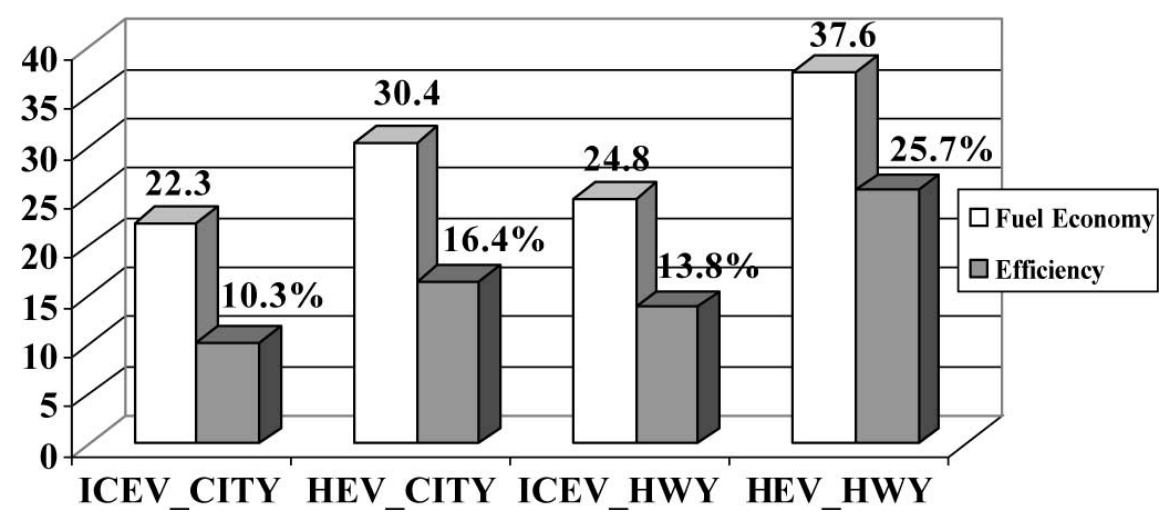

Figure 2.3: Comparative Fuel Economies and Drivetrain Efficiencies of FUDS and HEWFET Driving Cycles [2]

Efficiency is a driving factor of controller design and construction on todays EVs and HEVs. The power to weight ratio of gasoline compared to the power in batteries is very high, therefore every bit of power from a battery pack is highly valued. The same study mentioned above on a mid sized SUV showed an estimated efficiency of the electrical portion of an HEV. The HEV studied used a VFD with IGBTs and a 3 phase traction motor. The respective efficiencies are shown in Figure 2.4 under the FUDS and HWFET drive cycles [2]. This data shows a comparison point with which the Ward Leonard system can be gauged.

\subsection{Infinitely Variable Transmission}

An Infinitely Variable Transmission (IVT) offers advantages over standard or automatic transmissions [24]. An IVT is a device that allows a constantly varying ratio from input to output by 
Average System Efficiency Under FUDS (City) and

HWFET (Highway) Drive Cycles

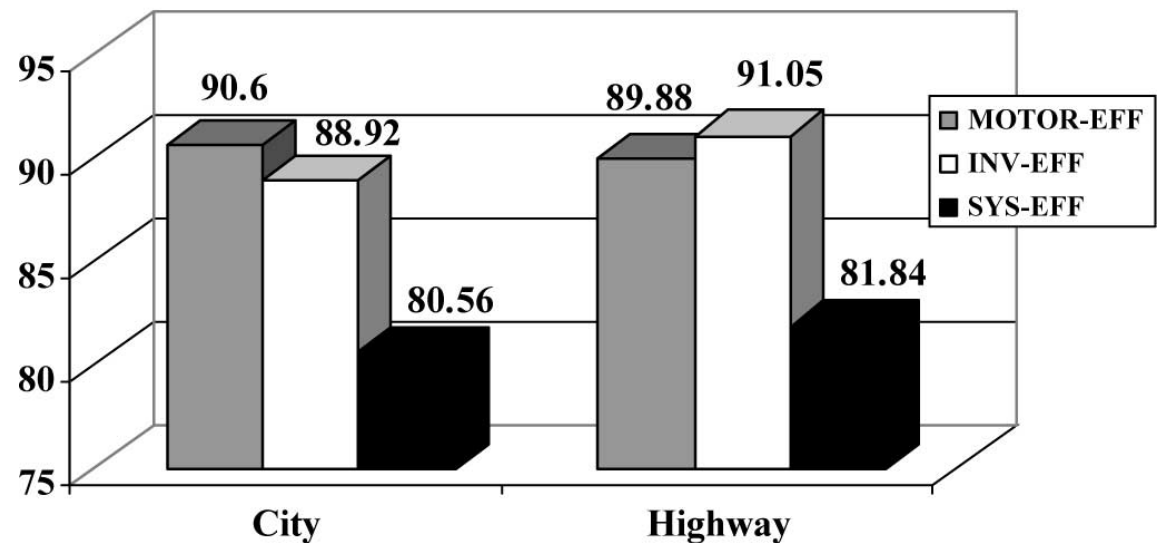

Figure 2.4: Overall Traction Drive System Efficiencies Using the FUDS and HWFET Drive Cycles [2]

changing the state of the device. Research has already shown that a power train that incorporates an infinitely variable transmission (IVT) can be more efficient than conventional transmissions [25]. The difference between an IVT and other transmissions in an automobile is that it is never in a fixed gear. The ratio is able to change infinitely without decoupling the input and output. IVTs are similar to a continuously variable transmission (CVT), yet offer improved performance. A CVT offers one direction of continually changing ratio where the IVT offers a complete reverse of direction without decoupling the input and output.

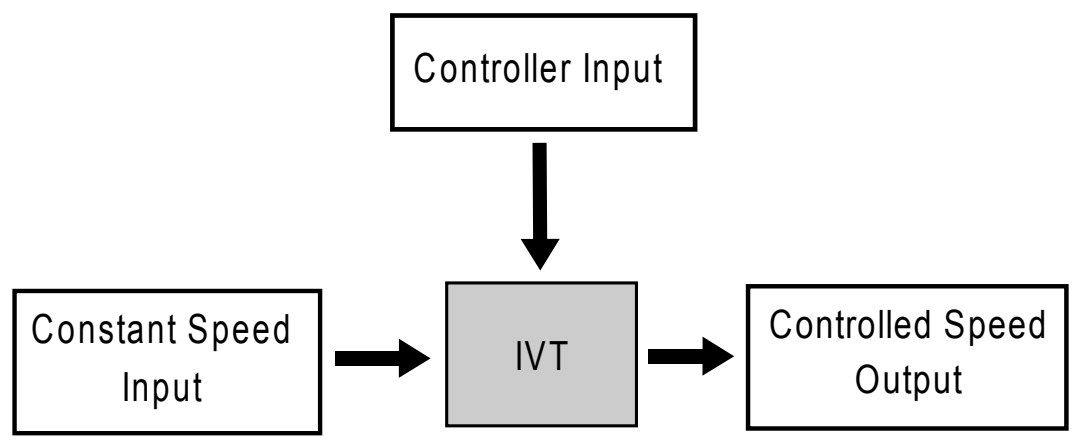

Figure 2.5: Basic Diagram of an IVT

In this application the input to an IVT is called the prime mover which is a constant speed input. The torque provided by the prime mover will vary depending on the draw from the IVT 
thus varying the power input. The power drawn from the prime mover depends on the state of the transmission and the torque it requires from the prime mover. The diagram shown in Figure 2.5 shows the basic black box operation of an IVT.

There several different types of IVTs. Some current IVT systems rely on fluid power, electrical resistivity and friction. These all have restrictions associated with each system. There is work on making a positively engaged IVT feasible. A few of these systems are explained below to gain further understanding.

\subsubsection{Hydrostatic Transmission}

In a hydrostatic transmission the mechanical energy of the input drive shaft is converted into hydraulic fluid under pressure and then reconverted into mechanical energy at the output shaft. A hydrostatic drive is common among high powered slow moving vehicles where various speeds are needed, such as grain harvesters and swathers. They are also used on small tractors and lawn mowers. This type of IVT uses a hydraulic fluid to transfer power, trading torque for speed or visa versa. A traction motor is coupled to a positive displacement hydraulic pump which spins at a constant speed, either for efficiency or power. The displacement of the pump is variable which can be controlled by a swash plate or other means which controls the stroke of the piston therefore controlling the flow rate of the pressurized hydraulic fluid [26]. In most cases the swash plate is able to produce a positive or negative displacement, thus enabling forward and reverse operation. The fluid transfers power to a hydraulic motor which speed is controlled by the amount of flow delivered by the pump. Therefore a small controller input to the swash plate varies the characteristics or state of the pump allowing for an infinitely controlled output speed. The basics of a hydrostatic drive are shown in Figure 2.6. Another benefit of a hydrostatic drive is that the control power is only required when changing speeds and is not an input during steady state operation.

\subsubsection{Mechanical Differential}

A mechanical differential is a device with three input/outputs (IO) [24]. In order for this device to act as an IVT one IO is powered at a constant speed as an input. Another IO is driven at a variable rate which changes the effective gear ratio between the first IO and the final IO that 


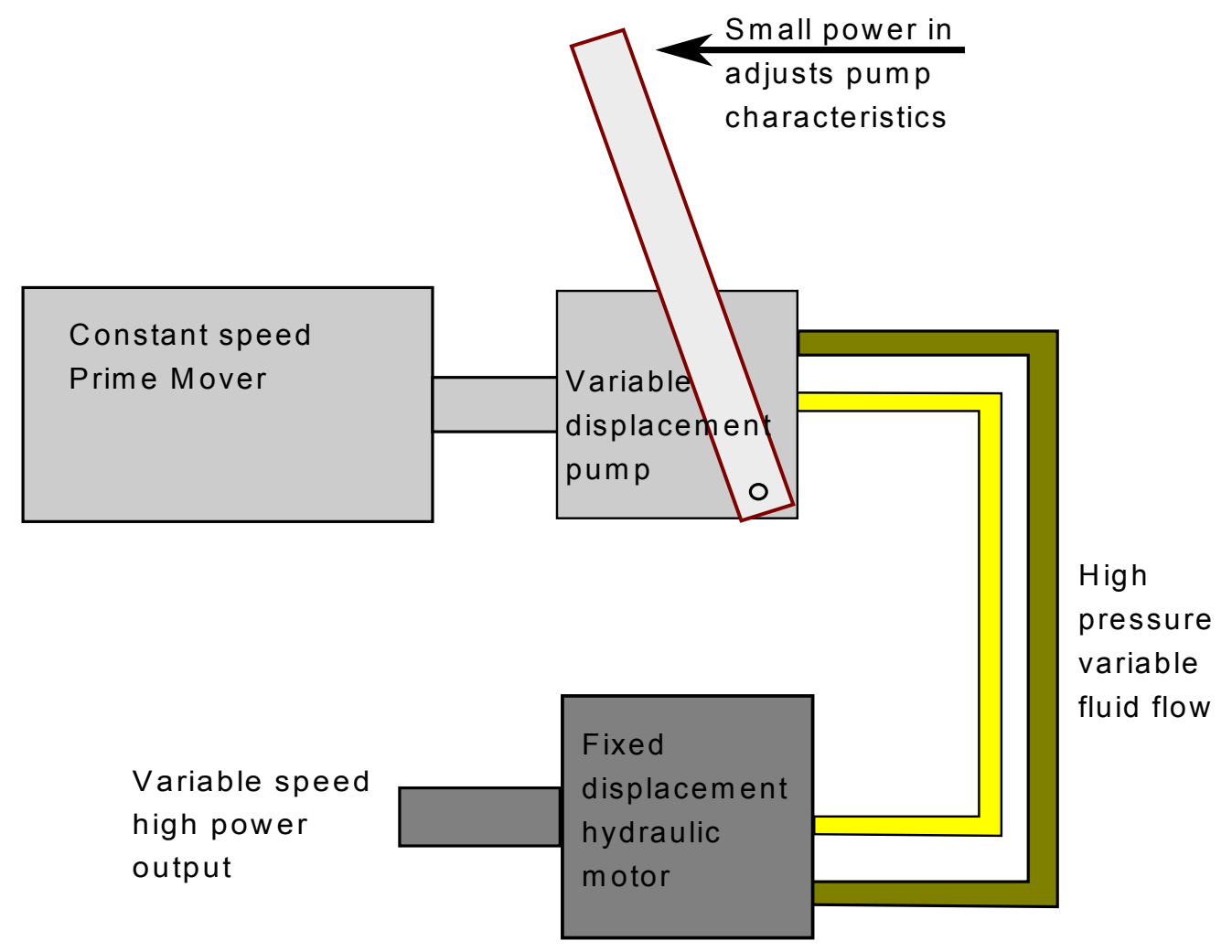

Figure 2.6: Basic HydroStatic Drive

acts as an output. Ideally a large traction motor could be coupled to the first IO as a constant input. The second IO is a smaller control motor, simple to control which varies the ratio between the first and third IOs, completing the IVT [24]. This type of IVT can be constructed using any differential configuration, a planetary differential is shown in Figure 2.7. The Toyota Prius and Chevy Volt already use a planetary gear set to gain some benefits of an IVT yet also include expensive and complicated electronics and battery management systems.

The limiting factor and drawback for most CVTs today is that they rely on friction to transfer torque from the input to the output. The advantage of using a differential as an IVT is that the input and output are always positively engaged, this allows for higher torque and efficiency capabilities. There are also challenges that are being worked on with this type of IVT. Currently the motors have to be equally sized to eliminate the input back driving the controller input. This topic can be explored more in reference [24]. 


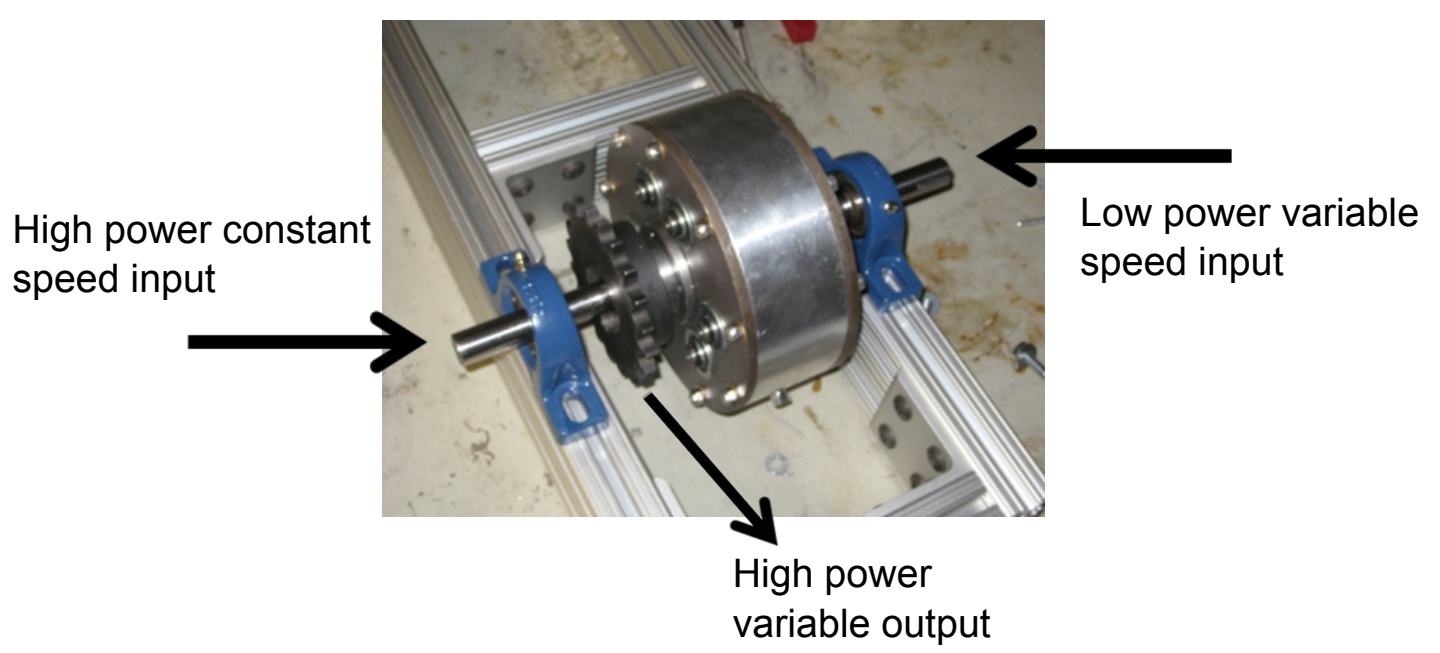

Figure 2.7: Mechanical Planetary Differential Used as an IVT

\subsection{Transistors}

An analogous electrical system to the hydrostatic drive and the mechanical differential is a transistor. The primary use for a transistor is to control the amount of current in a circuit [27]. Transistors are often used as amplifiers in electrical circuits. A transistor is constructed of two types of materials, $\mathrm{N}$ type and $\mathrm{P}$ type. These materials are in a sandwich configuration, either NPN or PNP. The three sections are labeled emmiter, collector and base as shown in Figure 2.8. By increasing the voltage to the base on an NPN transistor, more charge carriers will be available and more emitter-collector current will flow. Likewise if the voltage to the base is decreased the emitter-collector is decreased. As a result, a relatively large amount of power can be controlled by a small amount of power, thus displaying the characteristics of an IVT. The power gain of a transistor can be 40,000 or higher in some applications. [27]

\subsection{Ward Leonard}

\subsubsection{History}

The Ward Leonard Motor Control system was patented by in 1891 as a means to control the speed of a DC electric motor [28]. It was the most widely used method of controlling elevators from the early 1900's until the mid 1980's [29]. It was used in industrial applications where 


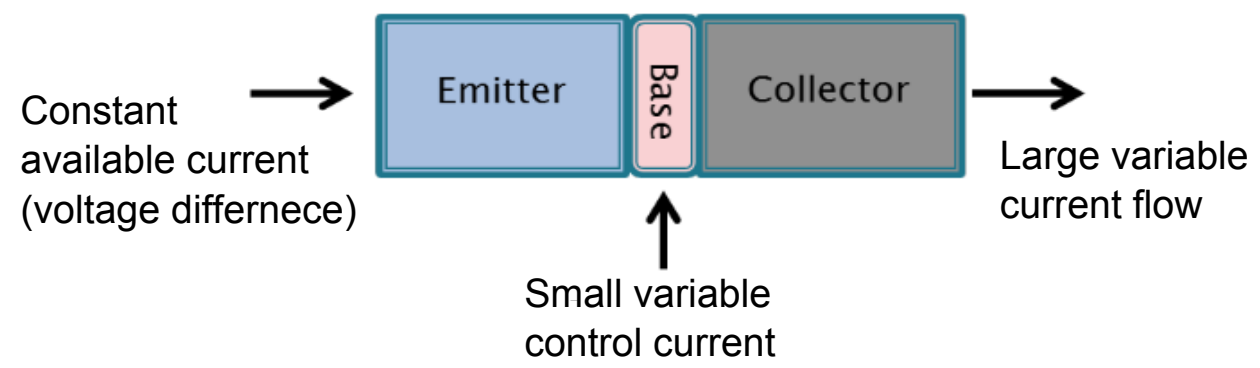

Figure 2.8: Basic Transistor Operation

variable speed drives were required. It provided a means of varying the speed of a motor supplied by constant power. The system was also used in early anti-aircraft tracking devices. The tracking motion of the system was extremely smooth and precise so designers chose it to equip the famous SCR-584 radar in 1942 [30]. The Ward Leonard system was first available on early excavators in 1920 with the added upgrad of field weakening five years later [31]. The system was first used as an IVT in 1918 on the first diesel electric locomotive [32]. An invention in 1922 by Hermann Lemp made the diesel electric locomotive controllable by a single lever. Its use was wide spread until the invention of thyristors or SCRs (silicon controlled rectifier) in the late 1950's [33,34].

Prior to the invention and use of thyristors there were many other control methods that attempted to replace the Ward Leonard system. The reason to replace the Ward Leonard system was the need for 3 equally sized electric motors needed for operation. In the case of the elevator an AC motor, separately excited DC generator and a DC motor were needed. The thyratron tube, the ignition tube, the excitron tube all were tried, but none eliminated all of the objections of the system and introduced some of their own. Magnetic cores, induction regulators, and variable output transformers tried to obtain an adjustable ac voltage, with diode bridge rectifiers to convert to DC but, again, none of these really overcame the need for 3 equally sized machines present in the Ward Leonard System [33].

The use of thyristors provided a method to convert a constant AC source to a variable DC voltage. This new method replaced only some of the applications of the Ward Leonard approach completely. The locomotive application, for example, did not use an AC power source but used a diesel engine as the prime mover. Yet with the advent of solid state switching devices there was some room for improvement. The cost of these new switching devices and inverters were 
expensive. In the 1970's the cost of an AC motor was 50\% more expensive than its DC equivalent, while AC drives where three times that of a comparably sized DC drive [35]. With this much of an increase in cost the savings of efficiency gains and decrease in maintenance in some applications were not viable. Yet with mass production AC industrial motors have become less expensive, yet in order to control the speed of these motors expensive electronics are still needed. There are some efficiency savings by using expensive AC control which do outweigh initial costs, for example, in the railroad industry. A locomotive would be employed for a number of years, over which a large amount of fuel would be consumed. A relatively small efficiency savings in percent would translate into a large cost savings in fuel. This cost would pay for the higher initial electronics cost many times over. This being said there are now numerous design schemes, most containing aspects of the original Ward Leonard system. This same trend is seen in other diesel electric applications like that of large scale dump trucks and machinery. There is no one all inclusive explanation of why the Ward Leonard system has been replaced. The reasons for its replacement vary greatly depending on application. Although its long use in other applications has been fading away, its simple construction and controllability make it a possible solution for the expensive controllers used today in EV and HEV automobiles.

\subsubsection{Layout}

The Ward Leonard system is an electrical device analogous in architecture to hydraulically operated hydrostatic devices. It provides a means of creating a variable DC voltage from a constant mechanical input. This variable voltage is used to provide a variable speed mechanical output. It consists of 1) a constant speed prime mover, 2) separately excited (SE) DC generator 3) DC motor and 4) variable DC power supply as shown in Figure 2.9. The prime mover in many instances is an $\mathrm{AC}$ motor yet can be any source of rotating machinery such as another DC motor or an internal combustion engine (ICE). The separately excited DC generator is mechanically connected directly or though a fixed gear ratio to the constant speed prime mover. The armature is connected with a fixed conductor to the DC motor. The variable DC power supply is the controlling source which is connected electrically to the field of the SE DC generator. This system is a 4 quadrant system allowing for forward and reverse operation with regenerative characteristics in both directions [36]. This system can be expanded with the use of a 5) SE DC motor in place of the 3) DC motor along 
with a 6) separate variable DC power supply connected the to field of the SE DC motor. The SE DC motor enables field weakening which increases the speed range of the output. In order to understand the detailed workings of the Ward Leonard system the principles of basic motor and generator operation must be understood. These along with field weakening are explained in some detail below.

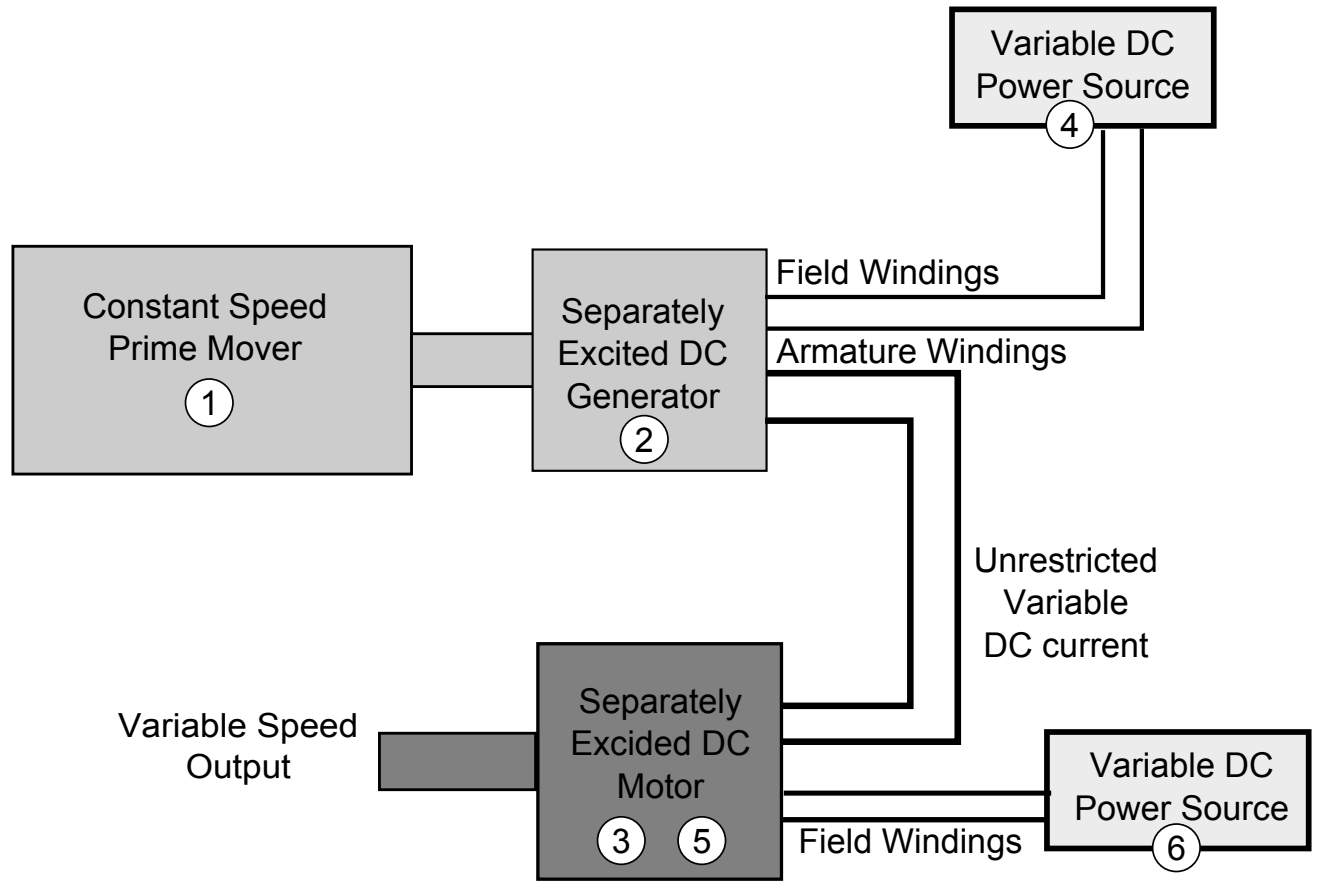

Figure 2.9: Ward Leonard Block Diagram w/ Field Weakening

\subsubsection{Electromagnetism}

A conductor carrying current in the presence of a magnetic field will have a resulting mechanical force. This force can be predicted using the right hand rule according to Equation $2.1[37,38]$.

$$
\vec{F}_{B}=\vec{L} I \times \vec{B}
$$

Where $\vec{L}$ is a vector pointing in the direction of current flow with a magnitude equal to the length of the conductor, $I$ is the current, $\vec{B}$ is a vector in the direction of the magnetic field and $\vec{F}_{B}$ is the 
resultant force vector of the interaction. Thus by increasing the strength of the magnetic field or by increasing the current in the wire, the force exerted on the wire will increase. As shown in Figure
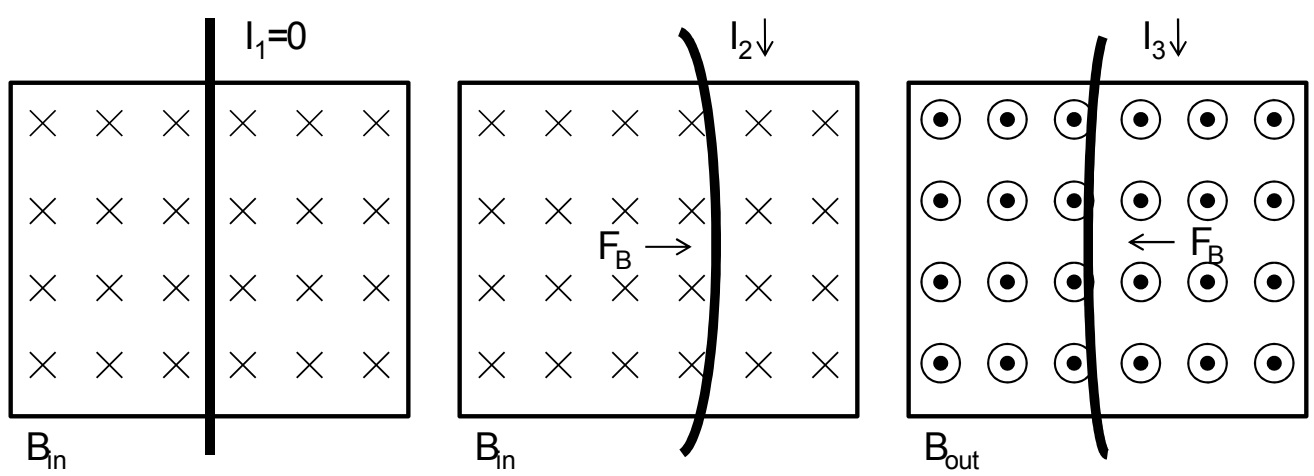

Figure 2.10: Current Carrying Wire Moves in the Presence of a Magnetic Field

2.10 and because of Equation 2.1, the direction of movement can be predicted using the right hand rule, where the thumb is the direction of the current $(I)$, the index finger is the direction of the magnetic field $(B)$, and the middle finger is the resultant force vector $\left(F_{B}\right)$ [37]. Electric motor construction allows this force to be applied as a torque for rotational power. All electric motors operate on this principle.

\subsubsection{Generators}

Electromotive force (EMF) is an electrical potential created by varying magnetic flux through a closed loop according to Faraday's law of induction, shown in Equation 2.2. EMF $(E)$ is measured in volts and drives current through a conductor according to Equation 1.1. EMF is directly proportional to the time rate of change of the magnetic flux $\left(\Phi_{B}\right)$ through a closed loop.

$$
E=-\frac{d \Phi_{B}}{d t}
$$

where

$$
\Phi_{B}=A_{c l} * \vec{B}
$$


The area of the closed loop $\left(A_{c l}\right)$ and the magnetic field $(\vec{B})$ represent a magnetic flux shown in Equation 2.3. The rotation of the armature loop in the presence of a constant magnetic field will cause a change in flux . Also a variation in magnetic field strength will cause a change in magnetic flux. Figure 2.11 shows the components of a DC motor/generator.

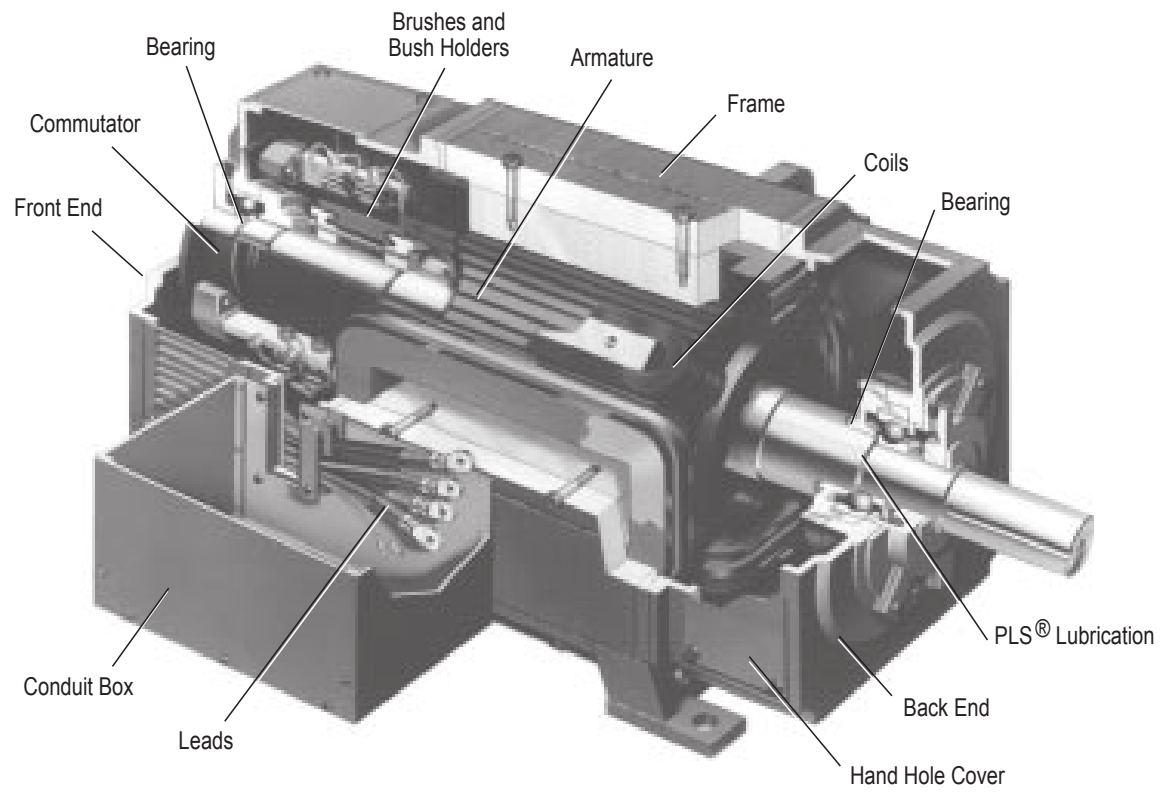

Figure 2.11: Components of a DC Motor/Generator [3]

\subsubsection{Separately Excited DC Machines}

All motors and generators need a magnetic field in which to operate. The field can be produced by permanent magnets or by electromagnets. In the case of SE motors and generators, the magnetic field is created by an electromagnet. The field and armature are connected to separate power supplies as shown in Figure 2.13 [36,39]. The magnetic field is produced by multiple turns of a wire with a current flowing through it, surrounding an iron core. The magnetic field strength can be predicted by using Figure 2.12. The magnetic strength $B$ or $M$ shown on the Figure is a linear relationship at low currents $I$, yet as a ferromagnetic material is pushed into saturation, the magnetic field strength reaches a limit shown in Figure 2.12 of which more current will not produce a higher magnetic strength. Also hysteresis has a effect on SE machines. Hysteresis is a 
residual magnetic presence on the iron core after the current flow in the coil is halted as shown in Figure 2.12 [4].

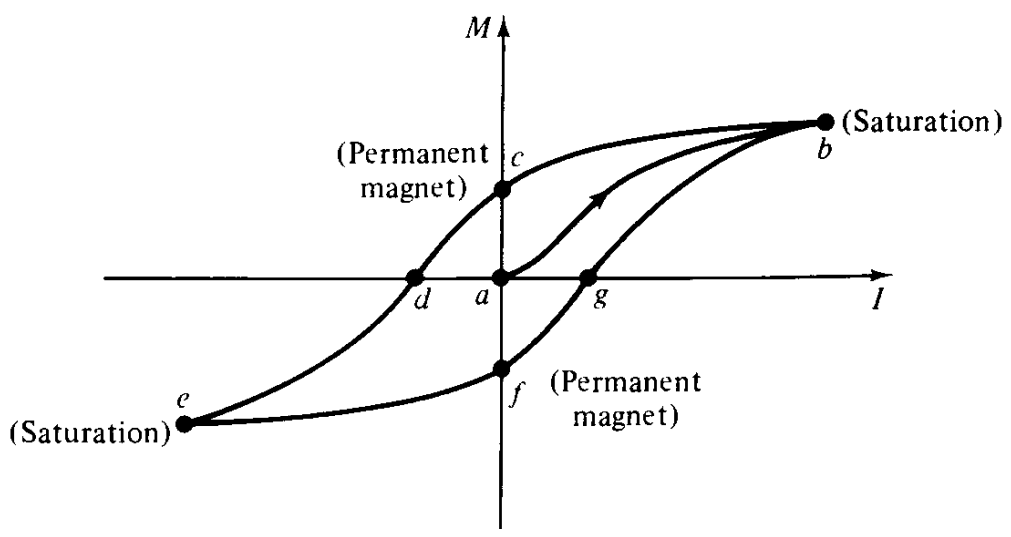

Figure 2.12: Magnetization of an Iron Core Showing Hysteresis [4]

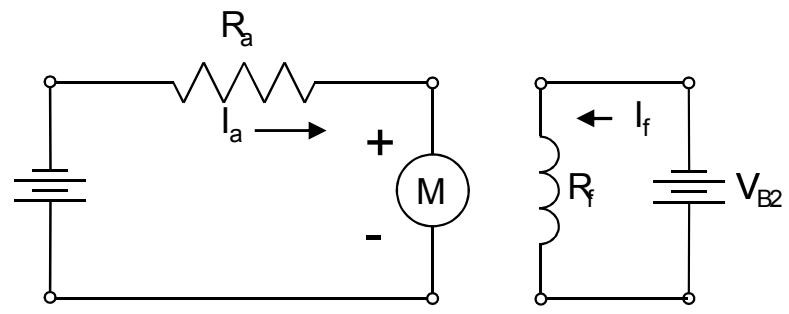

Figure 2.13: Schematic of a Separately Excited DC Machine

\subsubsection{Ward Leonard Empirical Model}

Voltage controls the rotational speed $(\omega)$ of a wound DC motor. The speed of the output is proportional to the voltage $(E)$ suppled to the armature [8]. Equation 2.4 shows this relationship where $\left(C_{m}\right)$ is a constant depending on motor construction and is found experimentally.

$$
\omega=C_{m} * E
$$

The voltage $(E)$ suppled to the armature of the motor is created by the generator according to Equation 2.2. The time rate of change of magnetic flux $\left(\Phi_{b}\right)$ is created by rotating the area $\left(A_{c l}\right)$ 
enclosed by the armature windings. The magnetic field $(B)$ is a scalar to the amount of magnetic flux created by the constant rotation from the prime mover. The magnitude of the magnetic field is proportional to the current $(I)$ running through the coils according to the magnetization curve of the iron shown in Figure 2.12. The current $\left(I_{f}\right)$ is proportional to the voltage $\left(V_{f}\right)$ supplied to the field of the generator where the resistance $\left(R_{f}\right)$ of the coils is a constant shown in Equation 2.5.

$$
I_{f}=\frac{V_{f}}{R_{f}}
$$

Therefore, the speed control of the Ward Leonard system comes from varying the voltage supplied to the field winding of the generator. The speed can be characterized by Equation 2.6 where $\left(C_{m}\right),\left(\frac{d A_{c l}}{d t}\right),(N)$, and $\left(R_{f}\right)$ are all constant. The relationship will then follow the curve shown in Figure 2.12.

$$
\omega=C_{m} * \frac{d A_{c l}}{d t} * N * \frac{V_{f}}{R_{f}}
$$

This characterizes the control of the output motor from zero up to its nominal speed, or speed of the prime mover. In order to increase the speed above that of the prime mover, field weakening must be used.

\subsubsection{Field Weakening}

The speed of the motor is essentially limited by the production of back EMF. Back EMF is a reverse voltage that the motor creates when running. SE DC motors have a self governing speed characteristic when at a constant. When a load is applied to the motor, the motor begins to slow down; as this happens less back EMF is generated according to Equation 2.2. With less back EMF being generated, this allows the motor to pull more current to the armature which produces more torque, which again speeds up the motor to its original speed. If the magnetic field of the motor is weakened the production of back EMF is decreased which allows the armature to pull more current which causes the motor to increase in speed. Therefore field weakening increases the speed range of the Ward Leonard system by trading available torque for speed while staying at the same power level [40]. The speed to motor field voltage relationship or field weakening capability is non linear and is capable of controlling up to $1 / 4$ of the maximum speed above the nominal speed. 


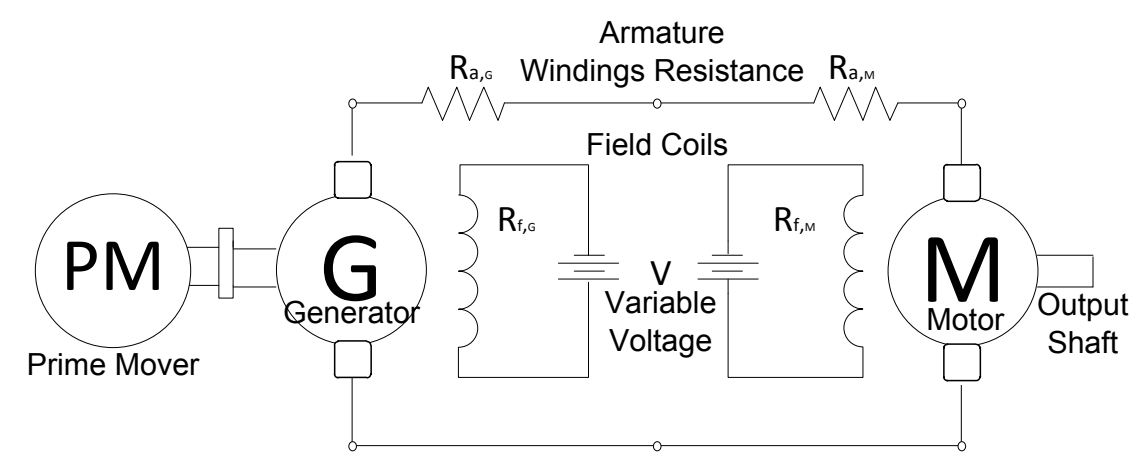

Figure 2.14: Schematic of Ward Leonard Motor Generator Set

\subsubsection{Prime Mover Control}

The prime mover is usually a constant speed machine. Early use of the Ward Leonard system in locomotives caused extra work for the train engineer. There were many different things to monitor such as diesel engine load and speed, generator load and traction motor current and speed. Although Lemp's single lever invention simplified many of these aspects there were constant improvements to control this type of system. Today train engineers have a single lever and all of the control is done electrically with microcontrollers. It is important to note that in this application of the Ward Leonard as an IVT that the prime mover is a constant speed device. In the case that the prime mover is an ICE there are common control methods today to make this possible.

It is possible to have the prime mover vary in speed. In the case of a ICE as a prime mover it may not add complexity to a vehicle yet provide for a more efficient control. If the power supplied to the generator and motor are not varied the speed of the output is directly related to the prime mover speed. The relationship of input to output speed is dependent on the field powers of the generator and motor. 


\section{CHAPTER 3. METHOD}

This chapter describes the objectives and methodology used to test and characterize the Ward Leonard control system for potential use in an automobile application. The objective of this chapter is develop a quantitative method to measure the ability of the Ward Leonard system for use in an EV or HEV. It is also to provide sufficient detail that will allow any researcher the ability to recreate the testing setup.

\subsection{Control Factor}

As described in Chapter 2 current control methods of EVs and HEVs require that all of the power to the motor pass through the controller as shown in Figure 3.1. The method of which the Ward Leonard would remove the controller for the main flow of power is shown in Figure 3.2

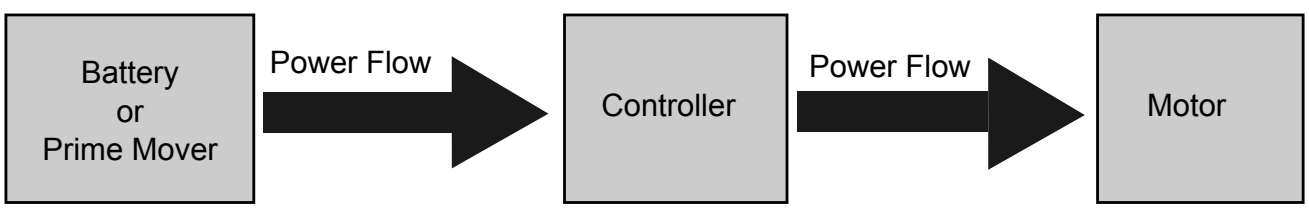

Figure 3.1: Typical EV Power Flow

The amount of control power that would be necessary the operation of the Ward Leonard system according to Figure 3.2 is found by the amount of power to excite the generator field. This power can be compared to the output of the system by using a control factor. The control factor defined in Equation 3.1 provides a factor of which the controller could be reduced in size.

$$
C_{f}=\text { PowerOut } / \text { ControlPower }
$$




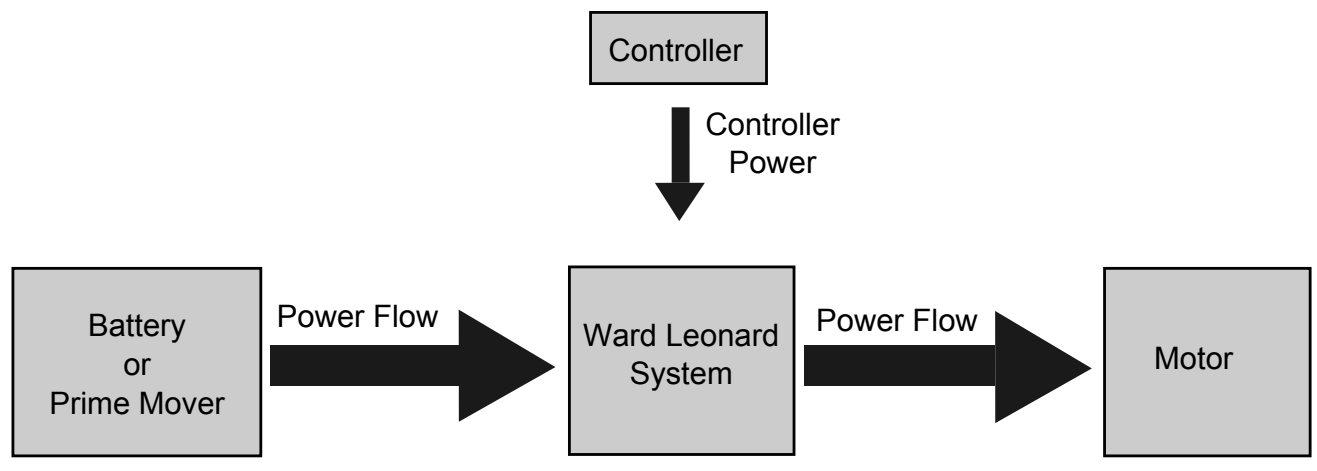

Figure 3.2: Ward Leonard IVT Power Flow

where the power out is divided by the controller input power. This number provides the factor of which the PWM controller power could be reduced if a Ward Leonard system is implemented compared to conventional controllers.

\subsection{Prime Mover}

It has been mentioned that the Ward Leonard system has the potential of lowering the voltage of the battery pack. It is important to identify how this could be accomplished. The ideal prime mover for an EV is shown in Figure 3.3. In this configuration high current could be used without the restrictions of a controller. With a high current connection the voltage of the battery could be reduced while keeping the same amount of power by increasing the current. PM DC motors are shown to have peak efficiencies upwards of 90\% [41]. The motor could be run at its most efficient operating speed coupled with an on/off switch without any losses from a controller. The size of the individual cells would need be larger due to the decrease in cell count. The management system would be less complicated because there would be less battery cells.

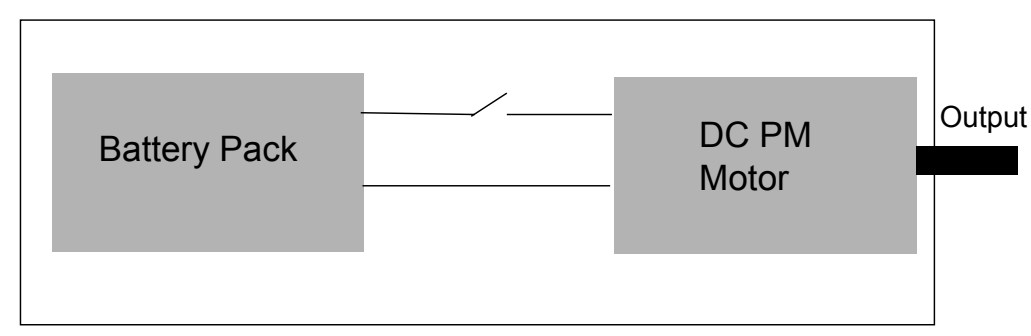

Figure 3.3: Ideal Electric Vehicle Prime Mover 


\subsection{Vehicle Application}

Figure 3.4 shows the block diagram of how this system was intended to replace the control scheme of current electric vehicles. Figure 3.5 shows how the Ward Leonard system could be used in a HEV. This configuration also enables the prime mover to be selected independent of the operation of the Ward Leonard system.

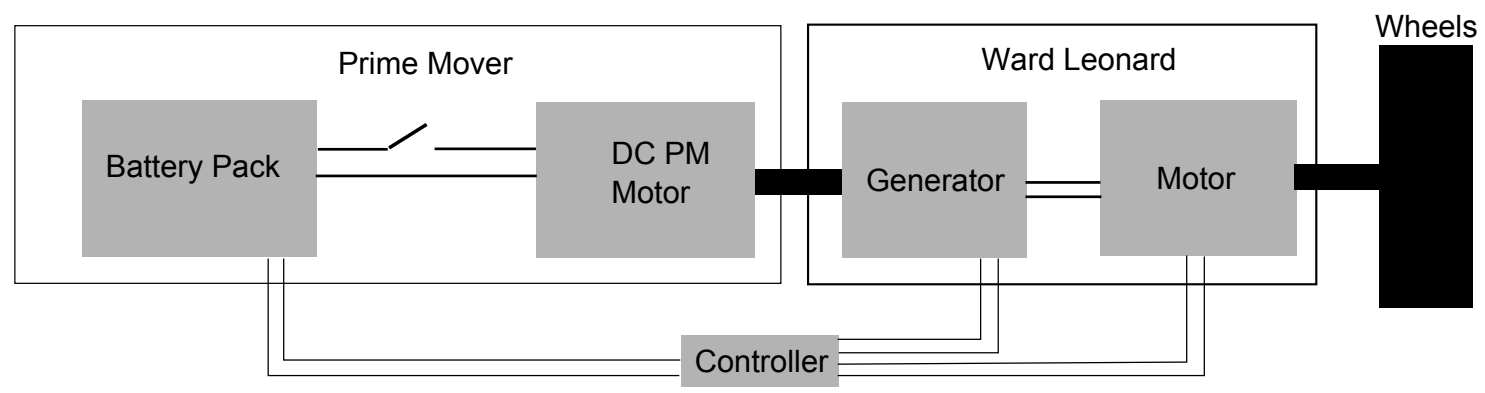

Figure 3.4: EV with Ward Leonard IVT

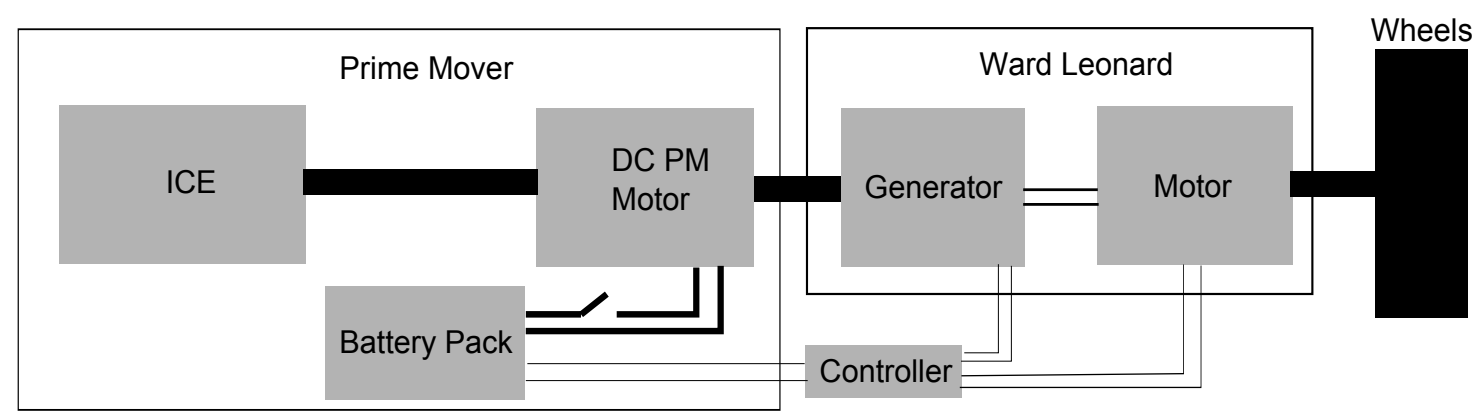

Figure 3.5: HEV with Ward Leonard IVT

\subsection{Testing Objectives}

The following is a list of objectives that were used during testing in order to characterize the Ward Leonard IVT.

1. Find the ability to control the generator output

2. Determine the speed control solely by generator field control 
3. Examine the added speed range by adding motor field weakening

4. Measure the efficiency of the system

5. Explore the torque relationships

6. Establish power use relationships and corresponding control factors

\subsubsection{Testing Block Diagram}

The block diagram shown in Figure 3.6 shows how the Ward Leonard system was set up for testing.

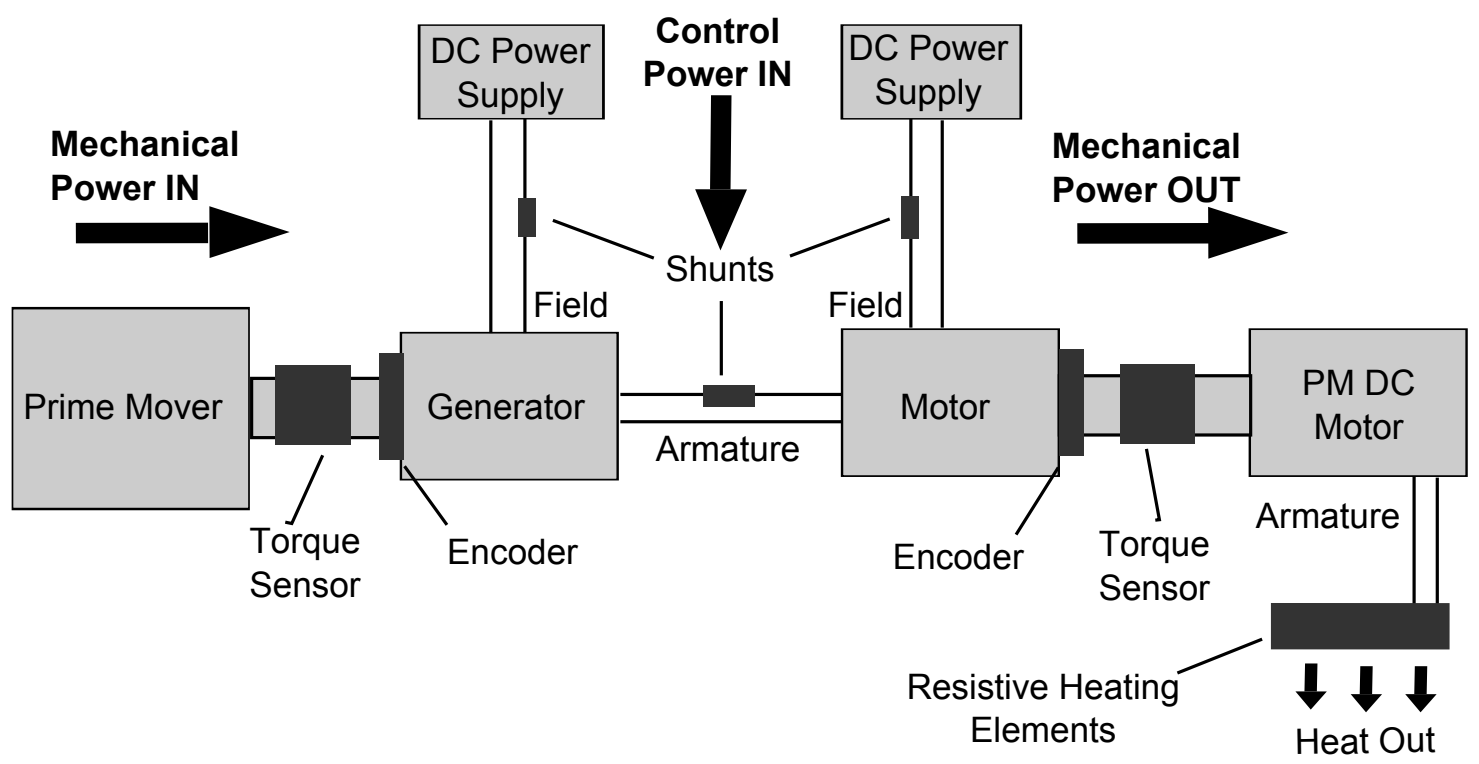

Figure 3.6: Test Setup

\subsubsection{Generator Control Testing}

The speed of the motor driving the vehicle will be dependent on voltage and current produced by the generator. Therefore understanding the output of the generator is necessary. The power supplied to the generator field determines the voltage of the generator armature spinning at a constant speed. The armature connected to a resistive load will cause current to flow, the 
power can then be calculated. Findings would include voltage variation of the generator armature depending on controlling voltage applied to the generator field. The controlling power supplied to the field compared to the power output of the generator will provide the control factor $\left(C_{f}\right)$ for different controlling field voltages.

Two tests were performed. For both tests the prime mover was set at a constant rotational speed of 1750 RPM, which was the rated RPM of the generator. The voltage and current supplied to the field were recorded along with field and voltage of the armature. The armature was connected to a DC motor to provide an electrical load. For the first test no load was applied to the output, for the second test, the full load of the stalled motor was applied. For each test the field voltage was varied in 5 volt increments. During the first test the voltage of the field and armature were recorded, for the second test the power to the field and from the armature were calculated by multiplying the voltage and current of each. Fifty data points were recorded and averaged at each setting.

\subsubsection{Speed Control by Generator Field Manipulation}

This test objective was to find the speed control characteristics by controlling power to the field on the generator. The Ward Leonard system was set up according to Figure 3.6. The prime mover was set at a constant 1750 RPM. The motor field was given a constant of 50 volts to simulate a basic PM motor. The generator field voltage was varied from 0 to 50 volts in 5 volt increments, an average of 100 data points were taken at each. The speed curve under no load should follow that of Equation 2.6 according the the magnetization curve shown in Figure 2.12 as explained in Chapter 2. Various other tests were performed using a PM DC motor to apply a load to the output motor. The load was varied by changing the heater resistance connected to the loading motor.

\subsubsection{Speed Control with Added Motor Field Weakening}

The objective of this test was to see the added speed range that could be obtained using field weakening. Various loads were placed on the output to see the effect of loading on field weakening and to find the extent of it usefulness. The speed of the prime mover was set at 1750 RPM. Due to equipment limitations the output motor was not tested above 2500 RPM. The motor field voltage was initially set at a maximum of 50 volts and the generator voltage set at 0 volts. The generator 
field was increased in 5 volt increments until a max of 50 volts was reached, then the motor field voltage was decreased by 5 volt increments. An average of 100 data points were recorded at each setting.

\subsubsection{Efficiency}

The efficiency of the system is important to know to enable good design decisions to be made for using the Ward Leonard system for an automobile application. Generator efficiency was tested at various loads. The electrical power output of the generator was recorded and divided by the mechanical power provided by the prime mover. The rated efficiency of the generator as a motor was calculated from the mechanical and electrical specification data found on the name plate of the motor. The rated voltage and current of both the field and armature were added and then the total divided by 186.4 watts or the rated 1/4 HP of the motor. The rated efficiency of the motors used was $68 \%$. The tested efficiency of the generator was found by dividing the electrical power from the armature by the recorded mechanical power in plus the field power in as shown in Equation 3.2. In theory the maximum efficiency that the motor was designed for should be the efficiency at its rated load.

$$
\eta_{G}=\left(V_{a} * I_{a}\right) /\left(T * R P M+V_{f} * I_{f}\right)
$$

The efficiency of the system as an IVT is the combined efficiency of the generator and motor in series. As the generator and motor where identical with a rated efficiency of $68.2 \%$ the combined rated efficiency in series is $46.2 \%(.68 * .68=.462)$. To find the efficiency of the system the mechanical output power of the motor was divided by the mechanical input from the prime mover plus the power from each field. This efficiency is dependent on the load of the system and power to the fields. The rated load of the system is $1 / 4 \mathrm{HP}$ or 186.4 watts. The efficiency with out taking in account the motor field control is also calculated to find the potential efficiency of a system that uses a PM DC motor as an output. The calculated efficiency is $52.7 \%$.

It is obvious at an output speed of 0 RPM the efficiency will be zero yet in this state there is nearly 0 torque at the input, therefore the only losses are due to the rotating mass, friction, and hysteresis in the prime mover and generator. The power loss at this state will be found experimentally 


\subsubsection{Torque Output Control}

As a vehicle is at a stop light the control over torque is important because torque is what enables acceleration to be created in the vehicle and a smooth acceleration is a desired quality of an automobile. Electric vehicles typically have an advantage over conventional gasoline automobiles with the ability to create strong yet smooth torque from a complete stop. It is important to be able to control this starting torque. For this reason a test was performed to test this ability. For this test the loading motor was stalled while the power supplied to the generator field was increased. The prime mover speed was set at 1750 RPM and the motor field voltage was set at a maximum to simulate a PM motor. Torque at the prime mover was recorded also for comparison reasons.

\subsubsection{Power Relationships and Control Factor}

One of the objectives of this research is to determine the feasibility of reducing the size of an expensive controller using the Ward Leonard control system. Thus the power needed to control the fields compared to the power of the system must be established. Theoretically for this system the maximum power required by the generator field is 32 watts and the maximum output is 186.4 watts as calculated from the motor specifications. Therefore the control factor of the system would be 5.8 at maximum operating conditions without field weakening capabilities. In order to have field weakening capabilities a SE DC motor must replace the PM DC motor. The SE DC motor requires an additional power supply cutting the control factor in half to 2.9. The power relationships of controlled output power and the controller power was recorded. Basic theoretical parameters along with control factors are shown in Table 3.1.

Table 3.1: Theoretical Parameters

\begin{tabular}{|c|c|c|}
\hline Parameter & Generator Field Control & Motor Field Weakening \\
\hline Max Power & 186 Watts & 186 Watts \\
Controller Input & 32 Watts & 64 Watts \\
Control Factor & 5.8 & 2.9 \\
Speed Range & $0-1750 \mathrm{RPM}$ & $0-2200 \mathrm{RPM}$ \\
System Efficiency & $52.7 \%$ & $46.5 \%$ \\
\hline
\end{tabular}




\subsection{Testing Hardware}

In order to gain the desired insight from the experiments explained above, speed and torque from the prime mover and output motor needed to be measured. The voltage and current of the field on both the motor and generator along with the voltage and current of the armatures were measured. In total this required that 3 Voltages, 3 Currents, 2 RPMs and 2 torques be measured in the system. To make this possible, the following hardware was used for the experiment:

- National Instruments cRIO (1)

- National Instruments Modules (3)

- Prime Mover (1)

- DC Shunt Wound Motors (2)

- Power Supplies (2)

- Load Motor (1)

- DC Shunt (3)

- Encoders (2)

- Torque Sensor (2)

A photograph of the setup is shown in Figure 3.7. Components were used from the Mechanical Engineering, Physics and Electrical Engineering Departments at Brigham Young University.

\subsubsection{National Instruments cRIO}

The National Instruments cRIO was selected because of its versatility and availability. This device works as an interface with the LabView program and is a data collection point for all of the instrumentation. This device, with the aid of the software, takes the raw voltages from the sensors and power supplies and converts them into useful information. The cRIO is also the physical location where data are stored during testing. The on-board clock of the Field Programmable Gate Array (FPGA) was capable of measuring responses up to $40 \mathrm{MHz}$. This resolution was especially necessary due to the high frequency pulses delivered by the encoders at high RPMs of the motor 


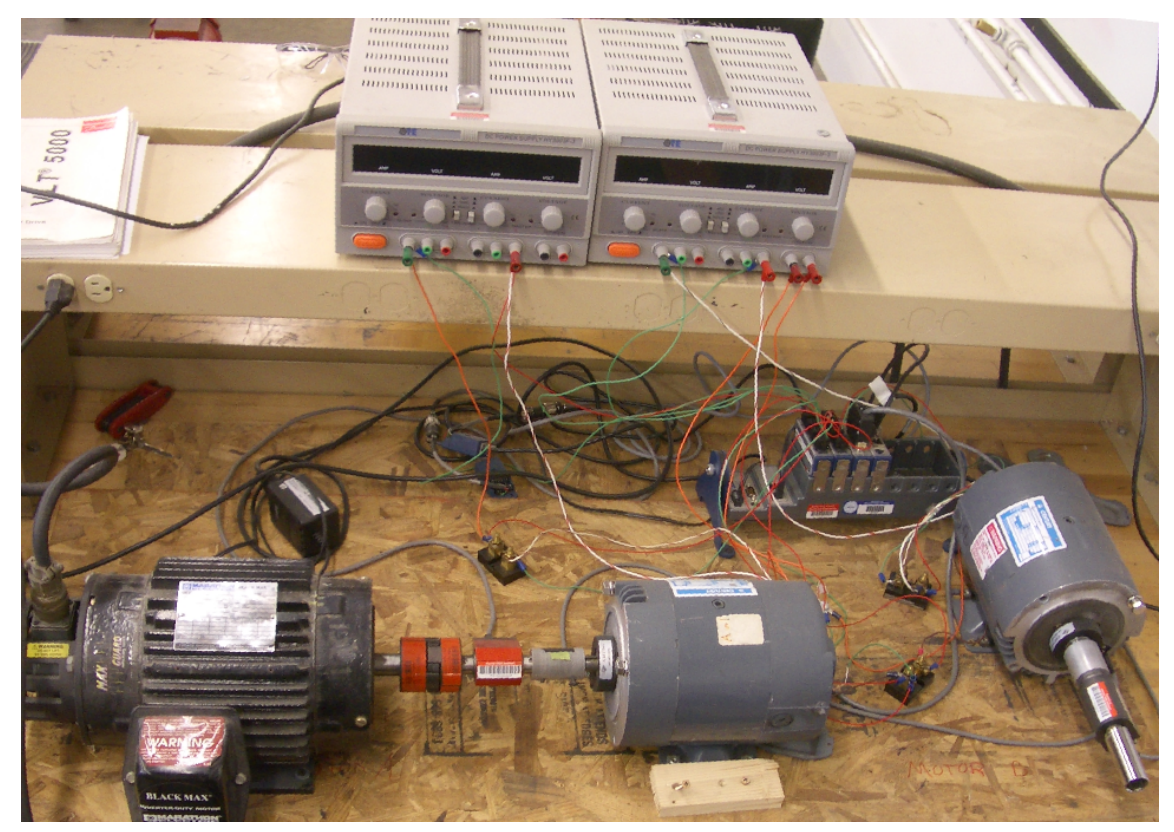

Figure 3.7: Photograph of Test Setup

and generator. Additionally the re-programmable features of the FPGA allowed for easier modification of the code. The cRIO also used plug-in modules that could interface with sensor hardware for data acquisition.

\subsubsection{Modules}

As depicted in Table 3.2, four modules were used in the experiment with the following specifications:

Table 3.2: National Instruments cRIO Modules Used in Experiment

\begin{tabular}{|c|c|c|c|c|c|}
\hline Module & Quantity & Av. Channels & Measurement & Connection & Voltage \\
\hline $\mathbf{9 2 1 9}$ & 1 & 4 & Voltage & Wire & $+/-60 \mathrm{~V}$ \\
$\mathbf{9 2 1 9}$ & 1 & 4 & Current & Wire & $+/-60 \mathrm{~V}$ \\
$\mathbf{9 4 0 1}$ & 1 & 8 & RPM & D Pin & $+5 \mathrm{~V}$ \\
$\mathbf{9 2 3 7}$ & 1 & 4 & Torque & Ethernet & Var. Excit. \\
\hline
\end{tabular}




\subsubsection{Prime Mover}

The Prime Mover used in the experiments was a 2 HP 3 phase induction motor with a Danfoss VLT500 variable frequency drive shown in Figure 3.8. The motor and controller provided a constant rotational speed with significant power to overcome any loading torque without loss of RPM. The prime mover controller displayed the prime mover's speed.

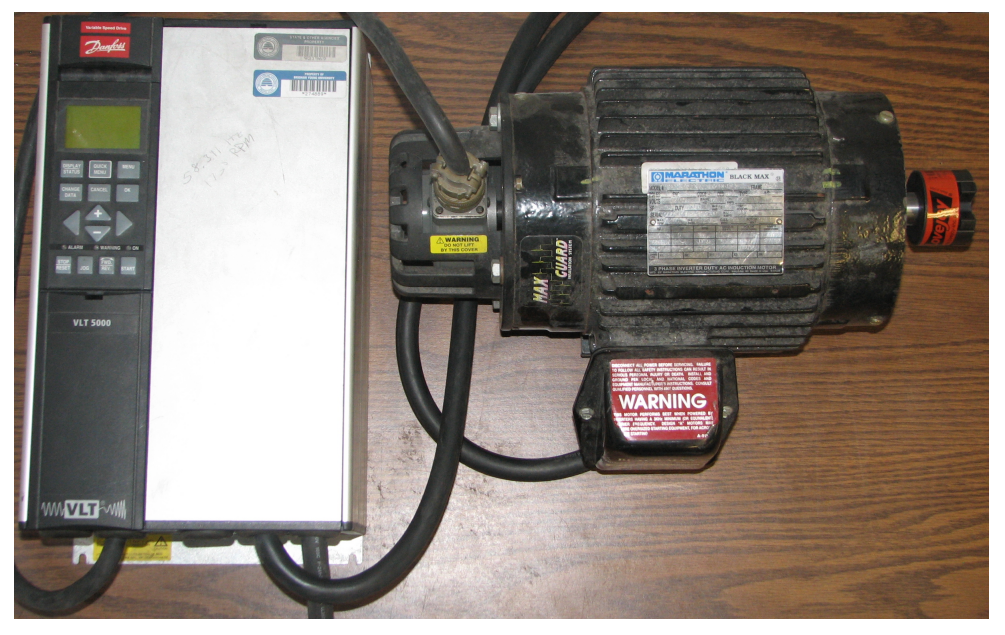

Figure 3.8: Prime Mover with Controller

\subsubsection{Motor and Generator}

Two identical DC shunt-wound motors, shown in Figure 3.9, were used for this experiment. The motors were first independently tested to ensure that they had the same performance characteristics. The motors also had high and low voltage settings. For testing, the motors were configured to accommodate the lower voltage setting which worked better for the power supplies that were used. The motors were wired to be separately excited using external power supplies connected to the field. Table 3.3 gives the specifications of the motors that were used.

\subsubsection{Power Supplies}

Two identical power supplies were used. The power supply was a Mastech two channel $30 \mathrm{~V}-3 \mathrm{~A}$ power supply model No:TE HY3003F3, which was used to power the field of each motor. 


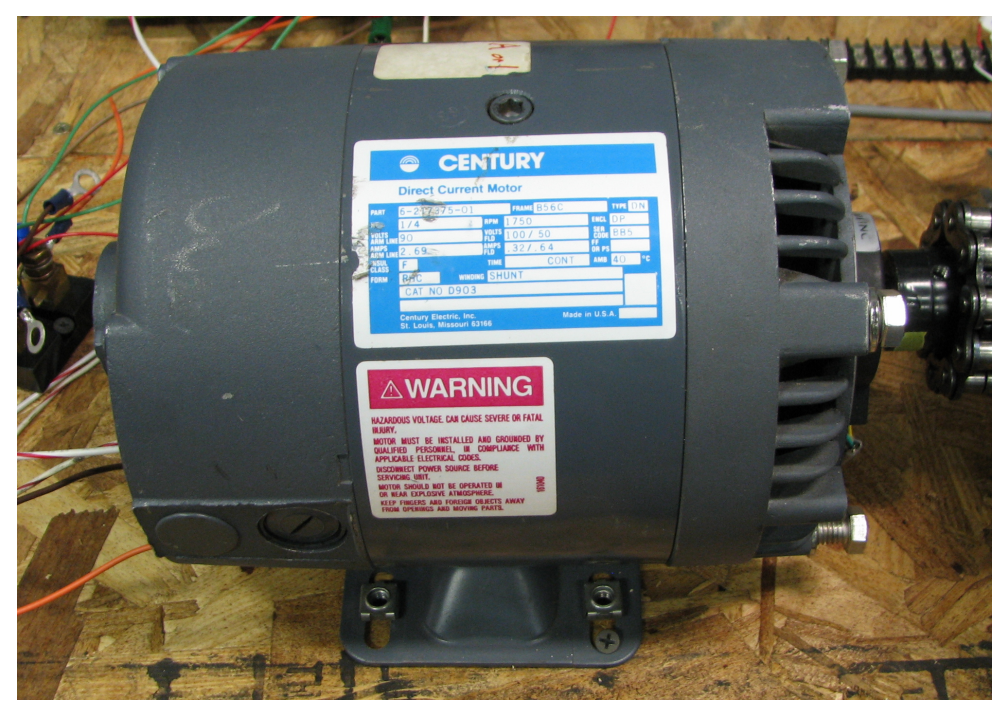

Figure 3.9: DC Shunt Wound 1/4 HP Motor Used in Testing

Table 3.3: Specifications of Motor Used in Table Top Experiment

\begin{tabular}{|c|c|}
\hline Parameter & Specification \\
\hline Manufacturer & Century Electric \\
Arm Voltage & $90 \mathrm{~V}$ \\
Arm Current & $2.69 \mathrm{~A}$ \\
Field Voltage & $100 / 50$ \\
Field Current & $.32 / .64 \mathrm{~A}$ \\
Power & $1 / 4 \mathrm{HP}$ \\
Max RPM & 1750 \\
Part & $6-217375-01$ \\
Frame & B56C \\
\hline
\end{tabular}

Because this type of power supply could only put out a maximum of $30 \mathrm{~V}$ and $3 \mathrm{~A}$ per channel, the two channels were hooked up in series to add the voltages, thereby allowing the power supply to produce a total of $60 \mathrm{~V}$ at $3 \mathrm{~A}$. Voltage was regulated manually by means of the controls on the power supply.

\subsubsection{Loading Motor}

To load the motor, another PM DC motor was used as a generator. The Fincon 1/3 HP motor was rated at 1725 RPM and 3.5 amps and is shown in Figure 3.10. The output of the loading 
motor was dissipated as heat through a resistive heating elements shown in Figure 3.11. At times when the output was to be stalled, a braking mechanism was applied by hand. To run the system at zero load the loading motor was completely disconnected.

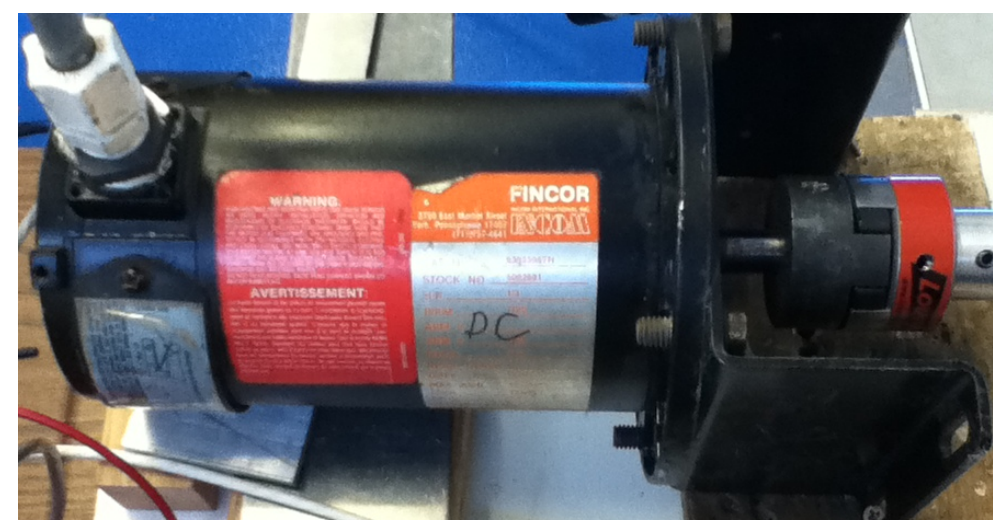

Figure 3.10: Photograph of Loading Motor Used

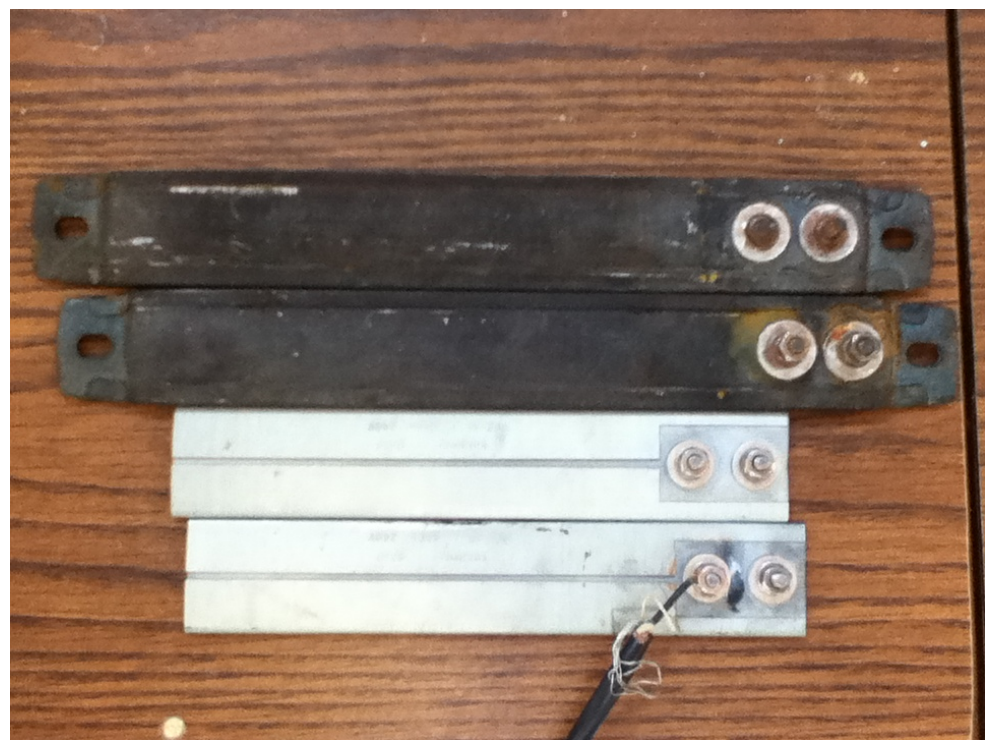

Figure 3.11: Photograph of Resistive Heating Elements 


\subsubsection{Sensors}

\section{Encoders}

An encoder was used to measure the RPM of the prime mover and output motor. The specifications of these encoders are listed in Table 3.4. These encoders had two optical channels that measured counts. This was necessary for the quadrature encoding described in section 3.6.1. An index channel was also available on the encoders, but was not used because position of the encoder shaft was not needed for the testing.

Table 3.4: Specifications of Encoders Used in Experiment

\begin{tabular}{|c|c|}
\hline Parameter & Specification \\
\hline Pulses Per Revolution & 1000 \\
Type & Optical Quadrature \\
Supply Voltage & $+5 \mathrm{~V}$ \\
Frequency Response & $100 \mathrm{KHz}$ \\
Output Type & Voltage \\
Quantity & 3 \\
\hline
\end{tabular}

\section{Torque}

Two different torque sensors were used. The specifications for each are shown in Table 3.5. Prior to testing, the sensors were calibrated using a weight and lever arm to ensure accuracy.

Table 3.5: Specifications of Torque Sensor Used in Experiment

\begin{tabular}{|c|c|c|}
\hline Parameter & Input Torque & Output Torque \\
\hline Type & Slip Ring & Slip Ring \\
Measurement Method & Angular Deflection & Angular Deflection \\
Excitation Voltage & $+5 \mathrm{~V}$ & $+5 \mathrm{~V}$ \\
Calibration & $2 \mathrm{mV} / \mathrm{V}_{e x c}$ & $1.5 \mathrm{mV} / \mathrm{V}_{\text {exc }}$ \\
Max torque & $20 \mathrm{NM}$ & $200 \mathrm{InLbs}$ \\
\hline
\end{tabular}




\section{Current}

To measure the current, 3 DC shunts were used shown in Figure 3.12. These operate under the principle that by measuring the voltage drop across a known resistance, the current in the circuit can be calculated. This relationship is also linear and can therefore be interpolated using scaling factors to find the measured current. In this experiment, shunts rated at $10 \mathrm{~A}=50 \mathrm{mV}$ were used. Two leads from each terminal measured the voltage drop across the shunt, which was scaled by LabView to convert the output voltage to a current.

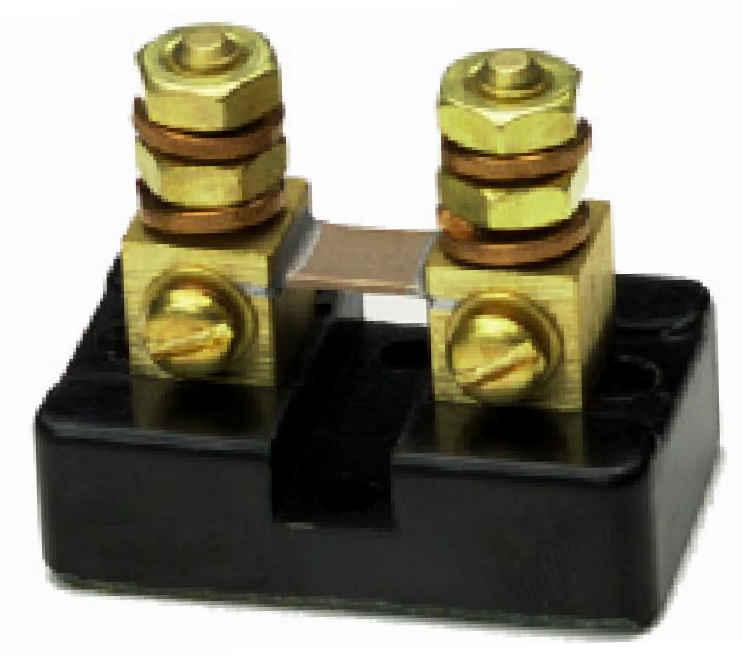

Figure 3.12: Photograph of Shunt used

\section{Voltage}

The 9219 module was capable of handling voltages accurately up to $+/-60 \mathrm{~V}$. This module is also designed with redundant systems that protect the components should it be exposed to $>60 \mathrm{~V}$. Because of this, leads from the terminals of the power supplies were connected directly to the inputs on the module to measure voltage. Because the generator voltage would reach $>60 \mathrm{~V}$ a voltage divider was constructed using two identical resistors in series that were placed in parallel with the armatures. The 9219 was connected between the resistors to read one half the voltage present. This was scaled by two in the LabView program to provide an accurate armature voltage. 


\subsubsection{Completed Assembly}

Once all of the hardware was collected it was assembled as shown in Figure 3.13. This setup allowed the operator access to control and monitor the various components during testing. A wiring diagram of the set up is shown in the appendix with Figure A.1.

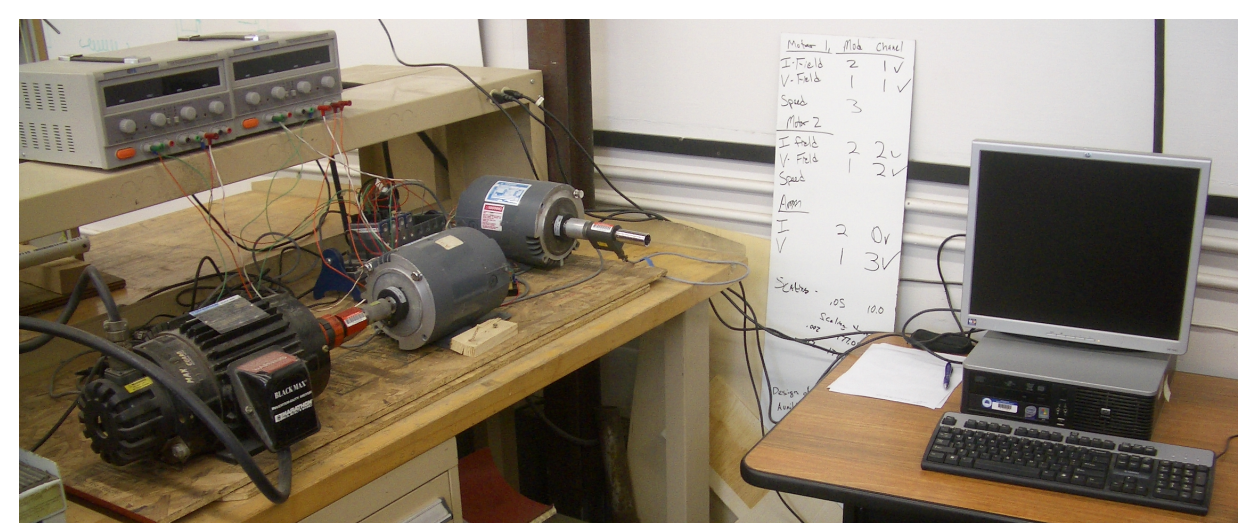

Figure 3.13: Photograph of Experimental Setup

\subsection{LabView Code}

\subsubsection{FPGA}

With the motor capable of running at 1750 RPM, and the encoder having 1000 pulses per revolution (PPR), it was necessary to utilize the $40 \mathrm{MHz}$ clock of the FPGA in order to determine actual RPM. The FPGA program first used boolean logic to determine when the encoder had a count. A count is the rising or falling edge of the encoder signal. Because the encoder can measure the rising and falling edges of the signal, it allows the encoder to have twice the resolution per channel. When two channels are separated by an offset, it was possible to utilize quadrature encoding. In essence, when the channels are offset as shown in Figure 3.14, the overall resolution of the encoder can be increased to four times the listed resolution. Quadrature encoding also allows the direction of rotation to be calculated, based on which signal rises or falls first [5].

Using the on-board clock of the FPGA it was possible to determine the duration between counts. As illustrated in Figure 3.15, a time stamp was made at each count and the time per count 
was calculated by subtracting the current time from the time of the previous count. This value was measured in ticks of the on board clock, which was eventually converted to seconds. The final value output to the display was in revolutions per second. This code was duplicated two times so that a total number of three loops were executed simultaneously, one for each encoder.

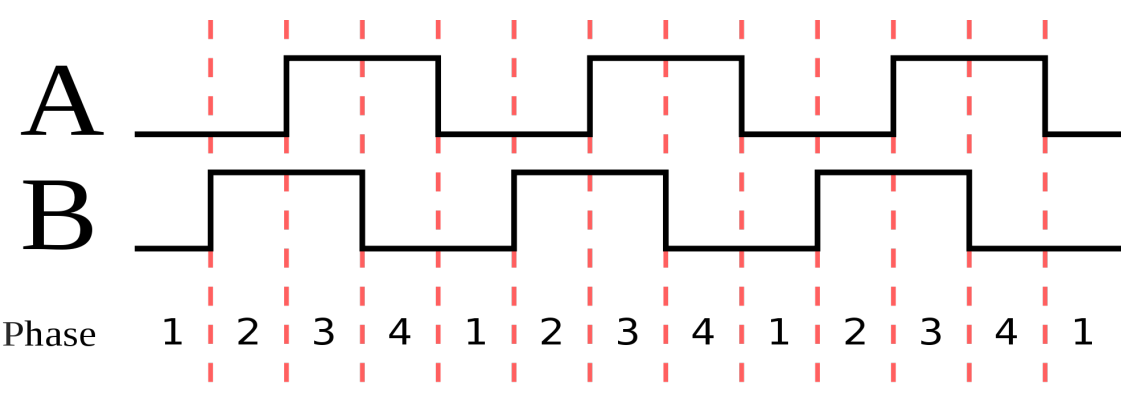

Figure 3.14: Quadrature Encoding [5]

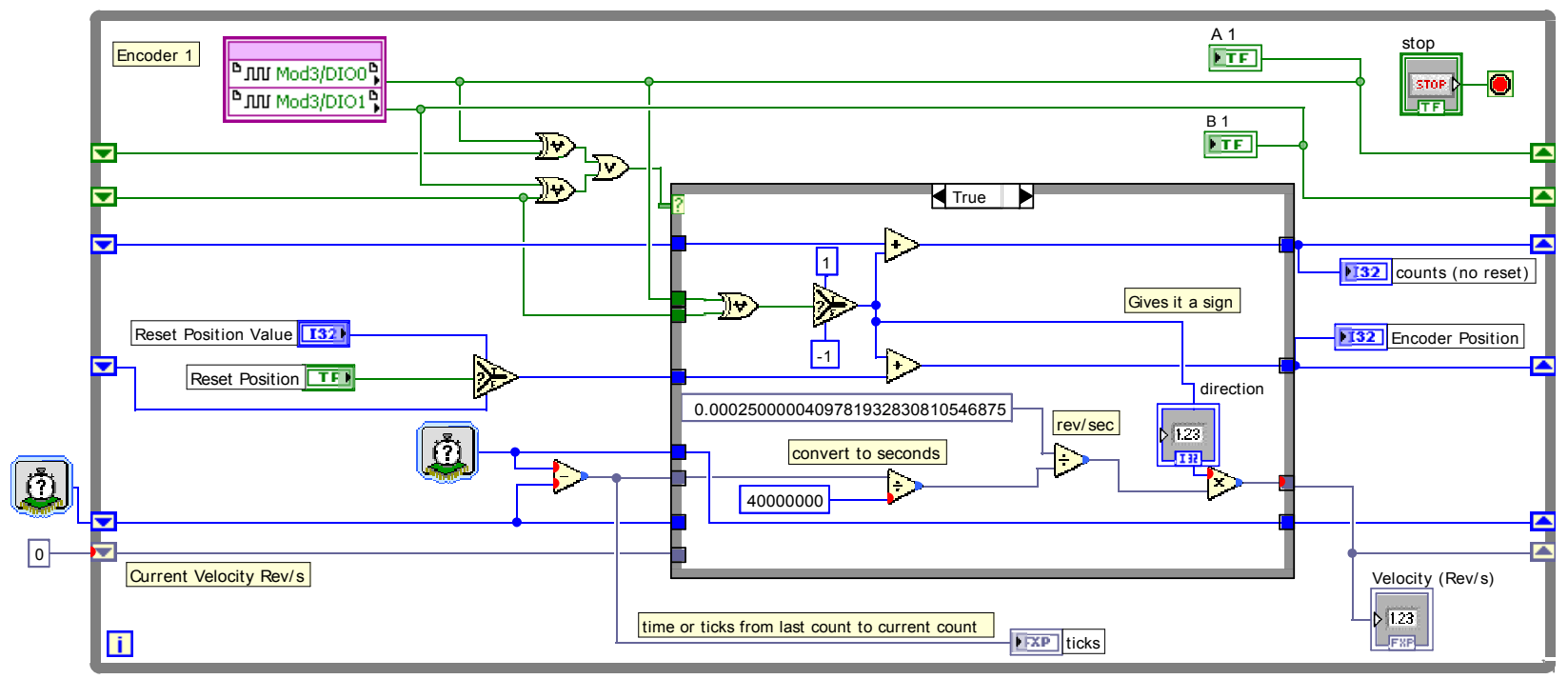

Figure 3.15: FPGA Block Diagram

\subsubsection{Block Diagram (Real Time)}

The real time component of the LabView program was designed to make testing, data acquisition and data interpretation easy. As shown in Figure 3.16, upon initial execution, the program 
displayed each variable on the front panel. Once all sensors were operational, data acquisition began. Data acquisition was accomplished through the use of one data acquisition button located on the front panel. During data acquisition the program was designed to grab the value of each variable, once per loop, and store that value into an array. The operator specified the number of data points via a dialog box on the program display. Once the desired number of data points were gathered, the loop could be terminated, which would cause the program to move to the next sequence of the program.

The next sequence took the array and then inverted it. It then took the array and output to a file on the cRIO server, which could then be imported into Excel for interpretation. The data acquisition button was designed so that it could only be clicked once until all of the desired data acquisition had been completed. Shift registers were employed to store data between loop executions. Other tools like the verification array, filename output and case structures for the graphs were for convenience for the operator.

\subsubsection{Front Panel (Real Time)}

The front panel of the LabView program was also designed to make testing intuitive and easy to operate. The upper portion of the front panel allowed the tester to input important parameters, such as which motor was being tested and what configuration it was in. There was also an area for extra comments if the user needed to put any relevant information or observations. After input, this information was appended to the actual data file that was created so that each test could be easily identified. Each variable was displayed on a graph that could be turned on and off. In total there were four graphs representing the four areas of data acquisition: Voltage, Current, Torque and RPM. Certain other features were included such as: a progress bar for use during data acquisition, a large emergency stop button and a verification array. As pictured in Figure 3.17, the layout of the front panel was designed such that the user would never have to scroll to operate the program. 


\subsubsection{Project Settings}

Scaling factors and excitation voltages had to be set in the project window. Additionally, all channels on the modules were labeled in the project window during wiring to reduce confusion. Figure 3.18 shows the respective variable assignments for each channel. In this project window the excitation voltage for the torque sensor was also set. Originally $10 \mathrm{~V}$ was assigned to this sensor, but upon measurement it was observed that $10 \mathrm{~V}$ was not actually being delivered to the sensor, and the excitation voltage was changed to $5 \mathrm{~V}$ which performed much better. The scaling factors for the torque sensor and DC shunts were also input for their respective module properties. The voltages of each field could be read directly without scaling factors, but the properties of the module had to be set to allow voltages of up to $+/-60 \mathrm{~V}$. The voltage of the armature was scaled by 2 to counter the voltage divider explained in Section 3.5.7 due to module limitations.

\subsection{Calibration and Troubleshooting}

Upon completion of programming and compiling, the entire system was checked and verified to make sure that sensors were reading accurately and functioning properly. Torque sensors were compared and verified using a calibrated torque wrench, and RPMs were verified with a strobe meter. Voltages and currents were verified with a digital multi-meter.

During troubleshooting errors were corrected, and measures were taken to improve program performance. For example, during one of the first executions it was observed that the loop time on the program was extremely slow when all of the graphs were turned on. This was a problem because it took more than a minute to gather 100 data points. This introduced extra variation especially because it was difficult for the operator to apply the load consistently over such a long period of time. At this point the graph toggles were added to the program so that the graphs could be turned off for more speedy data acquisition. 


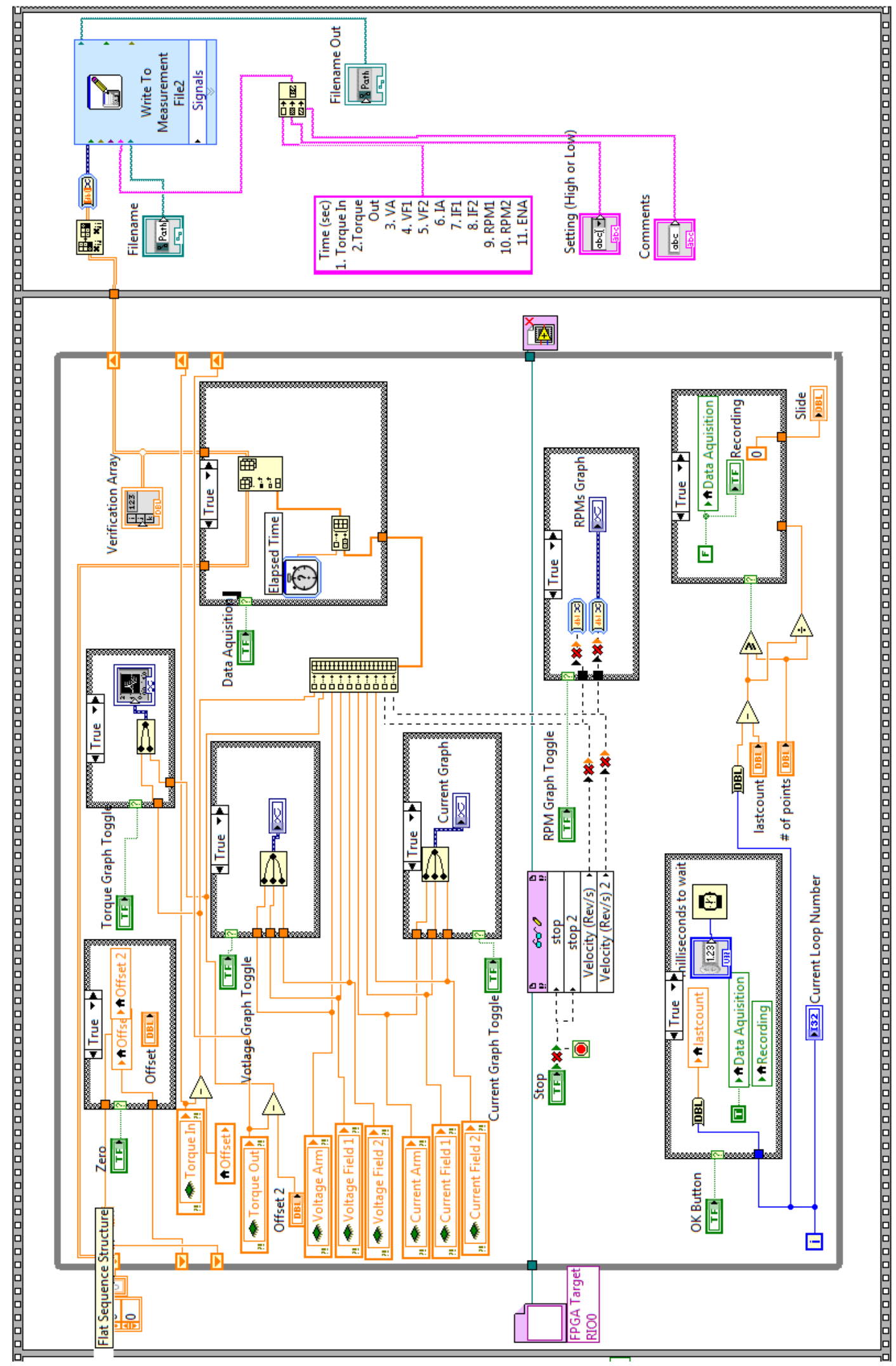

Figure 3.16: Real Time Block Diagram 


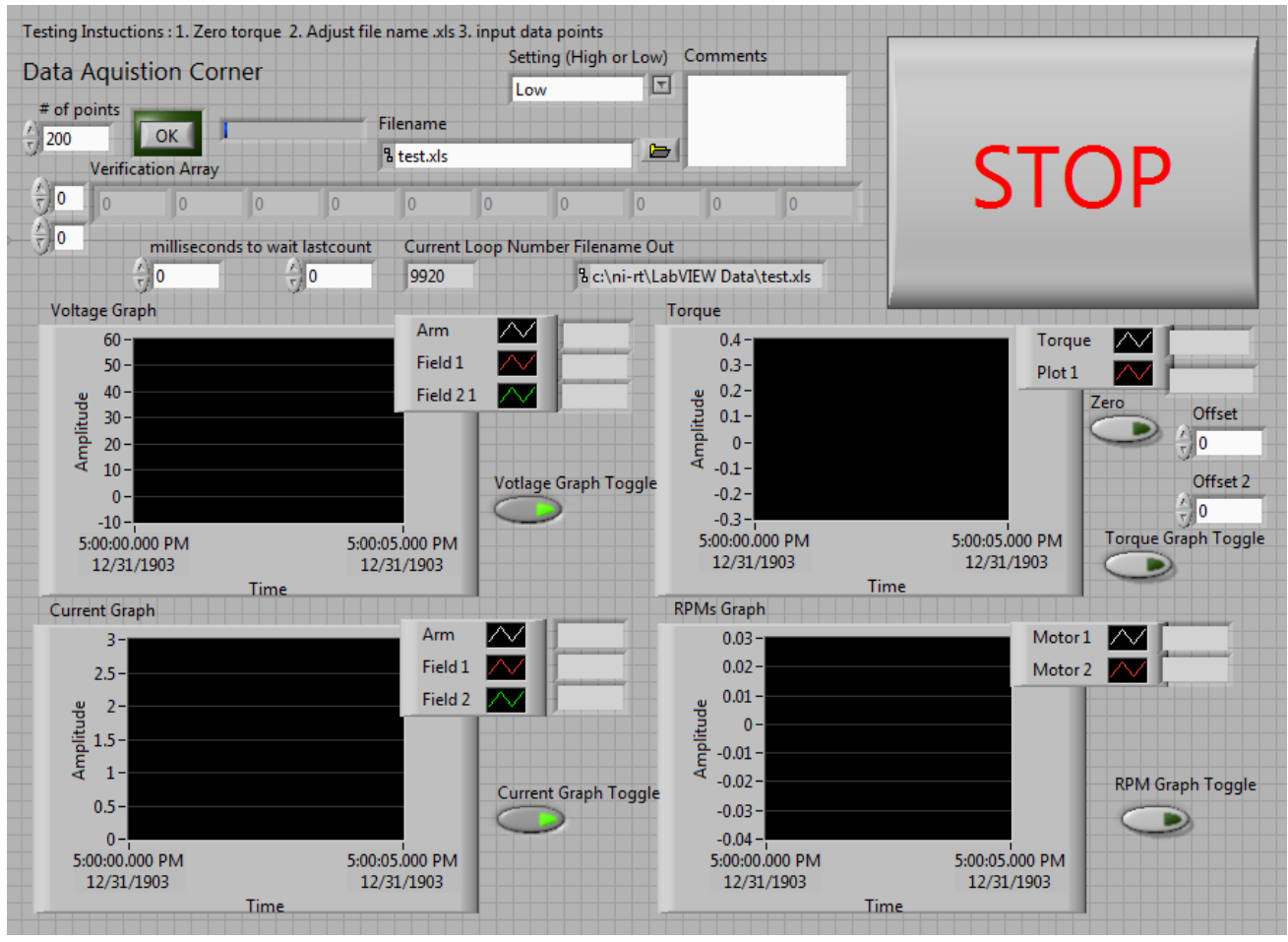

Figure 3.17: Real Time Front Panel

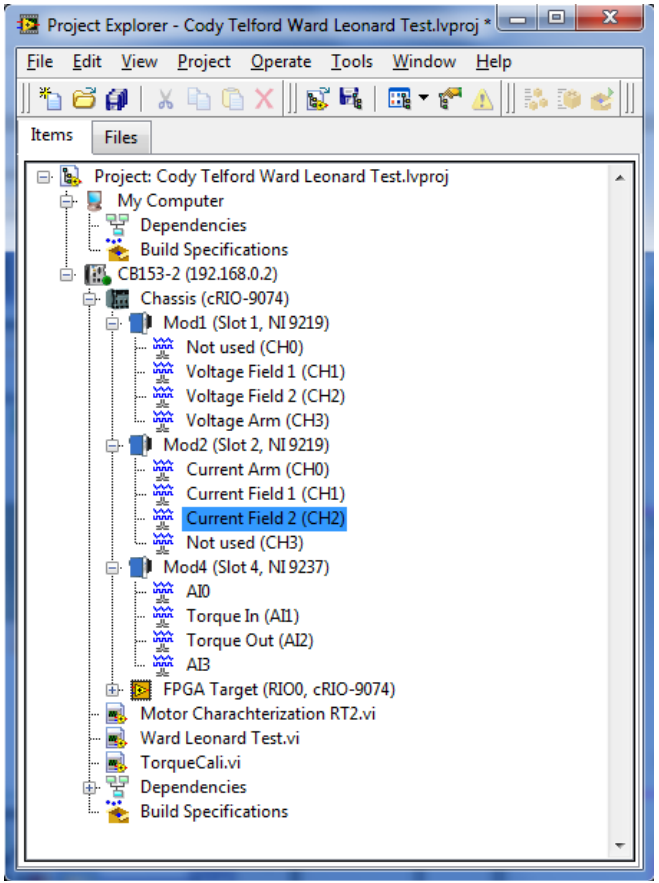

Figure 3.18: Project Window 


\section{CHAPTER 4. RESULTS}

This chapter provides the results of the bench top test setup.

\subsection{Testing Conditions}

There were 9 test performed, each with a different resistance placed on the loading motor with test 0 being disconnected from the loading generator. The test were numbered as shown in Table 4.1.

Table 4.1: Loading Tests

\begin{tabular}{|c|c|}
\hline Test Number & Resistance (Ohms) \\
\hline 0 & Disconnected \\
1 & Infinite \\
2 & 90 \\
3 & 55 \\
4 & 45 \\
5 & 34 \\
6 & 27.5 \\
7 & 21 \\
8 & 17 \\
\hline
\end{tabular}

In order to simplify the terminology it is important to understand what has been defined in the results as the 'Control Number'. The control number defines the state of both power supplies connected to the generator and motor field windings. During testing these were changed in 5 volt increments one at a time, yet to keep things simple a control number was incremented and is consistent with controller voltages throughout the tests. The number starts at 0 and increases in 2.5 steps with the generator field increasing in 5 volt increments until it reaches 50 volts. At this point the control number is 25 and as it increases by 2.5 the motor field decreases from 50 volts by 
5 volt increments. Figure 4.1 shows the corresponding voltages and Figure 4.2 shows the resulting power supplied to generator and motor fields according the the control number.

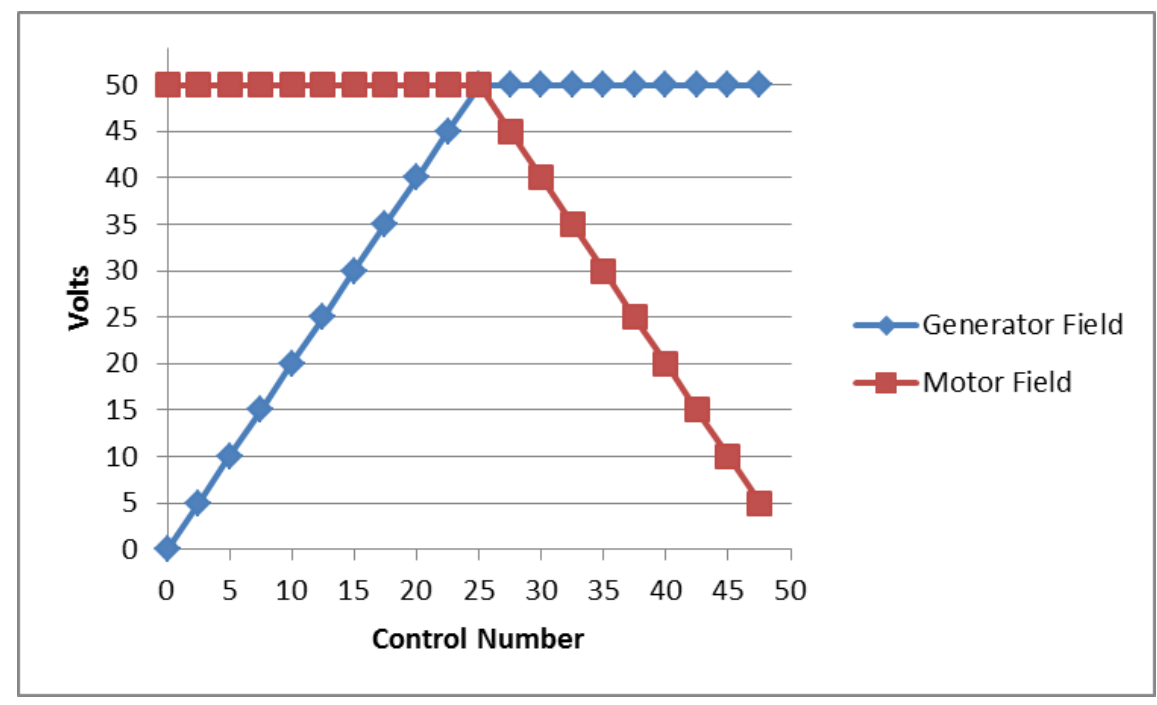

Figure 4.1: Control Number Defined by Field Voltages

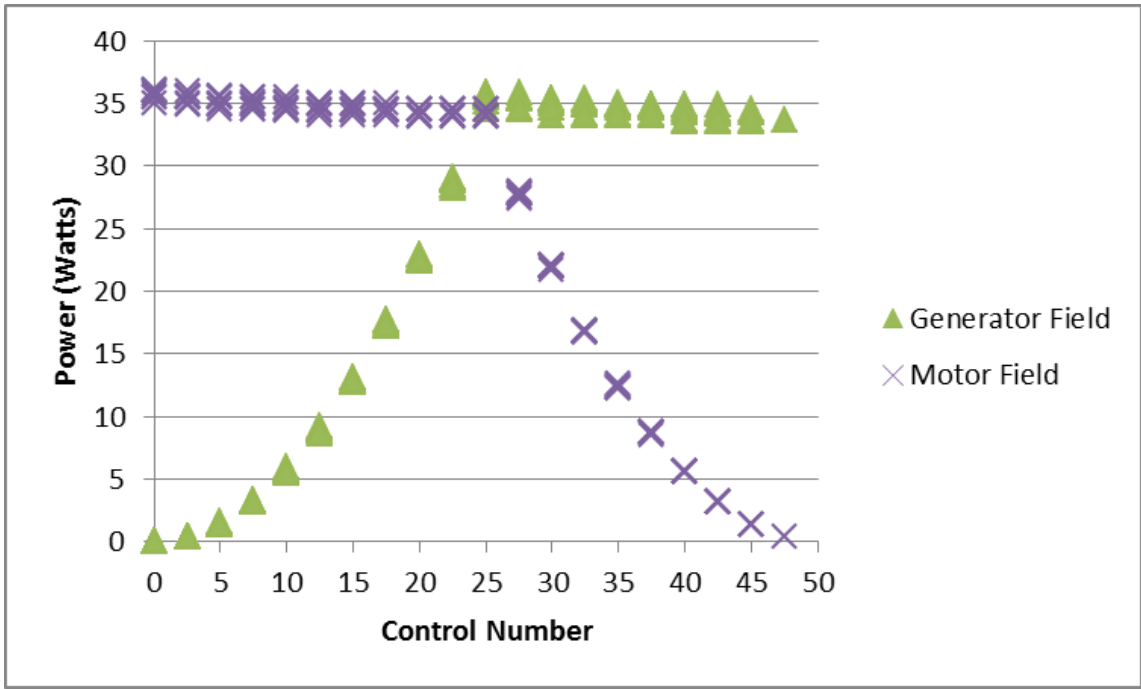

Figure 4.2: Field Power of All Tests According to Control Number 


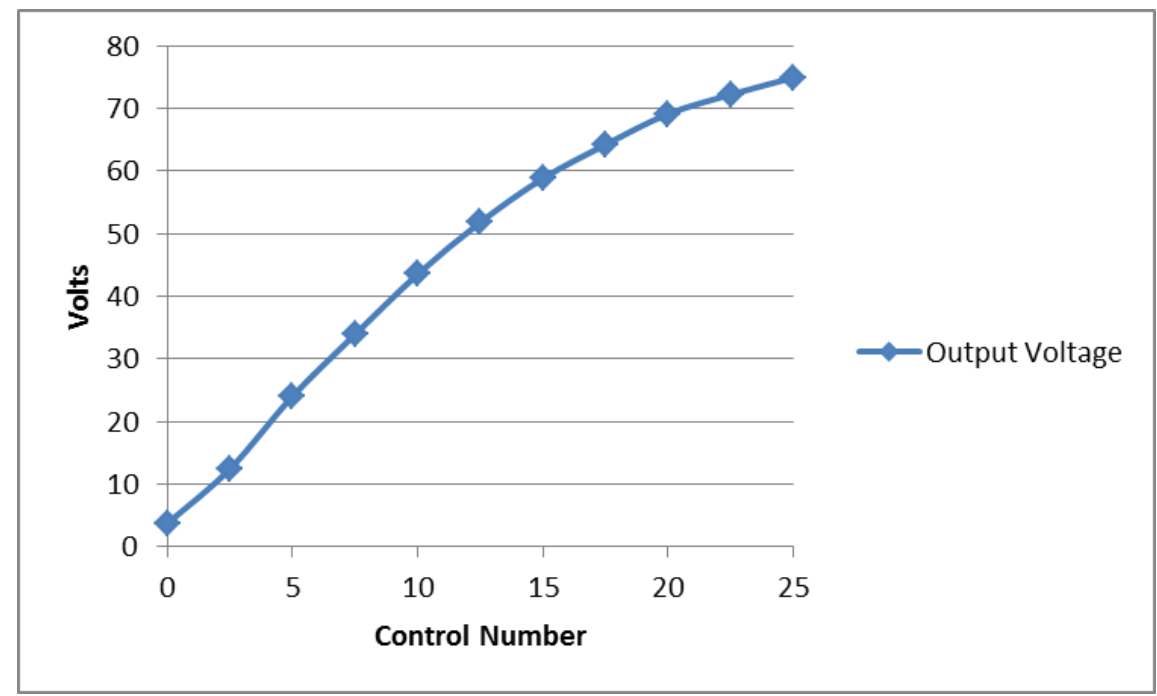

Figure 4.3: Generator Output Voltage Control

\subsection{Generator Test}

The power supplied to the field of the generator driven at a constant speed does indeed control the output of the generator. The DC voltage output of the generator under no load is directly dependent on the field power as seen in Figure 4.3. As a resistive load is placed on the armature of the generator current starts to flow. Due to a fix amount of available power the voltage drops as the current increases. Therefore the amount of power produced by the generator is determined by the load. A large resistive load (90 Ohms) and a small resistive load (17 Ohms) were placed on the output. Figure 4.4 shows that the power output is controlled by the power supplied to the field. The control power is also much less than the output power and this amount is shown by the control factor in Figure 4.5 for the two tests.

\subsection{Speed Control by Generator Field}

In these results a PM DC motor was simulated in place of the SE DC motor by setting the field power at 50 volts and the power in the motor field was ignored. Figure 4.6 shows the output speed for each control number. This shows that it is possible to control output speed by controlling the power to the generator field. It is also noted that the speed is affected by the load. Only 5 of the 9 tests are shown on this graph to enable distinction between tests. The power output for the same test is shown in Figure 4.7 to show that the load placed on the output affects the speed. 


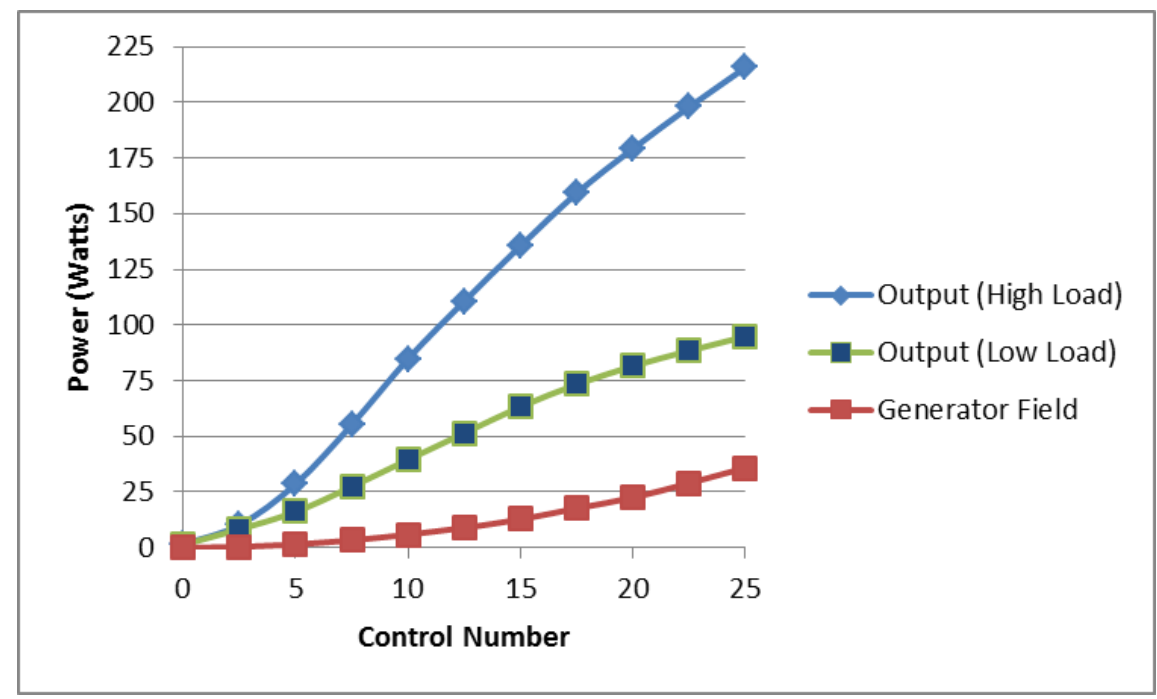

Figure 4.4: Generator Power Output Control and Corresponding Control Power

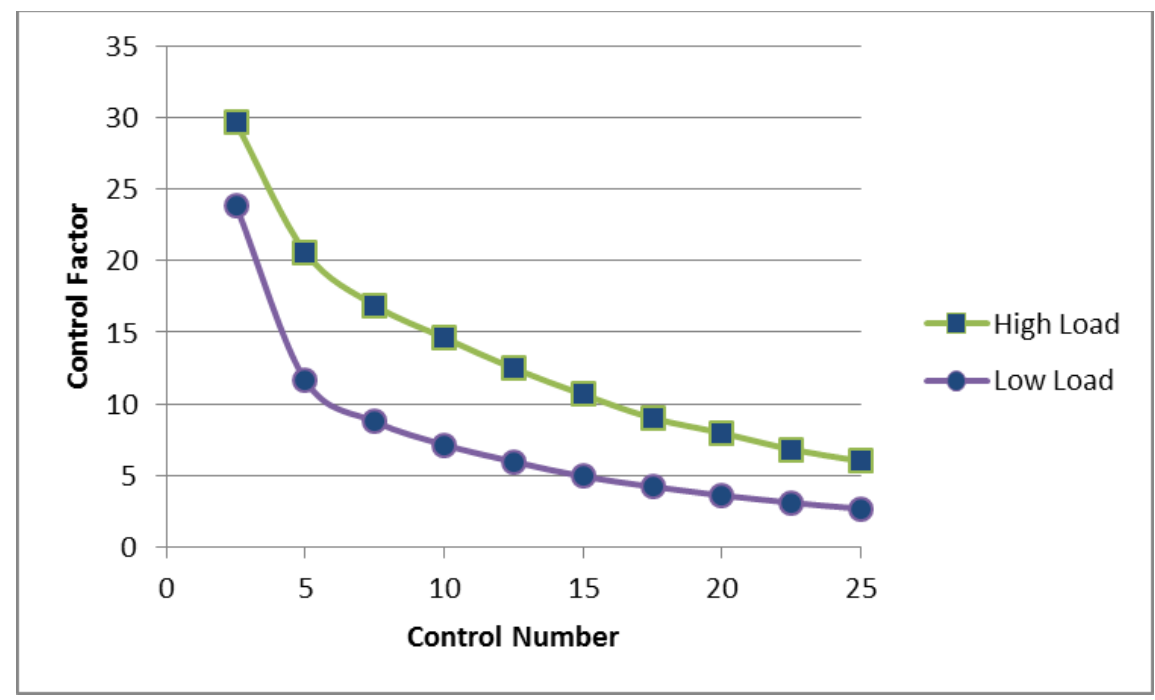

Figure 4.5: Generator Control Factor

\subsection{Speed Control with Motor Field Weakening}

Understanding the control number described above is important to study the effect of field weakening. Field weakening is in effect from control number 25 and up. Figure 4.8 shows the output speed of each test. The control of the output speed using both generator and motor field voltage control increases the speed range of the output, the amount of increase depends on load. Figure 4.9 shows output power of the motor for each test. By examination of these two graphs it 


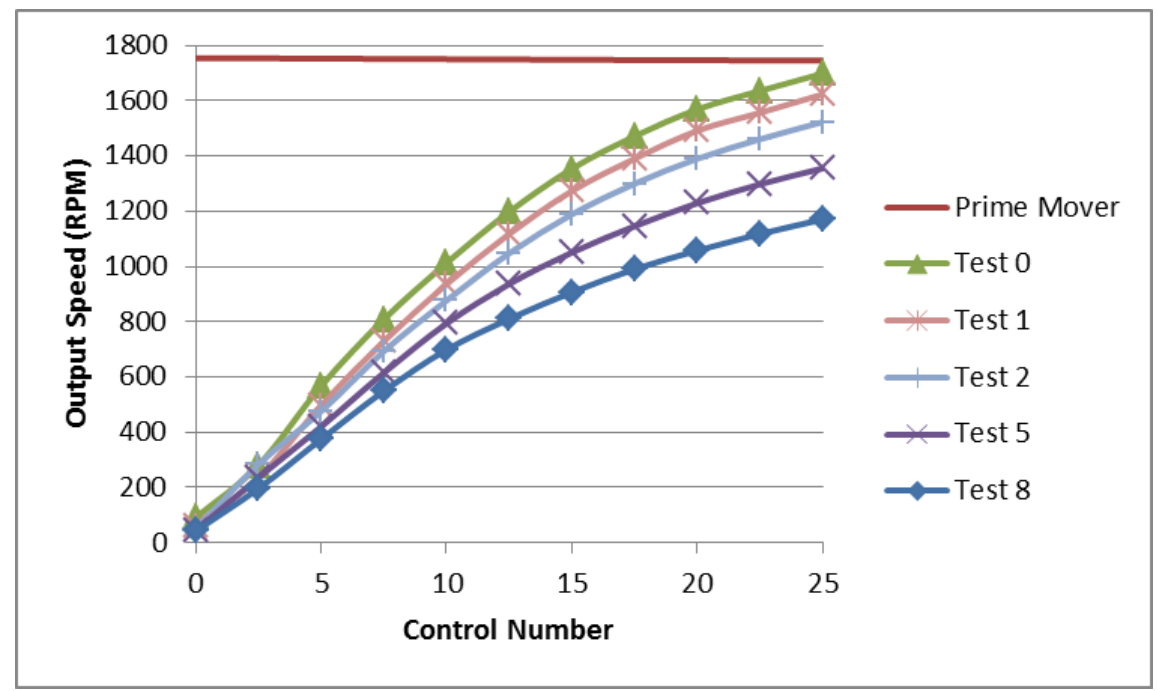

Figure 4.6: Speed Control by Generator Field Control

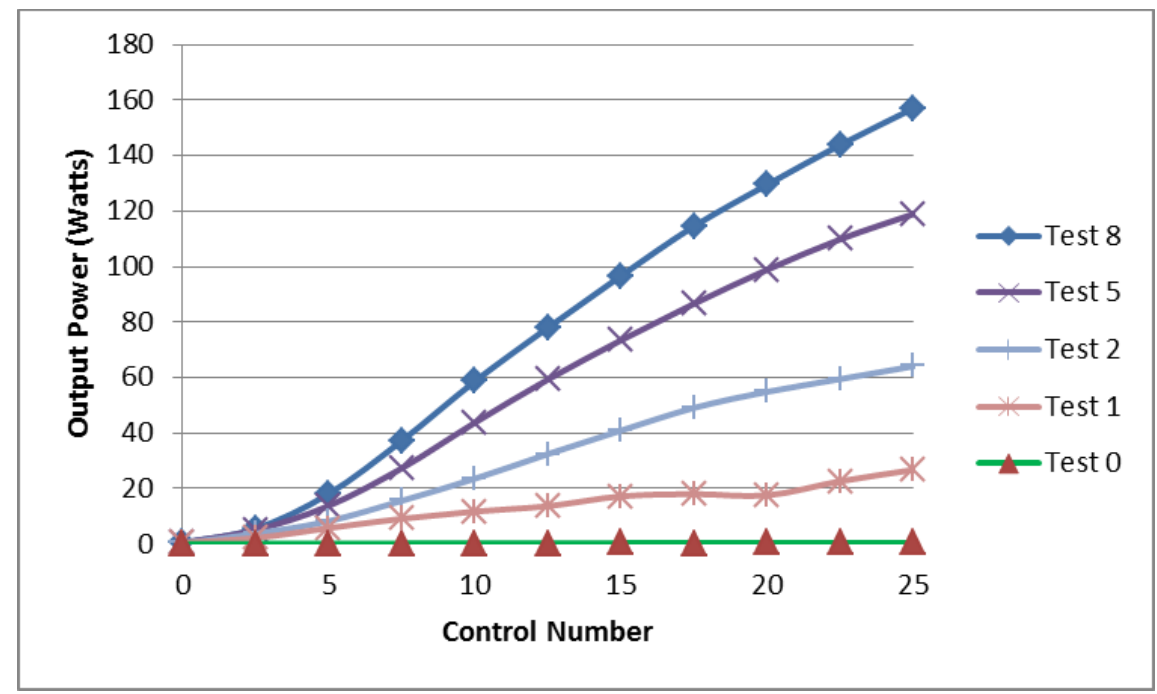

Figure 4.7: Power Output vs Control Number

can be shown that field weakening is only beneficial when the load is less than the rated load of the motor.

\subsection{Efficiency}

Figure 4.10 shows the efficiency of the generator through all loaded tests. The mechanical input power is calculated from RPM and torque supplied by the prime mover and is added to the 


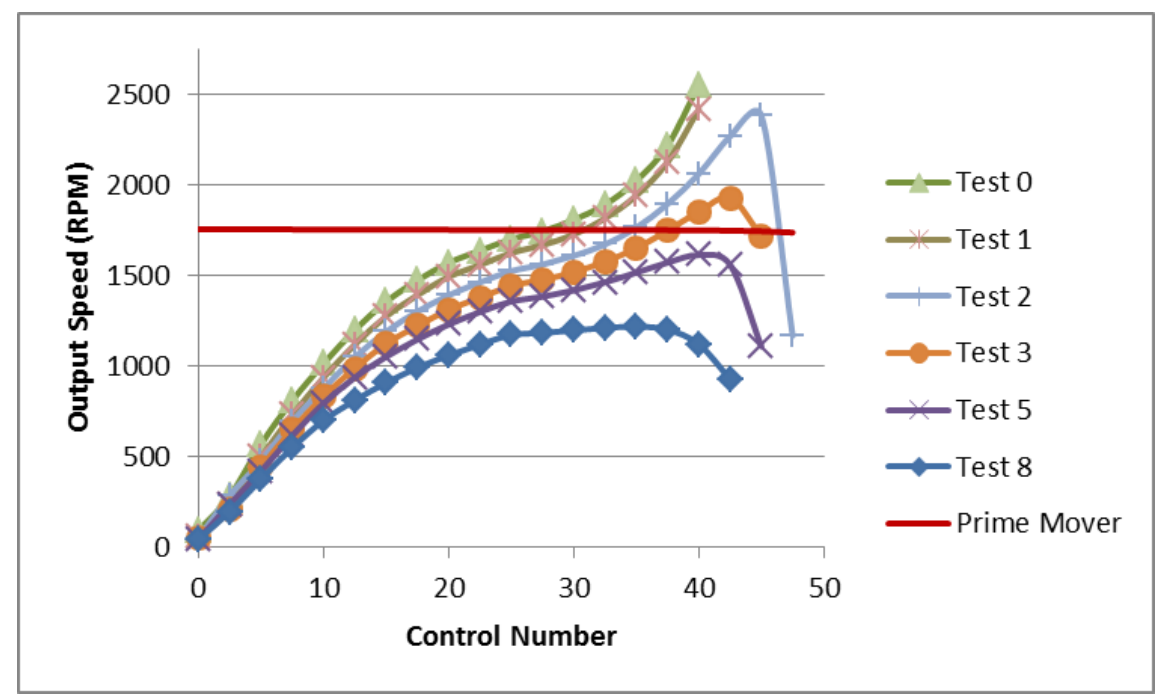

Figure 4.8: Output Speed Using Generator Field Control and Motor Field Weakening

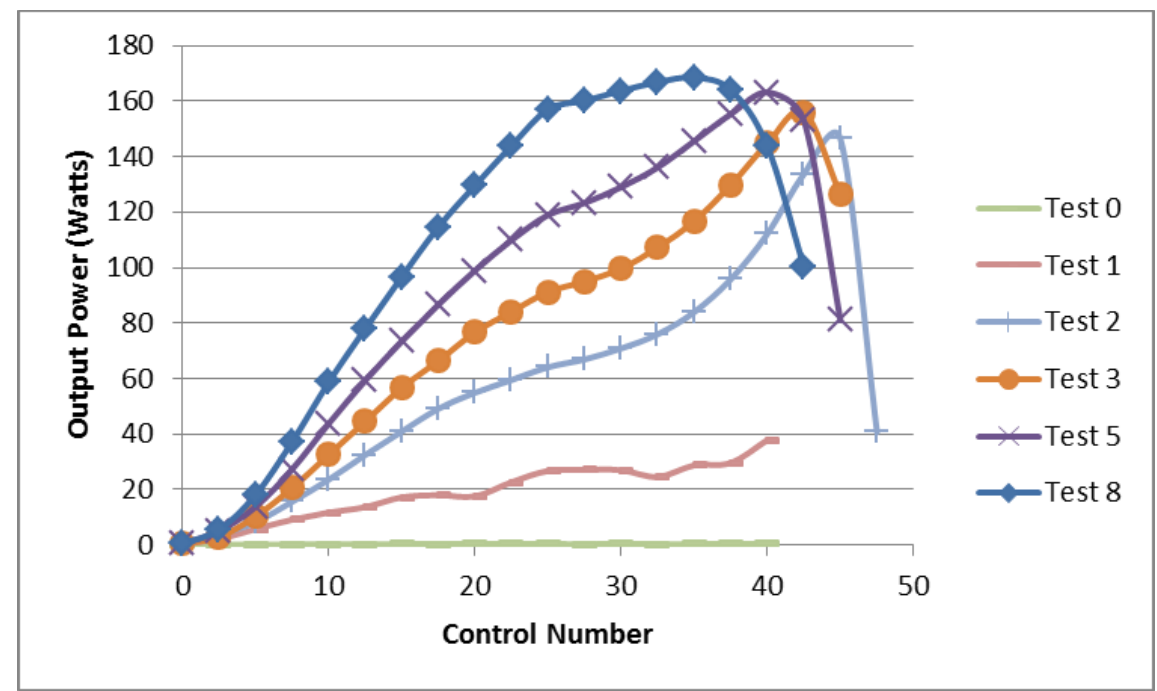

Figure 4.9: Power Output vs Control Number with Field Weakening

electrical power provided to the field. The output power is calculated by measuring current and voltage from the armature. The rated power of the generator is assumed to be the power rating on the name plate of 186.4 watts. The efficiency calculated from the name plate is $68.2 \%$.

Figure 4.11 shows the efficiency of the motor through all loaded tests. The input power was calculated from the voltage and current of the armature and the field. The output mechanical power was found by measuring the torque and RPM of the motor. The rated power is from the motor name plate of 186.4 watts. 


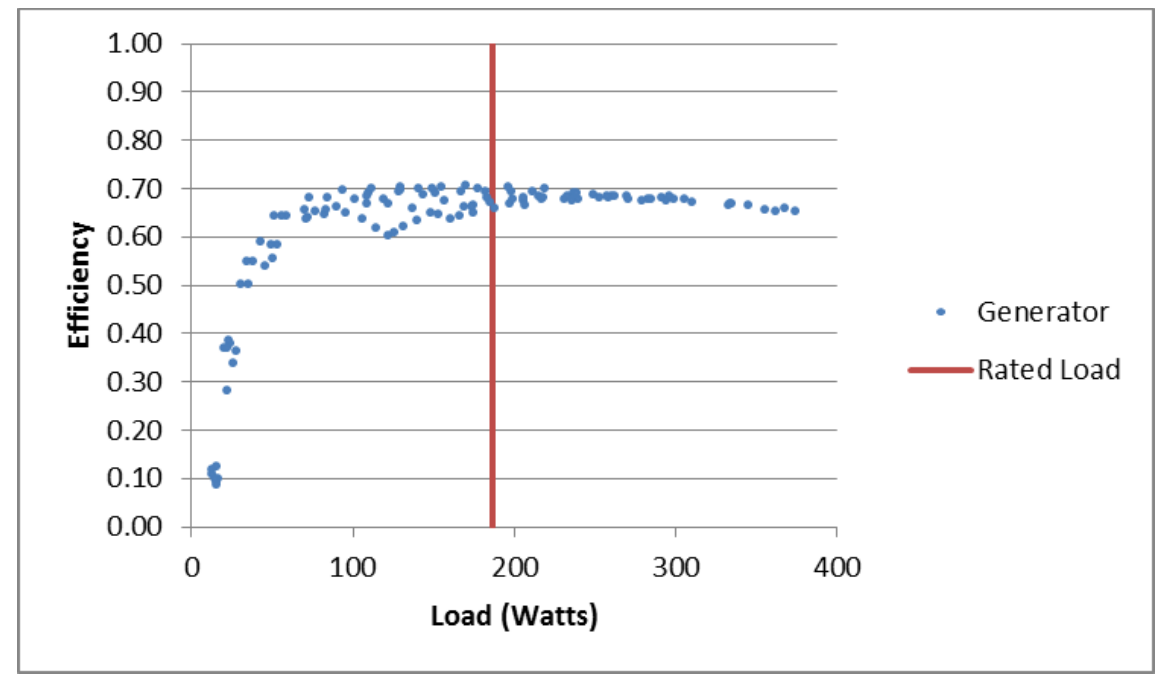

Figure 4.10: Efficiency of the Generator under Varying Load

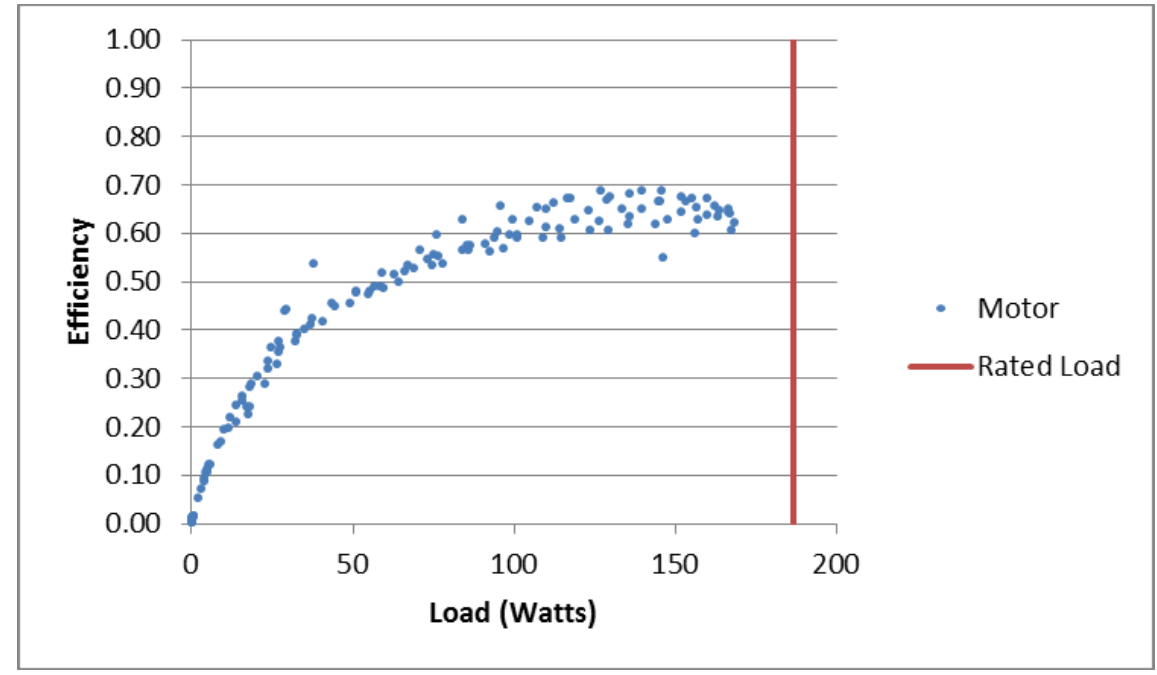

Figure 4.11: Efficiency of the Motor under Varying Load

With the peak efficiencies of the generator and motor reaching $65 \%$ to $70 \%$ the maximum possible for the system is around $45 \%$. Figure 4.12 shows the efficiency vs load of the output for the simulated PM DC motor tested in Section 4.3, where the inputs to the system are the mechanical power from the prime mover and the electrical power to the generator field. The power out is the mechanical power absorbed by the loading motor.

The efficiency drops slightly with the addition of field weakening due to the added motor field power input, yet shown in Figure 4.13 the total power out of the system is slightly higher. 


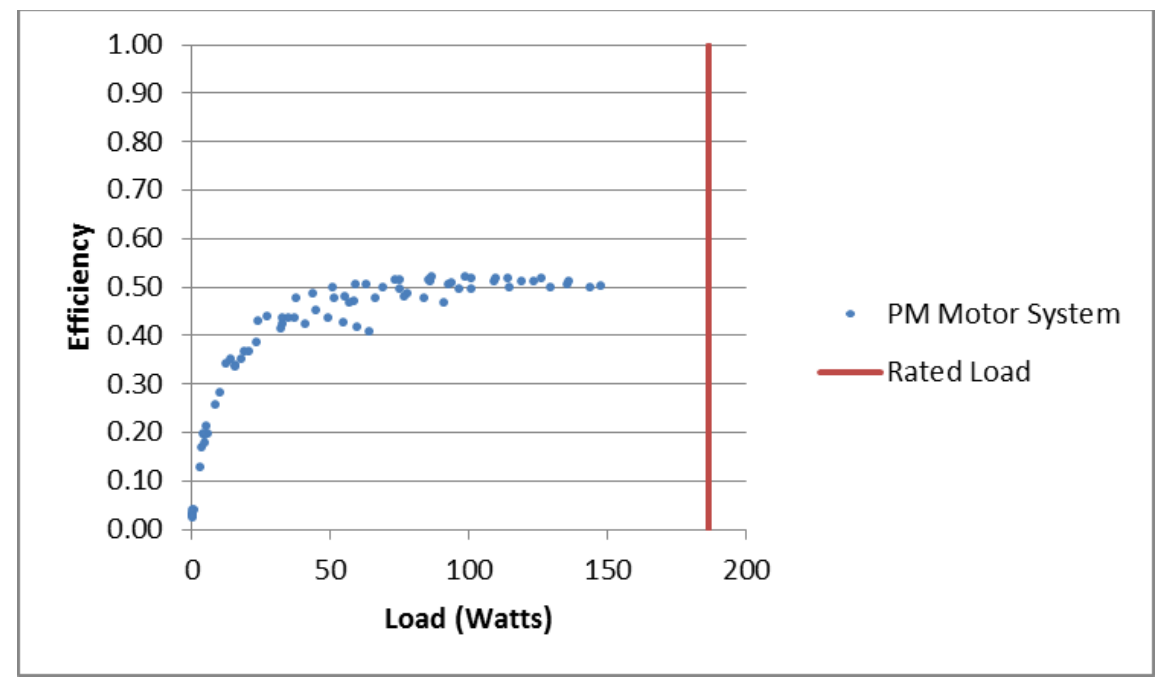

Figure 4.12: Efficiency of the Ward Leonard System with a PM Motor

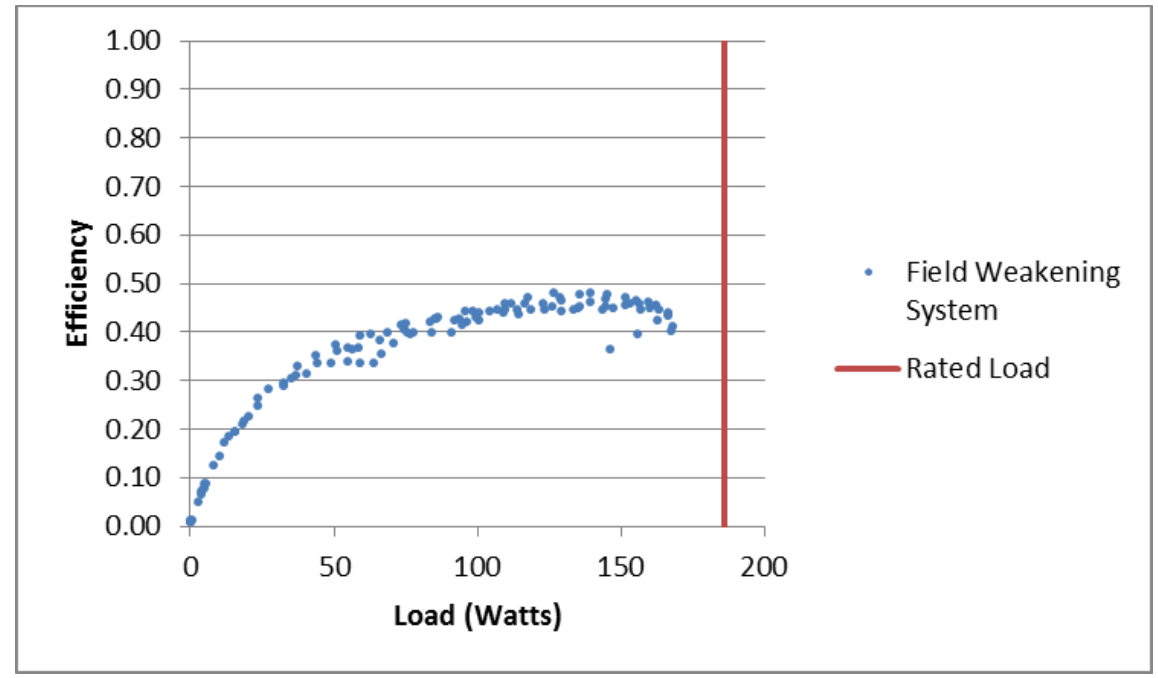

Figure 4.13: Efficiency of the Ward Leonard System with Field Weakening

\subsection{Torque Output Control}

The output torque of the motor in a stalled condition is shown in Figure 4.14 and found to be very controllable to provide a smooth acceleration. 


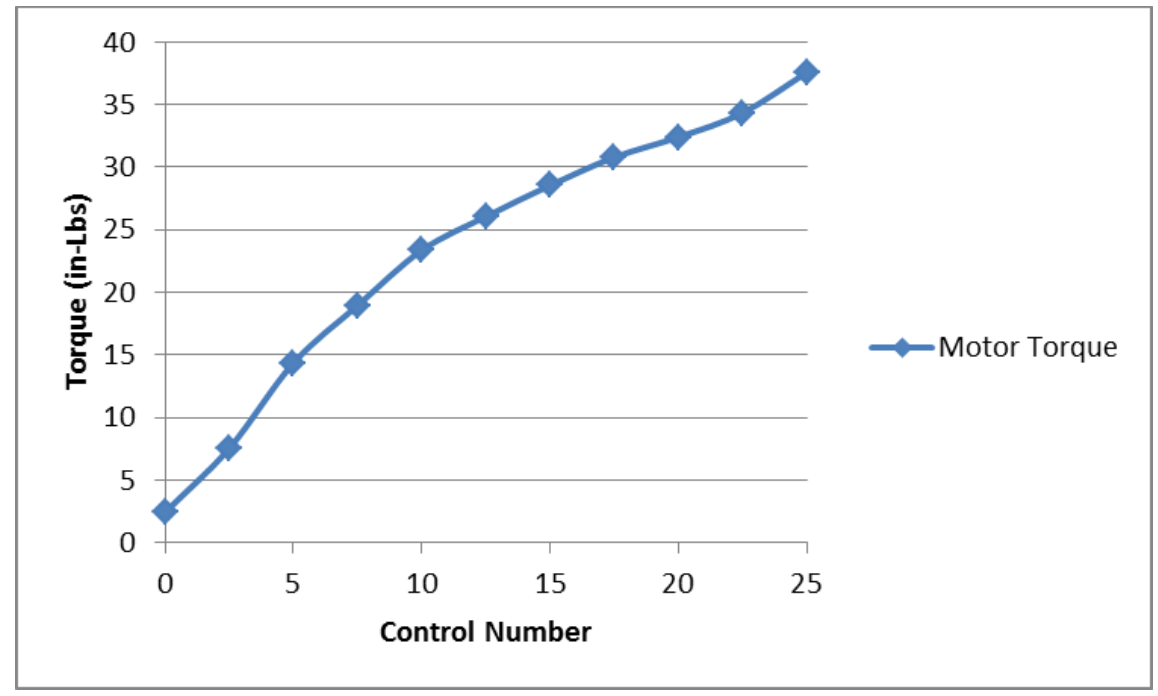

Figure 4.14: Torque Output of a Stalled Motor vs Control Number

\subsection{Power Relationships}

\subsubsection{Generator Field Control}

The control factor is what determines the power relationship of input control power to output power. The power of the control depends on the control number and is independent of the load as shown in Figure 4.2. Therefore the control factor will depend largely on the load placed on the system. The control factor for the generator field control only, as explained in Section 4.3, will only take into account the power to the generator field. The power relationships of output power and control power for different tests are shown in Figure 4.15. The power relationships show that during higher loads and lower power input the control factors are high but at full power out, the maximum control factor for this system is 4.4 as shown in Figure 4.16.

\subsubsection{Motor Field Control}

The control factor changes when a second controller is added to power the motor field on a SE DC motor. During lower control numbers the motor field power is at a maximum with out an increase in output power as compared to a PM DC motor, therefore resulting in a lower control factor. The added benefit of field weakening is the increase in speed range when the load is low. Figure 4.17 shows the power output of the system along with the combined generator and motor 


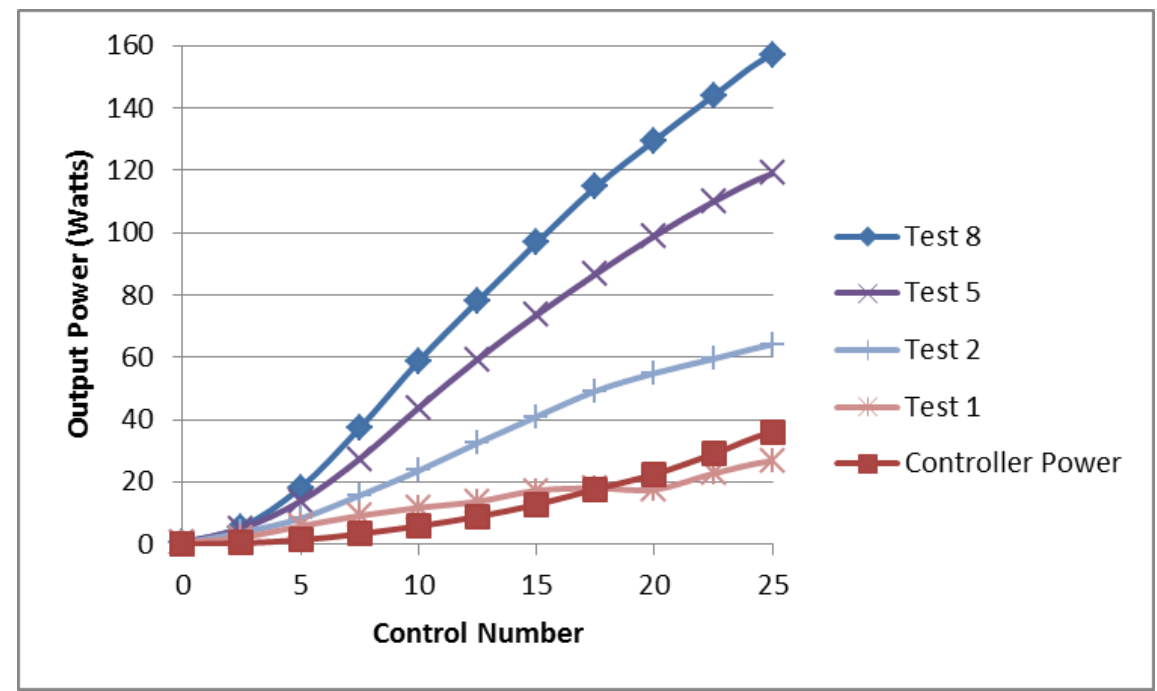

Figure 4.15: Relationship of Control Power to Output Power

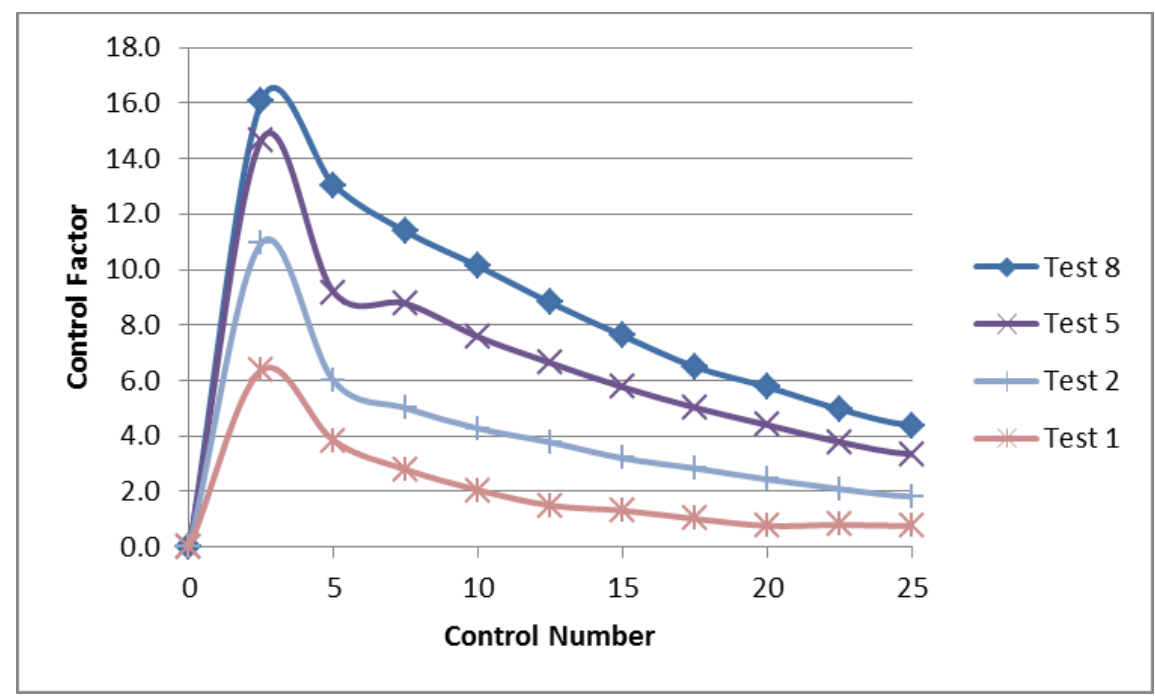

Figure 4.16: Control Factor Using Generator Field Manipulation Under Different Loads

field power in. Figure 4.18 shows the corresponding control factors for the tests shown in Figure 4.17 with a maximum of 2.23 . 


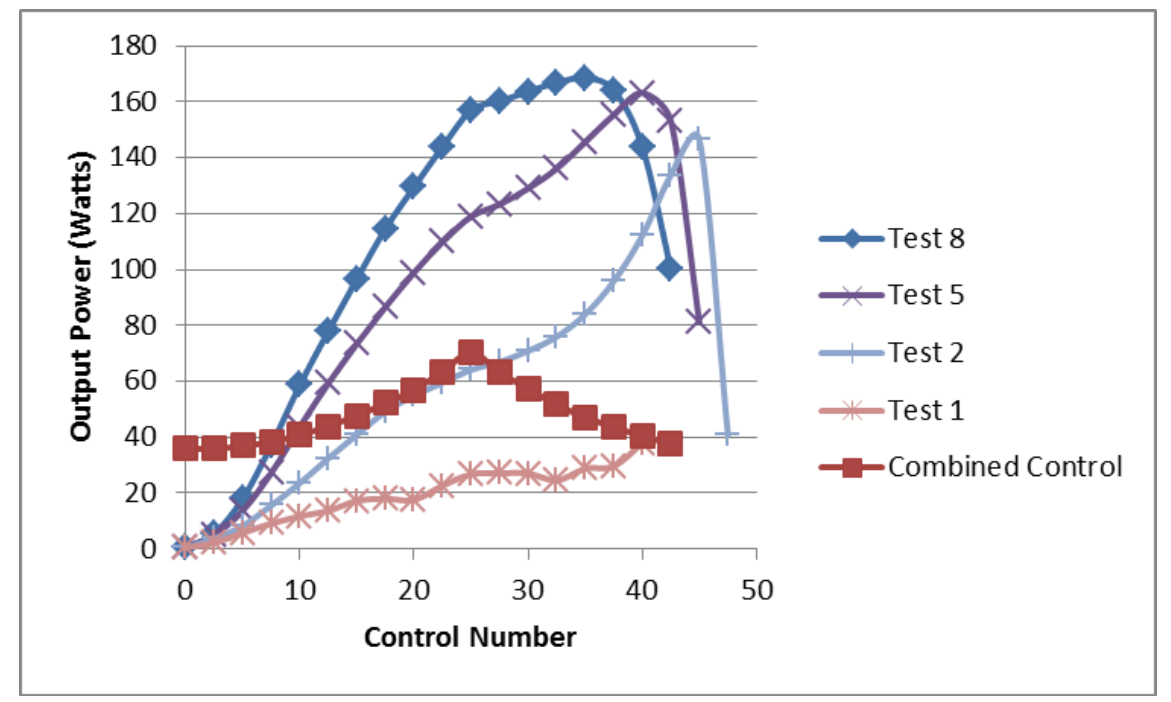

Figure 4.17: Output Power vs Combined Controller Power In

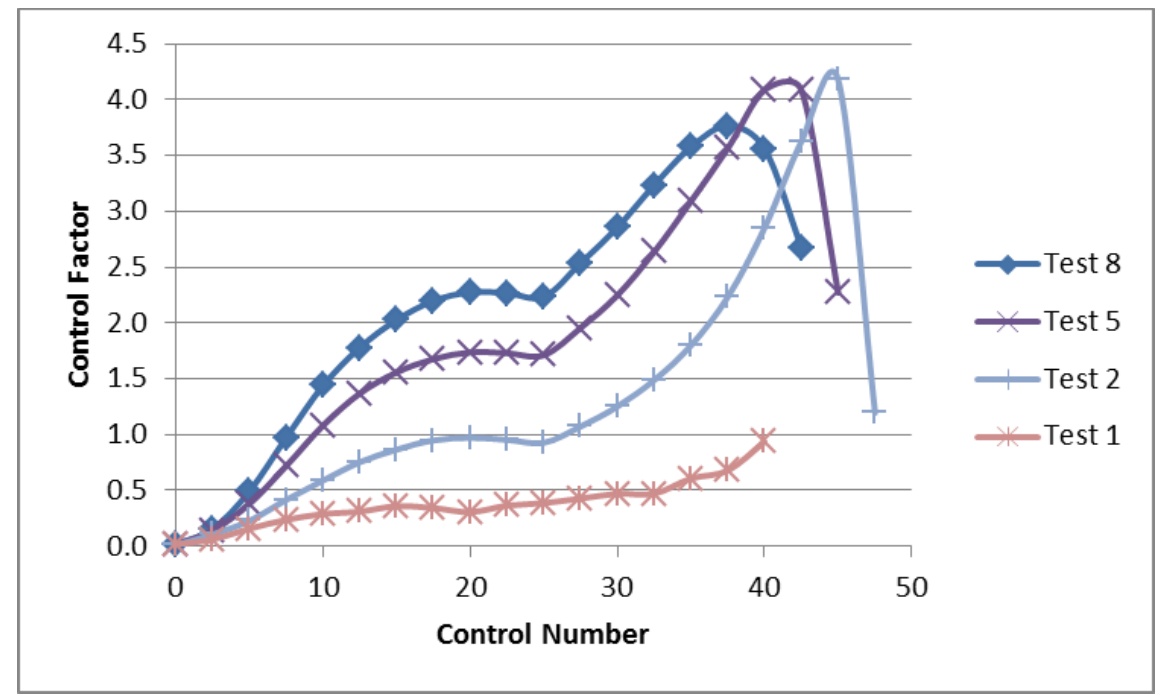

Figure 4.18: Control Factor of System with Field Weakening 


\section{CHAPTER 5. DISCUSSION OF RESULTS}

The following chapter discusses the results of the bench top test set up and its application in an automobile. It is important to know the significance of the term 'control factor' as applicable to this research. The control factor in essence is the ability to reduce the cost of the controller in an EV or HEV. The control factor compares the total power output to the controlling power of the system. For example if a $50 \mathrm{~kW}$ motor is controlled using todays architectural approach, the controller must be sized equally at $50 \mathrm{~kW}$. If the control factor of the Ward Leonard System is 5 then the controller size could be reduced to one fifth the size or $10 \mathrm{~kW}$, thus reducing the cost and potentially the operating voltage.

\subsection{Generator Test}

The control of the voltage output of a constant speed generator was verified in Figure 4.3. The amount of power used to accomplish this control is small relative to the amount of power produced by the generator as shown in Figure 4.4. The benefit of this type of control is that $100 \%$ of the power is not required to go through an electronic controller. The controller of an EV or HEV can be significantly smaller. The ammount smaller is shown by the control factor. In this set up, a motor rated at 1/4 HP was used as a generator and assumed the motor spinning at it's operating RPM could produce 1/4 HP of electrical power or 186 watts. On a conventional EV and HEV the electronic contoller would have to handle 186 watts. By using the theoretical control factor of 5.81 found by the motor field specifications the controller could be reduced to handle just 32 watts. Experimentally the maximum power output of the generator from Figure 4.4 was 215 watts. This was controlled by a maximum of 35 watts which gives a control factor of 6.0 shown in Figure 4.5. It is also noted that due to the load, the amount of power produced by the generator was more than the rated windings so it may need to be limited to not cause damage to the generator windings. 


\subsection{Speed Control by Generator Field Control}

The use of a PM DC motor for the drive motor would minimize the required size of the controller. For this reason, the system was tested with generator field control only. With an output motor being a PM motor, field control is unnecessary, thus being the simplest form of the Ward Leonard system. The power that is applied to the motor field was ignored in these results. There were 9 tests run under various resistance settings on the loading motor. These tests are numbered and shown in Table 4.1. As shown in Figure 4.6, the Ward Leonard system is capable of controlling the speed of an output motor near the nominal speed of the prime mover depending on load. This provides the similar characteristic as that of a hydrostatic drive explained earlier. The speed control of the output can also be controlled up to full speed in reverse by simply switching the polarity of the field on the generator. This provides the full functionality of an IVT. During testing it was noticed that the speed of the output was determined by the voltage output of the generator. As a load was placed on the output, the current from the generator increased. Because the total electrical power power from the generator was limited, the armature voltage dropped under high loads providing more current. Therefore output motor decreased in speed yet increase in torque to overcome the load.

\subsection{Speed Control with Motor Field Weakening}

There are advantages to using a SE DC motor as the output of the Ward Leonard system, yet these come at a cost. The advantage is a higher speed range, while the disadvantage is that a separate controller is needed. The speed range increase is shown in Figure 4.8 and varies depending on load. It was recognized during examination of the results, that field weakening is more than just a speed increase method. It is also a method to increase the power of a motor if not already fully loaded. Figure 4.9 shows that field weakening increases the power under low load situations by increasing the speed. The total power output of the system does not increase with field weakening but the speed does, therefore this added control trades torque for speed. This is desired in automobile applications where high torques are usually not needed at highway speeds. This is similar to an overdrive in a conventional transmission. Field weakening only provides a limited amount of added speed range due to its nonlinear properties as see in Figure 4.8. As the 
magnetic field is weakened the torque capabilities of the motor are reduced. There is a point where the magnetic field is so weak that the torque is not sufficient to overcome the load. This will result in a sharp drop off of speed as shown in Figure 4.8. This drop in speed shows a similar drop in power shown in Figure 4.9.

\subsection{Efficiency}

The efficiency of the Ward Leonard system is comprised of the combined efficiency of motor and generator. If the prime mover is an electric motor also then the total efficiency of the vehicle will be a product of all three electric machines. The efficiency of an electric machine will be at its highest when used at its rated load. This was verified by testing the motor and generator efficiencies in Figure 4.10 and Figure 4.11. The rated efficiency of the motor and generator used in this set up was $68 \%$ individually, therefore the generator and motor operated relativly close to their design. The system efficiency with these two motors in series is around $46 \%$. This shows that the system efficiency follows that of the motor and generator used. Efficiency of current more advanced DC motor are reaching $85 \%$ to $90 \%$ [42]. Therefore by using more advance DC motors efficiencies can be in the $70 \%$ range and $60 \%$ including a electric prime mover. In today's EV architectures there are several electrical components that cause inefficiencies. These are inverters, controllers, generators and motors. In some range extended EVs or EREVs there are 4 equally sized components; the generator, drive motor, generator controller and motor controller. Given state of the art AC design these components are reaching 95\% efficiencies but are more commenly around $85 \%$ to $90 \%$ as shown in Figure 2.4 . With 4 components at $90 \%$ efficient the total efficiency of the system will be $66 \%$.

\subsubsection{Generator Field Control}

With only generator field control the output motor was a simulated PM DC motor. This will be more efficient due to the PM supplying the field rather than a DC controller. The efficiency of the system is the combined efficiency of the generator and motor set and theoretically is $52.5 \%$. The tested efficiency of the Ward Leonard system with a PM DC motor is shown in Figure 4.12 which reaches around $50 \%$ 


\subsubsection{Motor Field Control}

With a separate controller to supply the magnetic field to the motor, the efficiency of the system will decrease. Theoretically the efficiency will drop from $52.5 \%$ to $46.2 \%$. This was shown with testing in Figure 4.13 where the system efficiency is around $45 \%$.

\subsubsection{Vehicle Efficiency}

In automotive applications the load on the vehicle is rarely at its engine's rated peak efficiency, unless at times of acceleration or when climbing a hill. Therefore most of the time the automobile will be running below its rated power. Figure 4.13 shows that the efficiency of the system drops significantly when below the rated load. This is also the case with ICE vehicles. Yet in the case of an underloaded system the amount of energy wasted is less due to the fact that the total amount of energy being used is less. It must also be mentioned that in the Ward Leonard system the prime mover is always on regardless of the load placed on the system. Figure 5.1 shows the amount of power supplied by the prime mover during test 8 , the highest load, and at a stall almost zero power is being used. The power used is to overcome friction and hysteresis. It must also be mentioned that field weakening can be used to draw more in the form of speed rather than torque in certain settings. There are more in-depth papers on control theory that can be applied to gain more efficiency from this type of system [43] [44] [45] [34].

\subsection{Torque Control}

The Ward Leonard system shows smooth control of torque in a stalled state. In automobile applications smooth torque control is a desired characteristic. Although the most important is power control, it is desirable to control torque because at a stall power is 0. For instance at a stop light, the power at the wheels is zero, an instant or uncontrolled torque would produce driver discomfort from jerky motion. As shown in Figure 4.14 the Ward Leonard system is capable of applying a smooth torque no matter what amount is needed to overcome the inertial forces of a vehicle. 


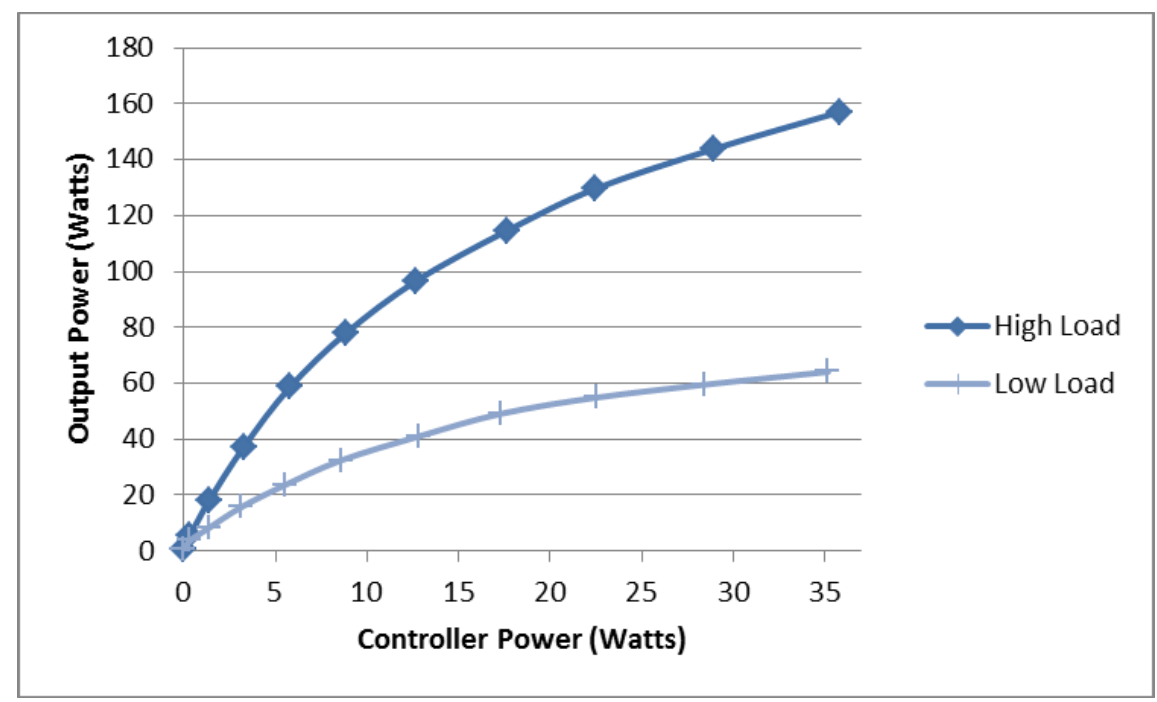

Figure 5.1: Prime Mover Power vs Output Power

\subsection{Power Relationships}

The speed of a DC motor is determined by the armature voltage with the creation of back EMF as explained earlier. The Ward Leonard system is a method of varying the voltage output of a generator. The voltage of the generator will determine the speed of a DC motor connected directly to the armature. Because these are limited power devices the voltage will drop when current increases in the system. Therefore power from the controller determines the voltage, the power of the generator will depend on the load placed on it. The ability to replace a high powered expensive controller with a smaller one is determined by the control factor at a peak operating power. This is examined in two different situations. One with only generator field control and a simulated PM output motor, the other with motor field weakening.

\subsubsection{Generator Field Control}

The power output of the system is simply an amplification of the controller power under high load. The amplification factor is determined by the load therefore the control factor at high load will be larger. The output power of two tests are shown plotted against the generator field power in Figure 5.2. The steep curve at lower controller input shows a more responsive control. This is due to the field coils reaching saturation where more current will provide little increase in 


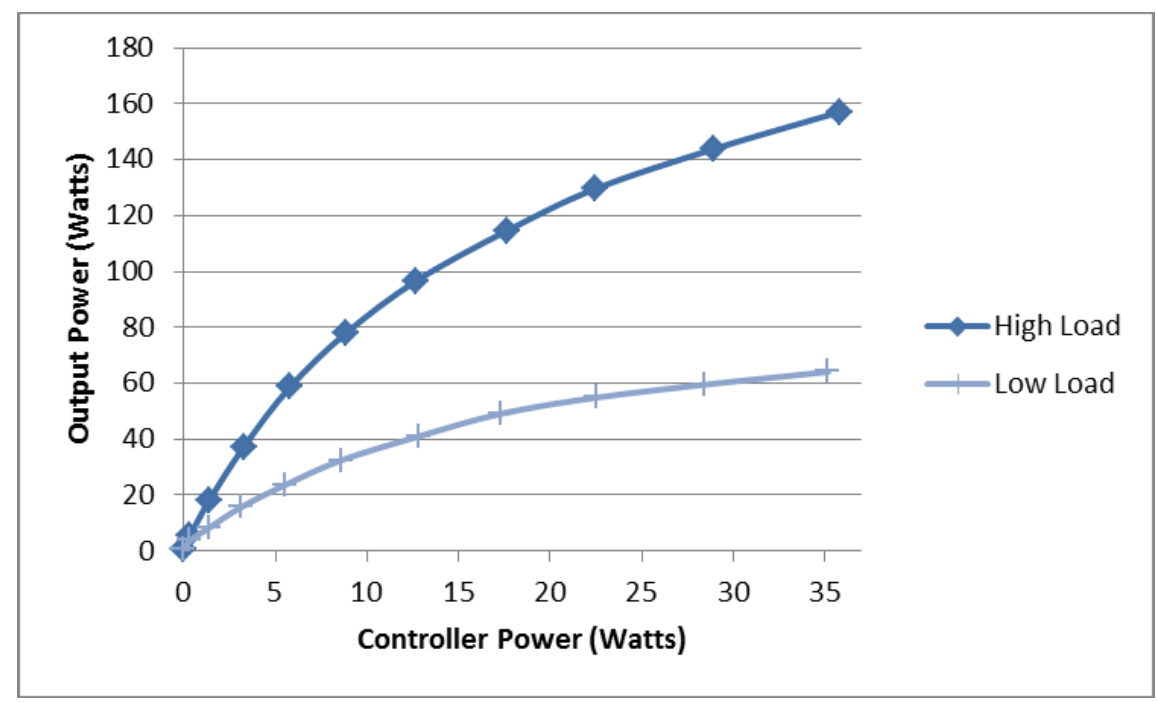

Figure 5.2: Power Output vs Controller Power

magnetic field strength. In this case the controllers ultimate power can be reduced by a factor of 4.4 .

\subsubsection{Motor Field Control}

Adding motor field control to obtain the benefits of field weakening increases the controller power. As shown in Figure 5.3 in the case of low load, the power from the controllers actually

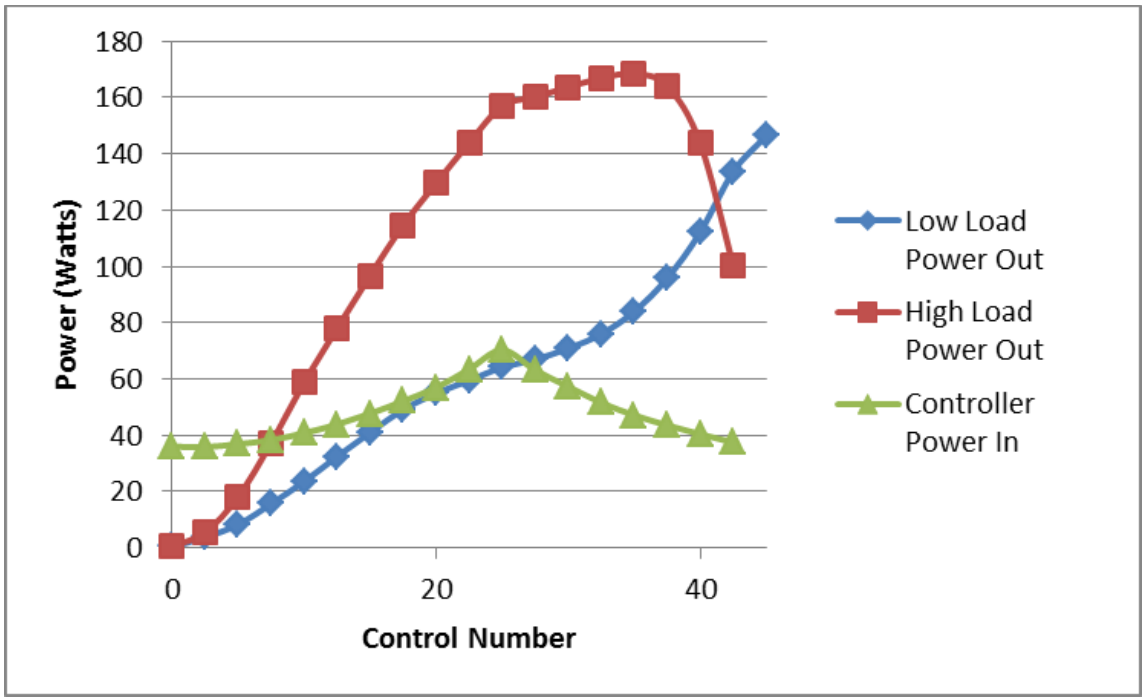

Figure 5.3: Power Output vs Controller Power 
passes the power out of the system. Although in this case the speed of output can be increased to take advantage of the power not used in the low load settings, like that of freeway driving. It was not tested in this setup but varying the generator and motor fields together a better control factor can be obtained for each loading situation.

\subsection{Control Factor and Cost}

Table 5.1 shows the resulting control factors as calculated from the experimental data along with other parameters. With the ability for the controller to be reduced in size using the Ward

Table 5.1: Experimental Parameters

\begin{tabular}{|c|c|c|}
\hline Parameter & Generator Field Control & Motor Field Weakening \\
\hline Max Power & 157 Watts & 168 Watts \\
Controller Input & 35 Watts & 70 Watts \\
Control Factor & 4.4 & 2.23 \\
Speed Range & $0-1623$ RPM & $0-2550$ RPM \\
Efficiency & $50 \%$ & $45 \%$ \\
\hline
\end{tabular}

Leonard system as shown by the control factor in Table 5.1, the corresponding cost can also be reduced. DC controllers were researched and corresponding cost and power ratings were recorded. The graph shown in Figure 5.4 was constructed to find a relationship between power and cost. Power of the controllers shown are based on voltage and peak current ratings. The control factor shows that the controller could be sized 1/4 of the power output by using generator field control only, therefore the cost reduction can be predicted. For example a system that typically would need the $700 \mathrm{~kW}$ controller priced at $\$ 5,000$ could be reduced by a factor of 4.4 to $160 \mathrm{~kW}$ therefore the corresponding price of $\$ 1,600$. By using the trend line shown on the chart the controller cost could be reduced by $68 \%$. With the control factor with added field weakening a seperate controller could be puchased or a dual chanel controller would be needed. Thus the controller cost would be reduced by $34 \%$ or less depending on controlling scheme. 


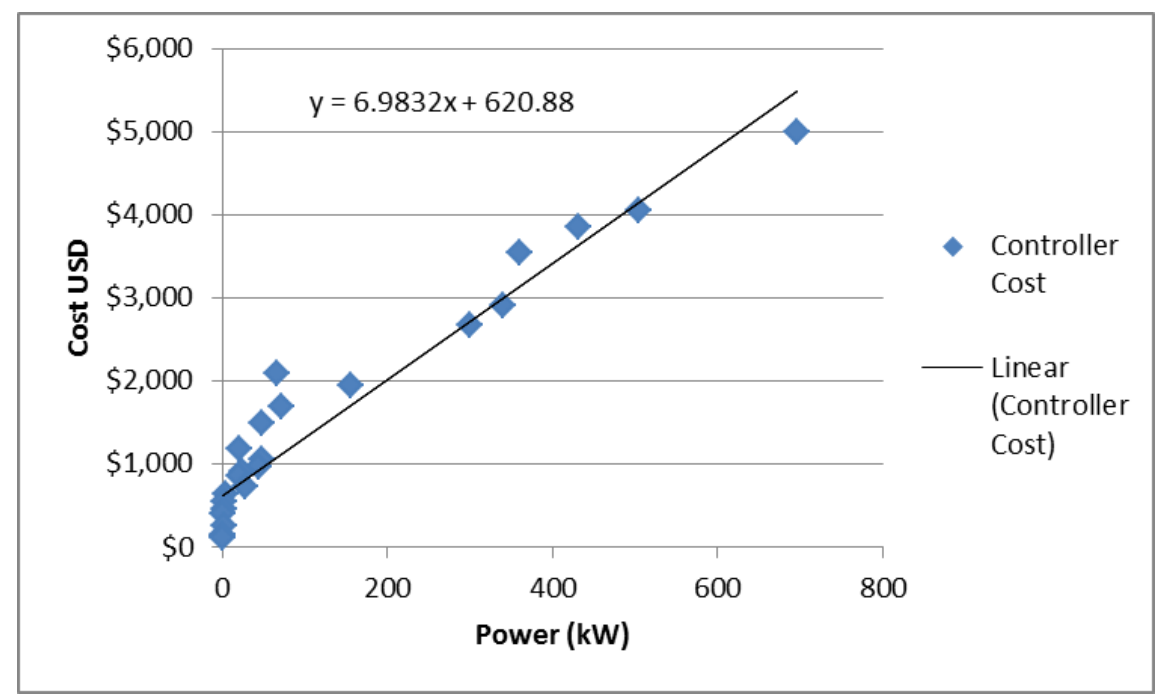

Figure 5.4: Trend of DC Controller Cost Based on Power Capabilities [6] [7]

\subsection{Theoretical vs Experimental}

It is important to see if the experimental data from the test corresponds to the theoretical data calculated from the name plates. This will allow designers to simply look at specifications and know that the results of there design will perform according to planned. Table 5.2 shows the results side by side.

Table 5.2: Theoretical vs Experimental

\begin{tabular}{|c|c|c|}
\hline Parameter & Theoretical & Experimental \\
\hline Generator Max Power & 186 Watts & 215 Watts \\
System Power Generator Control & 186 Watts & 157 Watts \\
System Power with Field Weakening & 186 Watts & 168 Watts \\
Controller Input Generator Field & 32 Watts & 35 Watts \\
Controller Input with Field Weakening & 64 Watts & 70 Watts \\
Speed Range Generator Control & $0-1750 \mathrm{RPM}$ & $0-1623 \mathrm{RPM}$ \\
Speed Range Field Weakening & $0-2200 \mathrm{RPM}$ & $0-2550 \mathrm{RPM}$ \\
Generator Efficiency & $68 \%$ & $68 \%$ \\
Motor Efficiency & $68 \%$ & $65 \%$ \\
System Efficiency Generator Control & $52.7 \%$ & $50 \%$ \\
System Efficiency with Field Weakening & $46.2 \%$ & $45 \%$ \\
Control Factor Generator Control & 5.8 & 4.4 \\
Control Factor with Field Weakening & 2.9 & 2.23 \\
\hline
\end{tabular}




\section{CHAPTER 6. CONCLUSIONS AND RECOMMENDATIONS}

The following chapter provides the conclusions of this research along with recommendations for the implementation of the Ward Leonard system and suggestions for future work for automobile design engineers.

\subsection{Restatement of Objectives}

\subsubsection{Objective 1}

Develop an empirical model based on equation that can be used to describe the Ward Leonard system Objective 2 was accomplished by studying the principles of electromagnetism and how it is applied to separately excited DC motors and generators. How the Ward Leonard system works and governing equations are contained in Chapter 2.

\subsubsection{Objective 2}

Define a quantitative method of testing the Ward Leonard's ability to reduce controller size and potentially cost. The control factor parameter was developed to identify the relationship of necessary controller power with respect to total power output of the system. This created a quantitative method to assess the ability of the Ward Leonard system to reduce controller size. Costs of available DC controllers were researched and a graph that related controller peak power and cost was fit with a linear relationship. This relationship shows that it is possible to reduce the cost of the controller with a reduction in size.

\subsubsection{Objective 3}

Construct and test a bench top model of the Ward Leonard control system to validate the quantitative theoretical data. The construction and testing of a bench top model was realized as 
described in Chapters 3 and 4 to meet Objective 3. It was shown in Chapter 5 that the theoretical data and parameters as derived from the motor and generator specifications corresponded closely to the experimental data thus allowing designers to use specifications for system design.

\subsubsection{Objective 4}

Test the extent and benefit of the addition of motor field weakening. The extent of motor field weakening was tested on the Ward Leonard system. It was found that it adds benefits to the vehicle design. The increased speed range would allow a vehicle to achieve higher speed like that of an overdrive. Field weakening also allows for greater flexibility of drawing power from the generator in the form of speed rather than torque. The drawbacks of field weakening are the reduced control factor plus the increase complexity of control method and added controller.

\subsubsection{Objective 5}

Provide recommendations base on result for implementing the Ward Leonard system in an EV or HEV powertrain. The Ward Leonard system is an alternative solution to todays expensive controlling components. The use of this system has challenges also. Following are the recommendations on the use of the Ward Leonard system in an EV or HEV.

\subsection{Conclusions}

The Ward Leonard Control System is an alternative method of motor control that could be used in an EV or HEV. The control characteristics are ideal for an automotive application. The PWM controller could be sized to $1 / 4$ of the power output of the vehicle. The use of an on/off DC prime mover would eliminate the need for an inverter. The DC prime mover could be directly connected to an ICE to become an HEV. The ICE could be operated in its sweet spot, or most efficient speed setting. With the used of an on/off DC prime mover the battery voltage could be lowered reducing the amount of cells necessary, thus reducing battery management complexity and cost. With a lower voltage, the safety of the vehicle would increase by eliminating a high powered, always energized source. The entire electric powertrain could be constructed with existing technology. 
The efficiency of the tested bench top model reached around 50\%. Today's EV and HEV electric powertrains are in the $60 \%$ to $85 \%$ range. The motors used in the bench top test were not designed with vehicle electrification in mind, therefore the rated efficiency of the motors were $68 \%$. The history of these motors was not known and could have been subject to abuse. The efficiency of the system follows that of the motor and generator used, therefore if there are more efficient motors available, the efficiency of the system would also increase and could approach that of todays expensive vehicles. The Ward Leonard System also provides simple regenetive braking.

The use of DC motors also adds some maintenance issues to be considered. A fall back to DC motor design are the brushes. Arcing from the brush to the commutator could occur during high load which is damaging to the motor. Another cost that comes with this design is the need for 3 equally sized DC motors, yet this is not a design constraint. It is possible to size the generator to power 2 or 4 smaller, less expensive motors at the drive wheels, eliminating any drivelines or gearboxes. The prime mover motor could also be sized differently to run at lower voltage or higher current to provide the best efficiency, due to the simple on/off control.

One of the dangers of field weakening control on a DC motor is the sudden loss of field. When a DC motor looses the field the speed instantly increases to a dangerous level. This danger is eliminated in this system due to the limited amount of current available for the motor to draw. The current is limited by the generator unlike that of a battery supply where current draw is limited by other electronics.

There is no single explanation why the Ward Leonard system has been replaced in other applications. Each use of the Ward Leonard system has been phased out due to application specific factors weather it be equipment cost, electricity availability, size constraints or control methods. The reasons for its replacement vary greatly. Its use to reduce the cost of an EV or HEV has been overlooked. The purpose of this research has been to present the Ward Leonard System as an alternative for EV and HEV powertrain design. An analysis of the Ward Leonard system has been presented to provide vehicle designers information when choosing a powertrain for an EV or HEV.

\subsection{Recommendations for Vehicle Design with Ward Leonard system}

Recommendations include: 
1. An investigation of a low voltage high efficiency DC prime mover with a low cost on/off switch. This would eliminate the need for a high current motor controller or DC to AC inverter. A large inexpensive contractor would be able to handle high current of a low voltage system.

2. The used of a low voltage battery pack with larger and fewer cells that simplify battery management. The larger, low voltage cells would be easier to manage while reducing the operating voltage of the battery pack. With a lower operating voltage, operators, passengers, emergency response teams and service technicians will be in less danger while in or around the vehicle and it's batteries.

3. Implement direct coupling of generator and motor armatures, with the use of large conductors or high voltage to eliminate losses. A large solid conductor would allow for large currents to be transfered while lowering losses due to heat and resistance. The use of high voltage between the generator and motor will not be as high risk as a battery pack considering the fact that the source is not always energized and would be shut off in the case of emergency or crash.

4. The employment of a simple Pulse Width Modulation (PWM) controller in order to supply power to the fields of both generator and motor. In the case of a PM DC motor as the output the PWM would only have to be large enough for the field on the generator. If a larger speed range is desired a SE DC motor could be employed with a separate PWM controller sized for the motor field. These controllers could be $1 / 4$ of the rated vehicle power output.

5. The use of an undersized ICE could be coupled directly to the prime mover to increase range. A clutch could be placed in between the ICE and PM prime mover to allow for electrical use on battery power only. With the clutch engaged the ICE could provide power to the generator while also using the PM prime mover as a generator to charge the battery pack.

\subsection{Future Work}

There is a drive for future work. Production on the Chevy Volt, one of GM's most prominent electric vehicles, has been halted due to its inability to produce sales [46]. It is still expected to be too high priced for the general public.

The increase in battery technology is a push for todays hybrids. The battery is currently the weak link of the electric vehicle. The cost of the battery pack alone reaches the combined cost of all other electrical components. The energy density of current battery technology is very low compared to gasoline. Extensive research is being conducted by many universities and large companies to enable a more resilient battery life while increasing range capabilities of EVs. Recent developments are promising for EV and HEV for extended range and durability [47]. 
Work on the development and realization of the homopolar motor are being conducted [48]. The theoretical advantages of the homopolar motor are a low voltage high powered motor with high efficiencies. The homopolar motor would work extremely well as the prime mover in this application. The homopolar motor could realize the lower operating voltage discussed in this paper.

Advances in brush design are enabling DC motors to reach efficiencies comparable to AC motors. Although AC motors are more efficient and require less maintenance, DC motors are viable contenders. They do not require inverters and offer the advantage of less expensive controls. Recommended future work on the Ward Leonard System would be to design a vehicle side by side a with conventional electrified drivetrain and perform a cost analysis. Research to find a correctly sized separately excited DC motor and generator set to provide sufficient power for a small sedan similar to the leaf. Compare all electric components cost to conventional means. Build a prototype vehicle to test the system and its efficiency and benefits over conventional vehicles. 


\section{REFERENCES}

[1] U.S. Energy Information Administration, 2012. Weekly U.S. All Grades Conventional Retail Gasoline Prices (Dollars per Gallon). Jan.

[2] Williamson, S. S., Emadi, A., and Rajashekara, K., 2007. "Comprehensive efficiency modeling of electric traction motor drives for hybrid electric vehicle propulsion applications." IEEE Transactions on Vehicular Technology, 56(4), p. 15611572.

[3] Bradley, A., 1999. Glossary of Motor Terms. Rockwell International Corporation, Feb.

[4] Griffiths, D., 1981. Introduction to electrodynamics. Prentice-Hall, Englewood Cliffs N.J.

[5] Wikipedia, 2009. Quadrature Diagram.svg - Wikipedia, the free encyclopedia. Mar.

[6] EVSource, 2012. The complete electric vehicle resource http://www.evsource.com/, Feb.

[7] Tecknowlegey, 2012. Electrical components source www.tecknowlegey.com, April.

[8] Groen, B. C., 2011. "Investigation of DC motors for electric and hybrid electric motor vehicle applications using an infinitely variable transmission." Thesis, Brigham Young University.

[9] Bellis, M., 2012. History of electric vehicles: The early years, electic cars from 1830 to 1930 http://inventors.about.com/od/estartinventions/a/History-Of-Electric-Vehicles.htm, April.

[10] Eckermann, E., 1989. World History of the Automobile. Society of Automotive Engineers SAE.

[11] Chang, L., 1993. "Recent developments of electric vehicles and their propulsion systems." IEEE Aerospace and Electronic Systems Magazine, 8(12), p. 36.

[12] Zhang, J., Wang, L., and Yin, C., 2010. "Design and research for a Cost-Oriented hybrid electric vehicle architecture." In Proceedings of the ASME 2010 International Design Engineering Technical Conference \& Computers and Information in Engineering Conference.

[13] National Highway Traffic Safety Administration, 2010. Fuel economy http://www.nhtsa.gov/fuel-economy, June.

[14] California Air Resource Board, 2010. Zero emission vehicle (ZEV) program http://www.arb.ca.gov/msprog/zevprog/zevprog.htm, June.

[15] Bureau of Transportation Statistics, 2011. Average fuel efficiency of U.S. light duty vehicles http://www.bts.gov/publications/national_transportation_statistics/html/table_04_23.html.

[16] Santos, A., MCGuckin, N., and Nakamoto, H. Y., 2009. Summary of Travel Trends:2009 National Household Travel Survey. U.S. Department of Transportation. 
[17] Dennis, L., 2010. GM-Volt: Chevy Volt Electric Car Site. June.

[18] Toyota, 2011. Toyota prius hybrid http://www.toyota.com/prius-hybrid/, Jan.

[19] Brooke, L., 2012. "Vehicle electrification.” Automotive Engineering International Online, Feb.

[20] Lunt, B., 2004. Electronic physical design. Prentice Hall, Upper Saddle River N.J.

[21] Occupational Safety and Health Administration, 2002. Controlling electrical hazards.

[22] Institute of Electrical and Electronics Engineers, 1983. "Recommended practices for safety in high voltage and high power testing." ANSI/IEEE Std 510-1983, pp. 1-19.

[23] andL. Geddes, R. F., 2003. Medical and bioengineering aspects of electrical injuries Lawyers \& Judges Publishing Company, Inc.

[24] Wells, D. B., 2010. "Investigation of a differential as a continuously variable transmission for a hybrid vehicle powertrain.” Thesis, Brigham Young University.

[25] Modak, G., and Sane, S., 2006. "Mechanical continuously variable transmission (CVT) for parallel hybrid vehicle." In Electric and Hybrid Vehicles, 2006. ICEHV'O6. IEEE Conference on, p. 14.

[26] Thoma, J., 1964. Hydrostatic Power Transmission. Trade and Technical Press.

[27] Lenk, J., 1976. Handbook for transistors.. Prentice-Hall, Englewood Cliffs.

[28] Leonard, H. W., 1891. Electrical transmission of power, Nov.

[29] Kulkarni, A. "Energy consumption analysis for geared elevator modernization: upgrade from DC ward leonard system to AC vector controlled drive." Vol. 4, IEEE, pp. 2066-2070.

[30] Bennett, S., 1993. A history of control engineering, 1930-1955. P. Peregrinus on behalf of the Institution of Electrical Engineers London, Stevenage Herts. U.K.

[31] Stevens, P. S., 1948. "Evolution of Ward-Leonard control for shovels and draglines." Transactions of the American Institute of Electrical Engineers, 67(2), Jan., pp. 1491-1497.

[32] McDonnell, G., 2008. Locomotives : the modern diesel and electric reference. Boston Mills.

[33] Robinson, C. E., 1968. "Redesign of DC motors for applications with thyristor power supplies." IEEE Transactions on Industry and General Applications, IGA-4(5), Sept., pp. 508514.

[34] Inaba, H., Onoda, Y., Shima, S., Ando, T., Kurosawa, T., Sakai, Y., and Maekawa, T., 1980. "A new Speed-Control system for DC motors and its application to elevators." IEEE Transactions on Industry Applications, IA-16(2), Mar., pp. 179-185.

[35] Kusko, A., 1972. “Solid-state motor-speed controls.” IEEE Spectrum, 9(10), Oct., pp. 50-55.

[36] Chapman, S., 2005. Electric machinery fundamentals., 4th ed. McGraw-Hill Higher Education, New York NY. 
[37] Serway, R., 2003. Physics for scientists and engineers., 6th ed. Brooks/Cole, Pacific Grove Calif.

[38] Rizzoni, G., 1996. Principles and applications of electrical engineering., 2nd ed. Irwin, Chicago.

[39] Chaston, N. A., 1986. Electric machinery. Prentice-Hall, Englewood Cliffs, N.J.

[40] DE, N. K., and SEN, P. K., 1999. Electric Drives. Prentice-Hall of India, New Delhi.

[41] Cloud Electric, 2012. EV, Auto, Solar, Industrial, RV, Marine Supply http://www.cloudelectric.com/.

[42] EVparts.com, 2012. EVParts, your one stop online solution for all your electric vehicle needs http://www.evparts.com/cms/picts/products/mt2120torquecurvebyus.PDF.

[43] Zhong, Q.-C., 2010. "Speed-sensorless AC ward leonard drive systems." International Symposium on Power Electronics Electrical Drives Automation and Motion (SPEEDAM), pp. $1512-1517$.

[44] Bouton, E. M., 1924. "Variable voltage control systems as applied to electric elevators." American Institute of Electrical Engineers, Transactions of the, XLIII, p. 199219.

[45] Chiasson, J., and Bodson, M., 1993. "Nonlinear control of a shunt DC motor." IEEE Transactions on Automatic Control, 38(11), p. 16621666 Compendex.

[46] Ewing, J., 2012. Electric cars seem to be falling out of favor after volt's slow sales http://www.mercurynews.com/cars/ci_20115128/electric-cars-seem-be-falling-outfavor-after?source=rss, March.

[47] Silvey, J., 2012. Mu professor's battery technology holds promise http://www.columbiatribune.com/news/2012/mar/08/mu-professors-battery-technologyholds-promise/, Aug.

[48] Thome, R., Creedon, W., Reed, M., Bowles, E., and Schaubel, K., 2002. "Homopolar motor technology development." In Power Engineering Society Summer Meeting, 2002 IEEE, Vol. 1, p. 260264 vol.1. 


\section{APPENDIX A.}

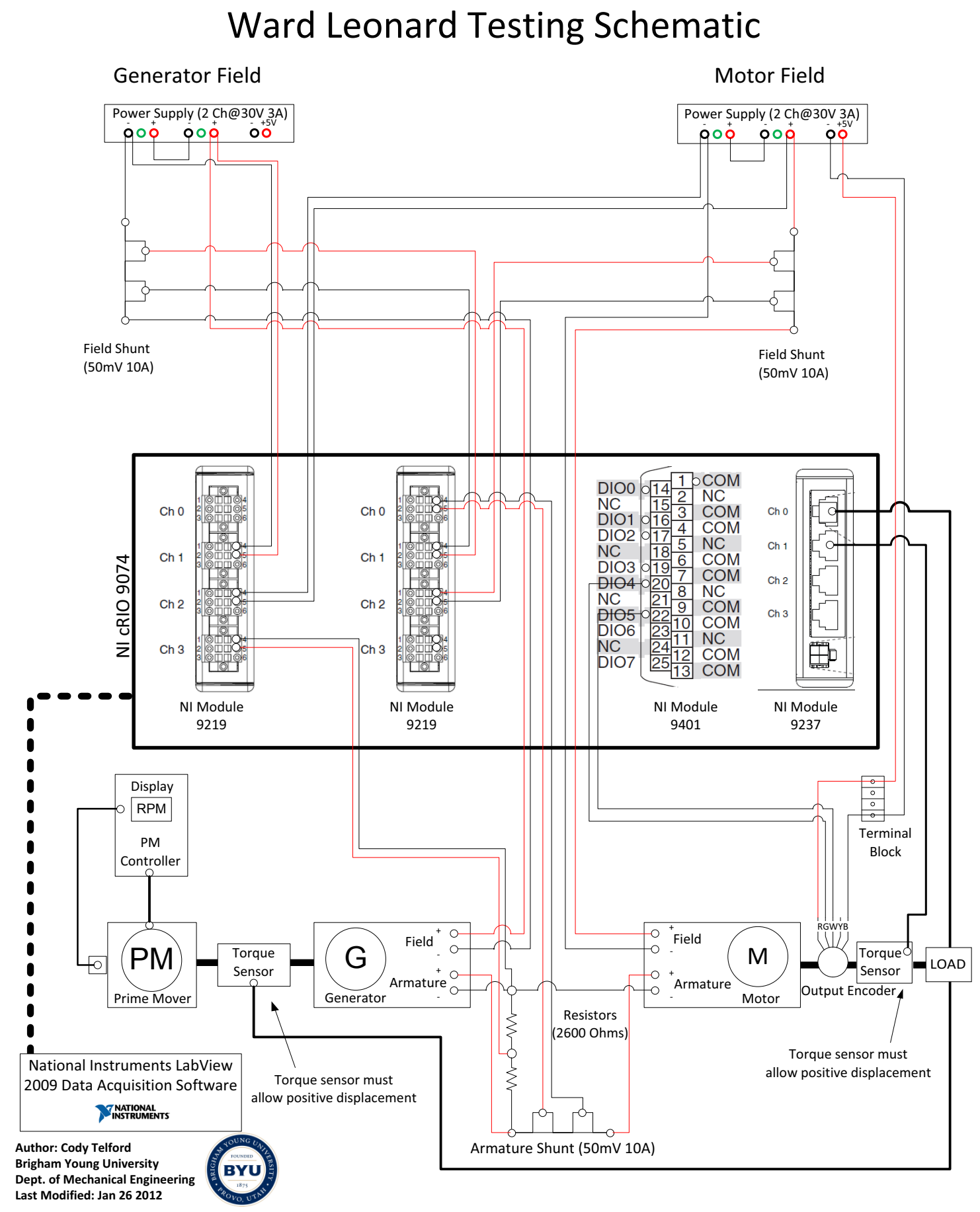

Figure A.1: Final Experiment Wiring 


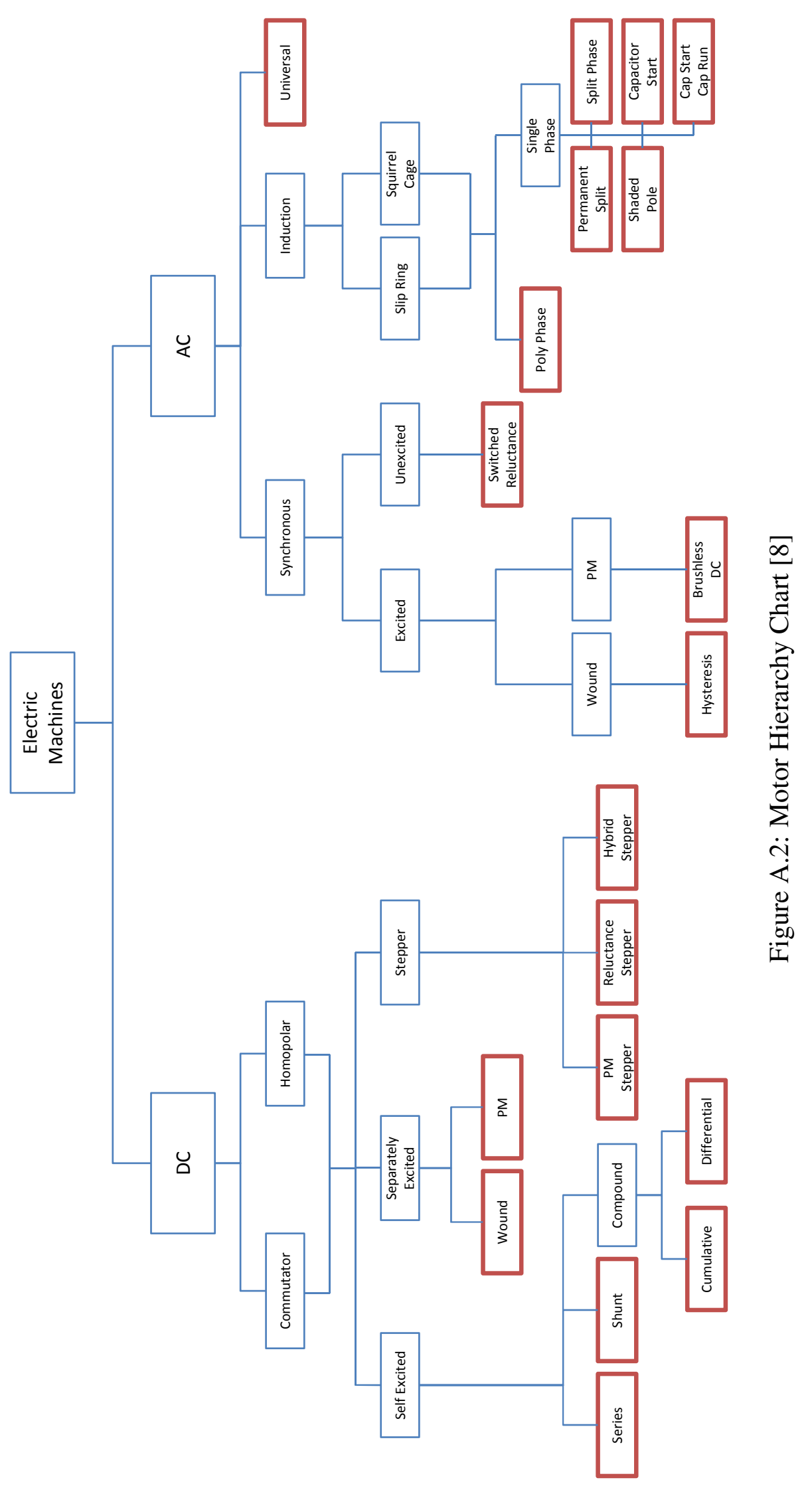

